\author{
INSTITUTO DE FÍSICA
}

\title{
ESTUDO DAS PROPRIEDADES QUIIMICAS, MORFOLÓGICAS E ESTRUTURAIS DE OXINITRETO DE SILÍCIO DEPOSITADO POR PECVD
}

\section{Wanderlã Luis Scopel}

Tese submetida ao programa de pós-graduação em Física da Universidadede de São Paulo como parte dos requisitos para obtenção do título de Doutor em Física.

\section{Banca examinadora:}

Prof. Dr. Adalberto Fazzio (IFUSP)

Prof. Dra. Lucy Vitoria Credidio Assali (IFUSP)

Prof. Dr. Marcelo Nelson Paez Carrenõ (EP-USP) Profa. Dra. Márcia Carvalho de Abreu Fantini (IFUSP-Orientadora) Marim 'C de au Fantui
Prof. Dr. Valmor Roberto Mastelaro (IFSC-USP)

São Paulo -S.P residente da/Copasssão de Pós Gradueséco 


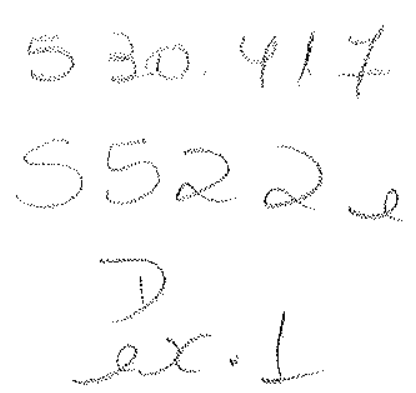

FICHA CATALOGRÁFICA

Preparada pelo Serviço de Biblioteca e Informação do Instituto de Física da Universidade de São Paulo

Scopel, Wanderlã Luis

Estudo das Propriedades Químicas, Morfológicas e Estruturais de Oxinitreto de Silício depositado por PECVD. São Paulo 2002.

Doutoramento (Tese) - Universidade de São Paulo Instituto de Física - Departamento Física Aplicada

Orientador: Profa. Dra. Márcia C. de Abreu Fantini Área de Concentração: Física da Matéria Condensada

Unitermos: 1. Amorfos; 2. Oxinitreto de Silicio;

3. Absorção de Raios-X; 4. Estrutura Atômica;

5. PECVD.

USP/IF/SBI-035/2002 
Estc trabalho recebeu apoio Financeiro da Fundação de Amparo à Pesquisa do Estado de São Paulo (FAPESP). 


\section{Agradecimentos}

Agradeço à Deus, à minha família, a todos os amigos e colaboradores cientílicos, professores, estudantes e técnicos, que contribuiram com seu apoio para a realização deste trabalho. 
"Há homens que lutam um dia e são bons,

Há outros que lutam um ano e são melhores,

Há aqueles que lutam muitos anos e são muito bons;

Porém, há aqueles que lutam toda vida, esses são imprescindiveis "

Bertolt Brecht 


\section{ÍNDICE}

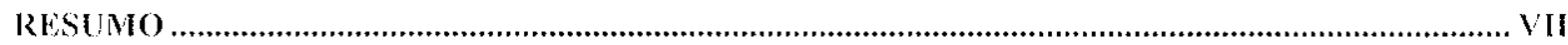

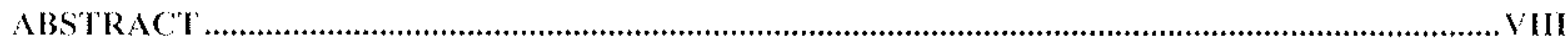

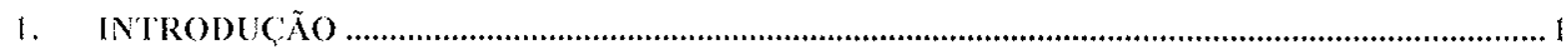

2. DESCRICÃO EXPERIMENTAL: DEPOSICÃO E CARACTERIZACÃO .................................

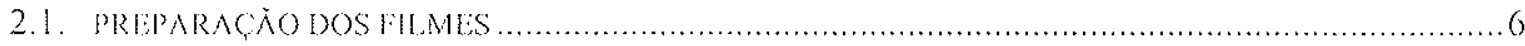

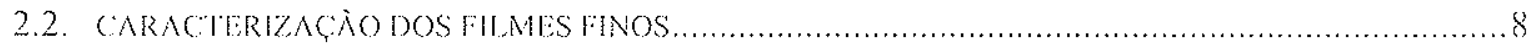

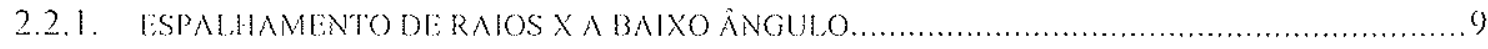

2.2.2. MICROSCOPIA ELETRONNCA DE TRANSMISSÃO E MEDIDA DE DENSIDADE...................1I

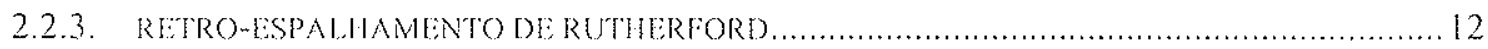

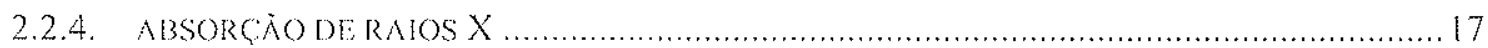

2.2.5. ISSPECTROSCOPA DE ABSORCAO NA REGIȦO DO INFRAVERMELHO ..............................2. 23

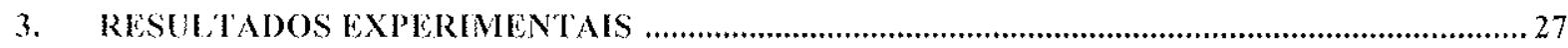

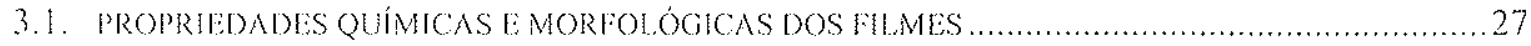

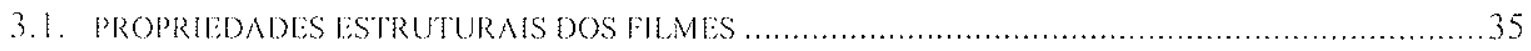

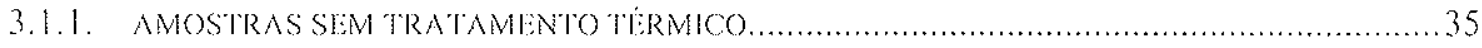

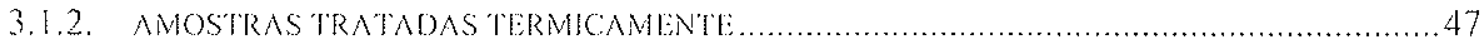

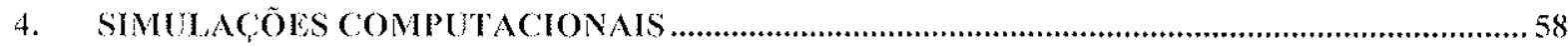

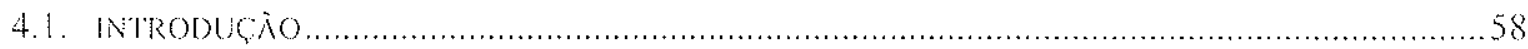

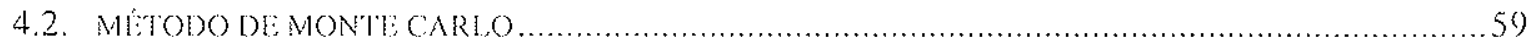

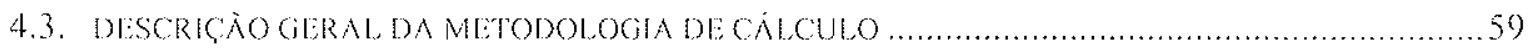

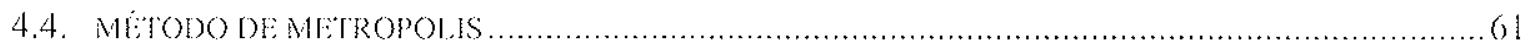

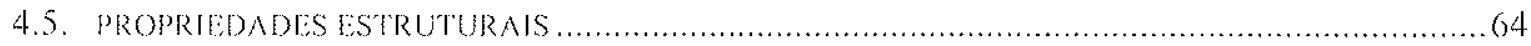

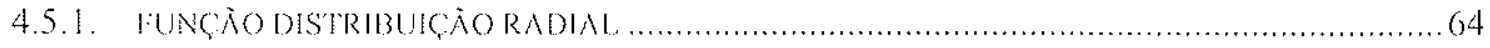

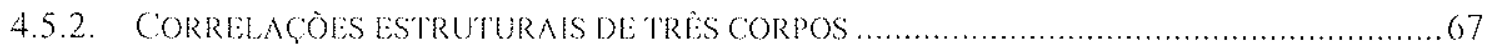

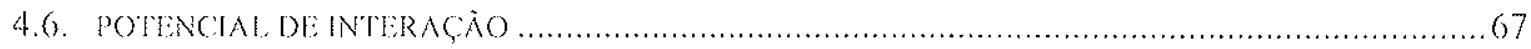

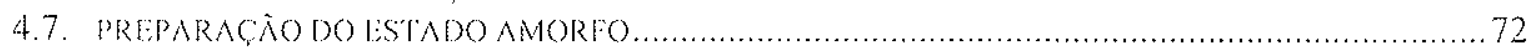

4.8. RESULTADOS DA ESTRUTURA ATOMICA: TEÓRICO E LXPERIMENTAL_..................................73

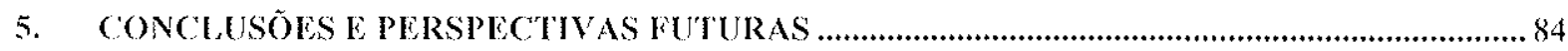

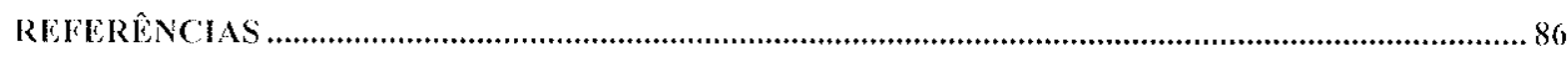

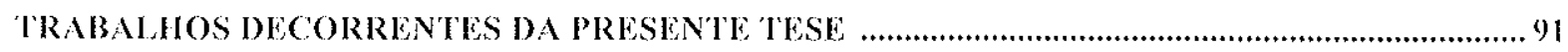

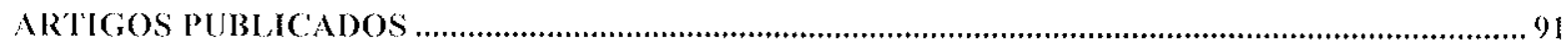

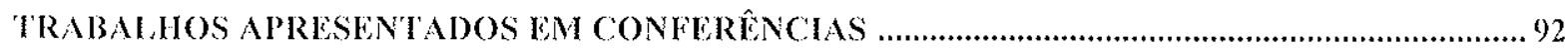




\section{RESUMO}

Neste trabalho, filmes amorfos de oxinitreto de silício ( $\left.a-\mathrm{SiO}_{\mathrm{x}} \mathrm{N}_{\mathrm{y}}: \mathrm{H}\right)$ foram crescidos pelo processo de Plasma Enhanced Chemical Vapor Deposition (PECVD) a temperatura de 320 "C. No processo de deposição loi utilizada a mistura dos gases óxido nitroso $\left(\mathrm{N}_{2} \mathrm{O}\right)$ e silano ( $\mathrm{SiH}_{4}$ ), variando-se a razão entre os seus fuxos (Re $\left.=\mathrm{N}_{2} \mathrm{O} / \mathrm{SiH}_{4}\right)$ num intervalo de $0,25 \leq R e \leq 5,00$. Foram obtidos filmes com diferentes composições químicas, sendo ricos $\mathrm{em} O(65$ at. \%) para $R e \geq 2,00$ e ricos em Si (44 at. \%) para Re $\leq 1,50$. A técnica de Rutherford backscattering spectroscopy (RBS) foi utilizada para determinar a composição química dos filmes. Os dados de RBS mostram un decréscimo da quantidade de $O$, cnquanto que as quantidades de Si e $N$ aumentam com o decréscimo de Re. A morfologia dos lilmes foi estudada por Small Angle X-ray scattering (SAXS), Tansmission Electron Microscopy (TEM) e medida de densidade pelo método de flutuação. Os dados de SAXS revelam a presença de centros espalhadores com raio médio que varia de 10 A a $100 \AA \AA$. Os resultados de TEM mostram a presença de aglomerados esféricos dispersos numa matri\% de mesmas espécies atômicas. A concentraçào de poros nos filmes é inferior a $10 \%$ e diminui com o aumento do conteúdo de oxigennio. Tanto a estrutura de ordem local quanto as ligações cuimicas foram investigadas pelas técnicas de X-ray Absorption Near Edge Suructure (XANES), Extented X-ray Absorption Fine Structure (EXAFS) e Fourier Transform Infrared spectroscopy (FTTR). Foi desenvolvido um potencial modelo de interação para simular a estrutura atômica do oxinitreto de silício amorfo e comparála com os dados experimentais. As simulações computacionais foram realizadas utilizando o método de Monte Carlo (MC)Metropolis. A análise estrutural das amostras ricas $\mathrm{cm} O$, tanto do ponto de vista experimental quanto teórico (obtidos por MC), mostram que a estrutura básica da rede é um telacedro, onde o átomo central é o Si conectado por O e N. Os resultados experimentais das amostras ricas em Si, apontam para a formação de agregados de $\mathrm{Si}$, embebidos dentro de uma matriz de Si-O-N. Tratamentos térnicos a vácuo em temperaturas entre 550 e 1000 "C promovem a efusão de hidrogênio e segregação de diferentes fases. 


\section{ABSTRACT}

In this work, thin films of amorphous silicon oxynitride $\left(a-\mathrm{SiO}_{x} \mathrm{~N}_{\mathrm{y}}: \mathrm{H}\right)$ were deposited by Plasma Enhaneed Chemical Vapor Deposition (PECD) at $320^{\circ} \mathrm{C}$. In the deposition process a mixture of nitrous oxide $\left(\mathrm{N}_{2} \mathrm{O}\right)$ and silane $\left(\mathrm{SiH}_{4}\right)$ was used, varying their flow ratio $\left(R e=\mathrm{N}_{2} \mathrm{O}_{\mathrm{SiH}}\right)$ in an interval of $0.25 \leq$ Re $\leq 5.00$. Films with different chemical composition were obtained, being $\mathrm{O}$-rich $(65$ at. \%) for $R e \geq 2.00$ and Si-rich (44 at. \%) for $R e \leq 1.50$. The Rutherford backscattering spectroscopy (RBS) was used to determine the atomic content of the films. The RBS data showed a decrease of the oxygen content, while the Si and $N$ contents increase with the decrease of Re. The film's morphology was studied by Small Angle X-ray scattering (SAXS), Transmission Electron Microscopy (TEM) and density measurements by the flotation method. The SAXS data revealed the presence of scattering centers with mean radius from $10 \AA$ to $100 \AA$. The TEM data showed the presence of spherical clusters dispersed in a matrix of the same atomic species. The concentration of pores in the material is less than $10 \%$ and decreases with the increase of oxygen content. The local atomic structure and chemical bonds were investigated by X-ray Absorption Near Edge Structure (XANES), Extended X-ray Absorption Fine Structure (EXAFS) and Fourier Transform lnfrared spectroscopy (FTIR). A model of interatomic potential was developed to simulate the atomic structure of the amorphous silicon oxynitride in order to be compared with the experimental data. The computer simulations were performed by the Monte Carlo (MC)-Metropolis method. The structural analysis of the O-rich samples, obtained by both experimental and theoretical simulations (obtained by $\mathrm{MC}$ ), showed that the basic structure of the network is tetrahedral, being $\mathrm{Si}$ the central atom connected by $\mathrm{O}$ and $\mathrm{N}$. The experimental results of the Si-rich samples indicate the formation of $\mathrm{Si}$ aggregates, embedded in a Si-O-N matrix. Annealing in vacuum, at temperatures between $550^{~ "} \mathrm{C}$ and $1000{ }^{\circ} \mathrm{C}$, promoted hydrogen effusion and segregation of different phases. 


\section{INTRODUÇÃO}

A indústria eletrônica atual é dominada pelo silicio. Em virtude de seu uso industrial, compostos e ligas a base de silício têm sido largamente investigados por pesquisadores na área de materiais. Em particular, filmes de óxido de silício amorfo $\left(a-\mathrm{SiO}_{2}\right)$ e de oxinitreto de silicio amorfo $\left(a-\mathrm{SiO}_{x} \mathrm{~N}_{y}\right.$ ), materiais investigados nesse trabalho, são muito utilizados em microcletrônica' e dispositivos ópticos integràdos". Uma rápida pesquisa na literatura ("Web of Science", junho 2002) utilizando como palavras-chave "amorphous silicon", "silicon dioxide", "silicon nitride" e "silicon oxynitride" lista 10675, 4480, 8031 e 652 antigos, respectivamente. Esses dados demonstram a relevância da pesquisa nesses materiais. É importante salientar que a liga ternária Si-O-N ainda não foi tão explorada quanto o a-Si c seus compostos binários, amorfos ou cristalinos. Dessa forma, se justificam os estudos acerca do crescimento desse material para fins especilicos, a fim de optimizar determinadas propriedades e particulamente, compreender a comelação entre estas e a estrutura do material. A seguir, faremos um breve relato sobre algumas caracteristicas relevantes dos materiais que investigamos.

Filmes de $a-\mathrm{SiO}_{2}$ (obtidos termicamente) possuem uma baixa densidade de defeitos na interfáce com o Si $\left(\sim 10^{10}\right.$ estados. $\left.\mathrm{cm}^{-2}\right)$, além de alta resistividade $\left(\rho>10^{15} \Omega(\mathrm{cm})\right.$, alta constante dielétrica $(k \sim 3,9)$, alta energia de banda proibida " $g a p " \sim 9 \mathrm{eV}) \mathrm{e}$ um alto ponto de fusào $(T,-2000 \mathrm{~K})$, o que viabiliza o uso deste material em dispositivos semicondutores (lo tipo MOS ("Metal Oxide Semiconductor") de alto desempenho. Estas propriedades foram extremamente importantes para a revoluçào na microeletrônica, que originou, por exemplo, o desenvolvimento de tecnologia planar. Por outro lado, estudos mostram a viabilidade do utilizar os filmes de a-SiO $\mathrm{N}_{y}$ no desenvolvimento de dispositivos ópticos integrados devido às suas excelentes propriedades ópticas, isto é, baixa perda por absorçào na regiào de comprimento de onda do visivel e infravermelho próximo. O índice de refraçào desses materias pode ser ajustado em um intervalo que vai desde $1,45\left(\mathrm{SiO}_{2}\right)$ até $2,00\left(\mathrm{Si}_{3} \mathrm{~N}_{4}\right)$. O controle acurado deste parânetro permite a labricaçào de guias de onda monomodal com baixas perdas. 
A demanda industrial para uma maior funcionalidade e execução dos circuitos inlegrados com baixos custos requer um aumento na densidade de circuitos, o qual exige uma maior densidade de lransistores por área. Dispositivos com tamanhos cada vez menores demandam por uma tecnologia de crescimento de filmes em nanoescala. Por exemplo, a espessura do dielétrico $\left(\mathrm{SiO}_{2}\right)$ dos dispositivos MOS deverá atingir, no futuro, valores menores que $40 \AA$, e algumas instabilidades poderão ser induzidas nesses dielétricos (por exemplo, no valor do "gap"). Neste sentido, alguns estudos teóricos e experimentais vêm sendo feitos nos filmes de óxido de silício sobre Si com espessura da ordem de 7 a $12 \AA$, para entender como o valor da banda proibida muda com o decréscimo da espessura." Entretanto, é proposto como uma altemativa para superar este desafio, a substituição dos dielétricos de óxido de silicio amorfo $\left(a-\mathrm{SiO}_{2}\right)$ térmico ultralinos por oxinitreto de silício amorfo $\left(a-\mathrm{SiO}_{x} \mathrm{~N}_{y}\right)^{5}$ a. 7.8 , uma vez que a incorporação de $\mathrm{N}$ melhora as propriedades dielétricas desses filmes (por exemplo, permissividade) quando comparadas às dos óxidos. Un outro avanço importante que advém da incorporação de $\mathrm{N}$ no óxido de silicio, é que este material atua como boa barrcira contra a penetração de boro" entre o eletrodo da porta ("gate"), que é um poli-silicio dopado por boro, c a regiào de canal ("channel") nos dispositivos MOS.

Além das aplicações en microeletrônica acima citadas, existe atualmente uma alta atividade científica e tecnológica relacionada ao estudo e à fabricação de dispositivos luminescentes a base de silício ${ }^{10,11,12,13}$. Isto, principalmente, porque o uso desse material lorna viável a integração de dispositivos ópticos e microeletrônicos no mesmo substrato de Si. O primeiro material estudado foi o silício poroso devido à sua alta fotoluminescência ${ }^{\text {14. }}$ 1. 16. Contudo, a instabilidade desses materiais, assim como suas frágeis propriedadeds mecânicas têm motivado a pesquisa de outros materiais a base de Si, que exibam propricdades ópticas similares. Recentemente, multicamadas de $\mathrm{Si} / \mathrm{SiO}_{2}{ }^{17} \mathrm{c}$ agregados de $\mathrm{Si}$ cm uma matriz de $\mathrm{SiO}_{2}$ vêm sendo pesquisados devido à intensa fotoluminescência clue eles também apresentam ${ }^{18.19}$. Resultados relacionados com este tema são freqüentemente mostrados na literatura ${ }^{20,21,22,23}$. Alguns trabalhos atribuem a fotoluminescência observada nestes matcriais a efeitos de confinamento quâtico ${ }^{24.25}$. Entretanto, o mecanismo responsável pela fotoluminescênciá ainda não é bem entendido ${ }^{26,27}$.

Filmes amorfos de óxido e oxinitreto de silício são obtidos basicamente por três processos: crescimento térmico, deposição química e implantação. O crescimento térmico 
desses materiais usualmente é feito em temperaturas muito maiores $\left(>10000^{\circ} \mathrm{C}\right)$ do que as utilizadas no processo de deposiçào e de implantação $\left.(<600)^{\circ} \mathrm{C}\right)$. A cinética das reaçòes químicas é extremamente dependente do processo utilizado. Além da dependencia com o processo utilizado, as propricdades lisicas, ópticas e elétricas dependem também da composição química dos filmes ${ }^{24,29}$.

Vários estudos ${ }^{30,31,32}$ mostram a viabilidade do uso de filmes espessos $(\sim 5 \mu \mathrm{m})$ de a- $-\mathrm{SiO}_{2}$ e a-SiOs $\mathrm{N}_{y}$ na indústria de microcletrônica e optoeletrônica, como camadas de cobertura protetora, microestruturas e dispositivos ópticos. A fabricação desses filmes, utilizando o processo convencional de oxidação ou oxinitretação térnica do silício a altas lemperaturas $\left(T>1000^{\circ} \mathrm{C}\right.$ ) é desvantajosa frente ao processo PECVD, devido aos longos tempos de crescimento e às tensões que estes materiais têm que suportar durante sua preparaçào ${ }^{33}$. Desta forma, a técnica de deposição química assistida por plasma (PECVD"plasma enhanced chemical vapor deposition") a baixas temperaturas $\left(\sim 320^{\circ} \mathrm{C}\right)$ e com altas taxas de deposição é uma alternativa promissora para a obtenção de fulmes espessos ${ }^{34 .}$, 3.0 processo de deposição química por PECVD fornece um certo número de variáveis (potencia de if, temperatura, lluxos de gases e pressão) que podem ser escolhidas durante o processo (le deposição do material. Assim, o ajuste adequado destes parâmetros de deposição permite a obtenção de materiais com características especificas para uma determinada aplicaçăo ${ }^{36}$.

Este trabalho, no qual crescemos e caracterizamos fímes de $a-\mathrm{SiO}_{x} \mathrm{~N}_{y}$, foi possivel graças a uma colaboração entre os seguintes grupos de pesquisa: o grupo de Novos Materiais e Dispositivos da Escola Politécnica da USP (Profá. Dra. Inês Pereyra e Dr. Marco I. Alayo), Laboratório de Cristalografia (Profa. Dra. Márcia Carvalho de Abreu Fantini) e grupo de Simulaçòes Computacionais de Materiais (Prof. Dr. Adalberto Fazzio e Prof. Dr. Antonio José Roque da Silva).

Em trabalhos anteriores ${ }^{34,35}$ do grupo da Poli/USP, foram encontradas condiçoes de deposiçào pelo processo PECVD, a altas taxas de crescimento $\left(1 \mu \mathrm{m} . \mathrm{h}^{-1}\right)$ e baixa temperatural $\left(\sim 320\right.$ "C), que permitem obter filmes espessos de a-SiO $\mathrm{N}_{y}$ e a-SiO 2 , esse último, estequiométrico com propriedades químicas e indice de refração comparáveis aos do óxido crescido temicamente. Neste trabalho, foi expandida a faixa de composiçoes possíveis nos filmes, obtendo-se desde $a-\mathrm{SiO}_{2}$ estequiométrico até $a-\mathrm{SiO}_{\mathrm{x}} \mathrm{N}_{\mathrm{y}} \operatorname{com} x \sim y \sim 0,5$ (composto rico $\mathrm{cm}$ Si), caracterizando-os quanto às suas propriedades químicas, morfológicas c estruturais. É importante salientar que os filmes estudados neste trabalho são hidrogenados". 
A discussão detalhada da escolha das rotas de preparaçăo das amostras encontra-se nas referências 34, 35 e 37, sendo a obtenção de filmes com um indice de refração bem controlado, a principal caracteristica positiva desse processo de preparação. As ligas ricás em Si possuem concentração de hidrogênio de até 30 at.\%, enquanto que as ligás ricas cm oxigento são pouco hidrogenadas, com concentração menor que 4 at.\%. Neste trabalho nos concentramos na investigação estrutural, combinando dados de estequiometria com os de espectroscopias de absorção no infravermelho e na faixa de raios $\mathrm{X}$, a fim de compreender a correlação entre composiçào, estrutura e propriedades físicas, não explorados nas relécências acima citadas, que se focalizaram no processo de obtenção do material. Alén disso, no decorrer deste trabaho uma nova linhá de pesquisa foi iniciada com a deposiçăo de lïmes ricos em silício, visando o desenvolvimento de dispositivos fotoluminescentes.

Na literatura sào reportados estudos ${ }^{28.38}$ sobre as propriedades físicas de filmes de a$\mathrm{SiO}_{x} \mathrm{~N}_{y} \mathrm{~cm}$ função dà composição quimica, morfologia e estrutura atômicá local. Particularmente, a correlação estrutura-propriedades físicas desse material ainda não está totalmente explorada. O conhecimento de tal correlação é fundamental para uma possivel aplicaçào tecnológica de filmes de a-SiO 2 e a-SiO $\mathrm{N}_{y}$. Por exemplo, a produção de dispositivos de alto desempenho à base de metal-oxinitreto-silício recuer uma baixa densidade de defeitos na interface $\mathrm{Si} / \mathrm{SiO}_{2}$. Existem dois modelos para explicar a estrutura atomica local do "bulk" de ligas de silício, são eles: modelo de mistura aleatória (RMM"Random mixture model") e o modelo de ligações aleatórias (RBM-"Random bonding model"). Estes modelos têm sido muito utilizados para descrever a estrutura de ordem local tetraédrica de ligas temárias a-SiO $N_{y}$ e das ligas binárias a-SiO $\mathrm{e} a-\mathrm{SiN}_{x}$.39. 40. 4 não estequiométricas. De acordo com o modelo RMM a liga a-SiO $x$ é composta pelas lases distintas $\mathrm{SiO}_{2}$ e Si, encluanto que a liga $\mathrm{SiO}_{x} \mathrm{~N}_{y}$ é composta pelas fases distintas $\mathrm{Si}_{3} \mathrm{~N}_{4}$ e $\mathrm{SiO}_{2}$. No modelo RBM supõe-se que as ligas a-SiOx e a-SiO $\mathrm{N}_{y}$ possuem umá rede com até cinco Ietraedros distintos de $\mathrm{SiO}_{v} \mathrm{Si}_{4-v}$ e $\mathrm{SiO}_{v} \mathrm{~N}_{4-v}$, onde $v=0,1,2,3$ e 4 , respectivamente. De acordo com a estrutura de ordem local do $\mathrm{SiO}_{2}$ e do $\mathrm{Si}_{3} \mathrm{~N}_{4}$, os sítios de $\mathrm{Si}$ sào toracdricamente coordenados por primeiros vizinhos de $\mathrm{O}$ ou $\mathrm{N}$, sendo o átomo de O ligado a dois átomos de Si, c o N localizado no centro de um triângulo equilátero de três átomos de $\mathrm{Si}^{42,43}$. No intuito de auxiliar na interpretação dos dados experimentais desenvolvemos um potencial modelo teórico para descrever a estrutura de "bulk" do sistema a-SiO $\mathrm{N}_{y}$, através de simulações computacionais utilizando o método de Monte Carlo (Metropolis). 
Dentre as técnicas de investigação da ordem local, a espectroscopia de absorçào de mios X (XAFS-"X-ray Absorption Fine Structure") é a técnica experimental mais indicada para obtenção de informaçŏes estruturais dos sistemas amorfos com múltiplos componentes. Isto porque a absorção dos fótons de raios $X$ é quimicamente específica; permitindo determinar a estrutura de orden local média em torno de uma determinada espécie atômicá. Essa foi uma das técnicas por nós empregada ná caracterização estrutural dos filmes de a$\operatorname{SiO}_{x} N_{y}$

Nesta introdução lizemos uma apresentação sobre o material estudado e stas possiveis aplicaçòes tecnológicas, assim como a motivação para a realização deste trabalho. No capítulo 2, descreveremos, de forma sucinta, o processo de deposição das amostras. Em seguida, faremos uma descriçăo das técnicas experimentais utilizadas na caracterizaçào química, morlológica e estrutural dos fílmes de oxinitreto de silício. No capítulo 3 , apresentaremos e discutiremos os resultados experimentais obtidos, assim como, os modelos utilizados nas análises. No capítulo 4, descreveremos o método computacional e o potencial modelo de interação utilizados para descrever a estrutura do sistema a-SiO $N_{y}$, e compararemos os resultados experimentais e teóricos. Finalmente no capítulo 5 aprescntarcmos as conclusões deste trabalho. 


\section{DESCRIÇÃO EXPERIMENTAL: DEPOSIÇÃO E CARACTERIZAÇÃO}

\subsection{PREPARAÇÃO DOS FILMES}

Os filmes finos $\left(a-\mathrm{SiO}_{\mathrm{X}} \mathrm{N}_{\mathrm{y}}\right.$ ) estudados nesse trabalho foram obtidos à temperatura de 320 "C por deposição química a vapor assistida por plasma (PECVD - "Plasmá Enhanced Chemical Vapor Deposition") no reator do Grupo de Novos Materiais e Dispositivos do L.ME da Escola Politécnica da USP. Nesse processo a cinética de deposição é baixa em temperaturas inferiores a $7000^{\circ} \mathrm{C}$. Sendo assim, utiliza-se normalmente uma fonte de rádio freqüencia (ri) para ativar a reação. O processo de deposição por PECVD consiste basicamente da mistura de gases apropriados, cujas moléculas são quebradas durante o processo de deposição devido ao impacto dos elétrons acelerados pela rádio freqüiencia aplicada entre os cletrodos.

Os radicais e moléculas resultantes das dissociações geradas pelo plasma de rf reagem entre si ainda na lase gasosa. Depois, os produtos dessas reações se depositam sobre um substrato aquecido, onde outras reaçöes físicas e quimicas podem ocorter. Nesse processo de deposiçào não existe consumo de substrato.

Os filmes foram depositados simultaneamente sobre três diferentes substratos, adequados as técnicas de caracterização. Os substratos utilizados foram: carbono amorfo ultra denso (UDAC- "Ultra Dense Amorphous Carbon"), mica natural e silício cristalino (100). Os gases ulilizados no processo de deposição foram silano $\left(\mathrm{SiH}_{4}\right)$ e óxido nitroso $\left(\mathrm{N}_{2} \mathrm{O}\right)$.

A espessura dos filmes depositados foi medida por um perlilômetro modelo Alpha step 500 da Teneor no Grupo de Novos Materiais e Dispositivos do LME da Escola Politécnica da USP. Este instrumento mede o perfil de superfícies de materiais sólidos através do movimento horizontal de una agulha sobre a superfície da amostra. 
As condiçòes experimentais utilizadas no processo de deposição por PECVD, assim como a laxa de deposiçào dos filmes (determinada a partir da medicla de espessura c do tempo de deposição), são mostradas na Tabela 2.1 , abaixo.

Tabela 2.1 - Condição de deposição das amostras; temperatura do substrato 320 "C; lluxo $\mathrm{SiH}_{4}=15 \mathrm{secm}$; potência de rf $500 \mathrm{~mW} / \mathrm{cm}^{2} ;$ rf $13,56 \mathrm{MHz}$.

$\begin{array}{cccc}R e=\mathrm{N}_{2} \mathrm{O} /\left(\mathrm{SiH}_{4}=15 \mathrm{sccm}\right) & \mathrm{N}_{2} \mathrm{O}(\mathrm{sccm}) & \begin{array}{c}\text { Pressão }(m \text { Torr }) \\ \text { Taxá deposição } \\ (\mathrm{mm} / \mathrm{h})\end{array} \\ 0,25 & 3,75 & 10 & 0,30 \\ 0,50 & 7,50 & 13 & 0,31 \\ 1,25 & 18,75 & 20 & 0,30 \\ 1,50 & 22,50 & 21 & 0,30 \\ 2,00 & 30,00 & 23 & 1,32 \\ 2,50 & 37,50 & 26 & 1,38 \\ 3,00 & 45,00 & 28 & 1,38 \\ 4,00 & 60,00 & 34 & 1,06 \\ 5,00 & 75,00 & 40 & 0,59\end{array}$

Na Tabcla 2.1 observamos que a pressão dentro da câmera de deposição aumenta com o aumento do fluxo de óxido nitroso. Esse resultado era esperado, una vez cue o lluxo de silano ć mantido constante. Outro resultado importante observado é que a laxa de deposiçào é baixa para as amostras com $R e \leq 1,50$, quando comparadas as amostras com $R e$ $\geq 2.00$. Tal fator experimental limita a deposição de filmes espessos. Filmes com espessura da ordem de $(-5 \mu \mathrm{m})$, só foram conseguidos para amostras com $R e \geq 2,00$, pois para as amostras com pequenos valores de Re, os substmatos apresentaram trincas e os filmes se (lesprenderam do substrato.

No intuito de medir a densidade dos fílmes de a-SiO $\mathrm{N}_{y}$ pelo método de flutuação ts. 46, filmes auto-sustentados foram obtidos utilizando o processo de fotogravação ${ }^{47} \mathrm{com}$ máscaras especiais. A obtenção desses fîmes requer uma resistência mecânica suficiente para definir estruturas tipo plataforma, praticamente sem qualquer apoio em sua região 
inferior. O processo de obtenção de filmes auto-sustentados consiste basicamente em fayer a deposiçào sobre substrato de Si (100) tanto na frente cluanto no verso. O fílme depositado no verso, fologravado com máscara adequada, permite criar uma moldura de silicio que no lim do processo servirá como suporte para sustentar o filme. O substrato foi removido $\mathrm{cm}$ soluçào de KOH. Devido à necessidade de filmes com umá resistência mecânica apropriada, somente a amostá com $R e=2,50$ foi obtida com sucesso, sendo que nas demais a plataforma degradou-se antes mesmo do término do processo de corrosão.

Filmes de $a-\mathrm{SiO}_{x} \mathrm{~N}_{y}$ depositados por PECVD a baixa temperatura, normalmente apresentam ligaçòes Si-OH, Si-H e N-H. Esses tipos de ligaçōes são indescjáveis quando esses matcriais são utillzados en dispositivos ópticos. Assim, estes filmes normalmente sào submclidos a tratamento térmico. No nosso trabalho, somente amostras com $R e=2,50 \mathrm{e} 0,25$ foram tratadas termicamente, uma vez que apresentam uma maior quantidade de ligaçòcs SiH c N-H, respectivamente (conforme discussão no cap. 3). O tratamento témico foi realizado $\mathrm{em}$ vácuo (10 $0^{-5}$ Torr) durante 2 horas nas seguintes temperaturas: $550,750 \mathrm{e} 1000$ ${ }^{\circ} \mathrm{C}$.

\subsection{CARACTERIZAÇÃO DOS FILMES FINOS}

O conhecimento do arranjo atômico e da morfologia de um material na fase sólida é essencial para o entendimento de suas propriedades físicas e químicas. Isso é válido tanto para um material cristalino como para um material amorfo. A estrutura de um material cristalino é construida a partir da cela unitária, isto é, a estrutura do cristal é gerada lazendose a repetição periódica da mesma no espaço. Então a determinação da estrutura de um material cristalino é baseada fundamentalmente em resolver a cela unitára que possui um número finito de átomos. Por outro lado, tal procedimento é impraticável para um sólido amorfo aperiódico, porque os sistemas amorfos possuem apenas ordem de curto alcance. Um sólido amorfo nào é aleatório no sentido estatístico, pois, para uma determinada escala de comprimento (menor que uma dezena Angstrom) exibe sua ordem local calacterística, muitas vezes bastante similar ao sólido cristalino.

Muitos dos fïlmes amorlos depositados por PECVD cxibem inomogeneidades de densidade eletrônica, isto é, vazios ou separação de fases para certas composiçôes. Assim, 
caracterizaçoes morfológicas foram realizadas em nossos filmes, utilizando as técnicas de espahamento de raios $X$ a baixo ângulo (SAXS -" Small Angle X-ray Scaltering"), Microscopia Eletrônica de Transmissão (TEM -"Transmission Electron Microscopy") c una medida de densidade por meio de densimetros ${ }^{48}$. A composição química dos filmes fó obtida por retroespalhamento de Rutherford (RBS -"Rutherford Backscattering Spectrometry") c as propriedades estruturais e químicas foram estudas por espectroscopia de absorção na região do infravermelho (FTIR - "Fourier Transform Infrared") e estrutura fina por absorçào de raios X (XAFS "X-Ray Absorption Fine Structure"), conforme descreveromos a seguir:

\subsubsection{ESPALHAMENTO de RAIOS X A BAIXo ÂNGULO}

\subsubsection{FUNDAMENTOS BÁSICOS}

Matcriais amorfos nomalmente apresentam inomogeneidades devido a defeitos de crescimento. Inomogeneidades da ordem de dezena a centena de Ansgstrons envolvendo Mutuaçào de composição ( entre vazios e matriz ou entre duas lases com diferentes composiçòes quimicas) podem ser determinadas por espathamento de raios $X$ a baixo ângulo (SAXS).

Considere um sistema em que existe um número grande de partículas idênticas distribuidas de forma totalmente aleatoria, e que o volume médio disponivel para cada particula é grande comparado com o volume das partículas. Então, em primeima aproximaçào, pode-se considerar que o sistema acima descrito é composto por $N_{p}$ partículas que nào interagem entre si. Quando um feixe de aios $X$ interage com esse sistemá, a intensidade total espalhada por esse conjunto de partículas é a soma da contribuição de cada uma das partículas. Se as partículas desse sistema possuírem mesma orientação, a intensidade espallhada scrá proporcional a $N_{p}$ vezes a intensidade espalhada por partícula. Por outro lado, se as partículas possuírem orientações aleatórias, a intensidade espalhada por uma simples partícula será a média sobre todas as suas possíveis orientações.

Considerando um sistena composto por $N_{p}$ partículas idênticas, monodispersas em tamanho, e esféricas, a intensidade espalhada ć dada por ${ }^{49}$ : 


$$
I(q)=N_{r}, \int 4 \pi r^{2} \Delta \rho^{2} \frac{\operatorname{sen}(q r)}{q r} d r
$$

onde $\Delta p$ é o contraste de densidade eletronica entre a partícula e o meio.

Fazendo uma integração por partes na eq. 2-1, temos que a intensidade média espalhada pode ser reescrita como sendo

$$
I(q)=N_{p}[\phi(q, R)]^{2}
$$

onde

$$
\phi(q, R)=\Delta \rho \frac{4}{3} \pi R^{:}\left\{\frac{3[\operatorname{sen}(q R)-q R \cos (q R)]}{q^{3} R^{3}}\right\}
$$

sendo $R$ o raio do objeto espalhador.

Por outro lado, supondo que o sistema seja composto por partículas esféricas de tamanhos diferentes, podemos reeserever a intensidade espalhada para esse conjunto de espathadores como sendo:

$$
I(q)=\int N(R)[\phi(q R)]^{2} d R
$$

onde $N(R)$ é a função distribuição de tamanhos.

No nosso trabalho, os dados de SAXS foram analisados considerando um sistema constituído de partículas ou poros isolados, não correlacionados. Assumindo esse modelo simplificado, e que os elementos espalhadores possuem forma esférica de diversos tamanhos (evidenciado por TEM), podemos determinar a distribuição de tamánhos desses centros espalhadores. A função distribuição de volume dos espalhadores é dada por:

$$
D_{,}(R)=\frac{4}{3} \pi R^{3} N(R) \text {. }
$$

Reescrevendo a eq. 2-4 como funçào de $N(R)$, temos :

$$
l(q)=\frac{3}{4 \pi} \int \frac{D_{n}(R)}{R^{3}}[\phi(q R)]^{2} d R .
$$

Neste trabalho, utilizamos o programa GNOM ${ }^{50}$ para obtenção de D..(R). Com este programa calcula-se a intensidade espalhada por um conjunto de esferas não interagentes 
con uma determinada distribuição de volumes $D_{N}(R)$. A funç̃o $D_{V}(R)$ é escolhida através de uma análise da qualidade de ajuste entre a intensidade calculada via eq. 2-6 a a curva experimental.

\subsubsection{PROCEDIMENTO EXPERIMENTAL}

O experimento de SAXS fo realizado na linha de SAS do Laboratório Nacional de Lu\% Sincrotron (LNLS), Campinas, S.P. O comprimento de onda monocromático do feixe de raios $X$ loi $\lambda=1,608 \mathrm{~A}$. Na geometria utilizadá o feixe pode ser considerado como ponto. A distancia amostra detetor foi ajustada para observarmos espalhamento numa regiào de q entre 0,01 a $0,3 \AA^{-1}$.

Para o experimento de SAXS, filmes de espessura da ordem de 5 fm foram depositados sobre substrato de mica natural. A intensidade espalhada dos filmes foi corrigida segundo a seguinte expressão ${ }^{51}$ :

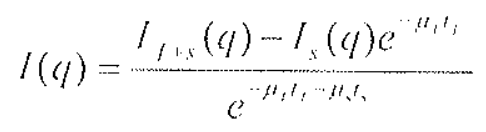

oncle $I_{f, s}$ ć a intensidade espalhada pelo (filme + stibstrato), $I_{s}$ é a intensidade espalhada pelo substrato, $\mu_{s} t_{s}$ é o produto do coeficiente de absorção pela espessura do substrato, c $\mu \mu_{f}$ loi obtido lazendo-se a razão da intensidade do feixe direto absorvida pelo filme mais substrato pelá intensidade do feixe direto absorvida pelo substrato (mica).

\subsubsection{MICROSCOPIA ELETRÔNICA DE TRANSMISSÃO E MEDIDA DE DENSIDADE}

As medidas de microscopia cletrônica de transmissão (TEM) foram realizadas no LNLS, Campinas, SP, utilizando um microscópico eletrônico de transmissão JEOL modelo JEM 3010. Para este experimento, fílmes com espessura da ordem de 200 A foram (lepositados sobre substrato de mica natural. O material depositado sobre a mica foi removido $\mathrm{cm}$ água tridestilada e en seguida colocado sobre uma grade de cobre para análise no microscópico.

A medida da densidade baseou-se no método de flutuação ${ }^{45.40}$, que parte do princípio que un sólido colocado dentro de un líquido de mesma densidade deverá permanecer 
estável depois que ele for submerso, isto é, não afundará, nem tampouco virá à superfïcie. Esse experimento foi realizado no LCr-IFUSP à temperatura de $24^{\circ} \mathrm{C}$ flutuando o filme aluto-sustentado cm solução de brometo de metila, $\mathrm{CHBr}_{3},\left(\rho=2,82 \mathrm{~g} . \mathrm{cm}^{-3}\right)$ e álcool ctílico, $\left(2, H_{6}, O,\left(\rho=0,787 \mathrm{~g} \cdot \mathrm{cm}^{-3}\right)\right.$. A curva de calibração dá densidade foi obtida em um intervalo de 1,60 até $2,60 \mathrm{~g}_{\mathrm{s}} \mathrm{cm}^{-3}$, usando densimetros construídos especialmente para o experimento ${ }^{4.8}$. Para verificamos a validade do método, utilizamos como referência o Si monocristalino (de densidade nominal $\left.2,33 \mathrm{~g} . \mathrm{cm}^{-3}\right)$, obtendo um valor de $(2,29 \pm 0,03) \mathrm{g} . \mathrm{cm}^{-3}$ galrantindo assim a confrabilidade dá medida.

\subsubsection{RETRO-ESPALHAMENTO DE RUTHERFORD}

\subsubsection{FUNDAMENTOS BÁSICOS}

No retro-espathamento Rutherford (RBS), um feixe de íns monoenergéticos colidem con os átomos de uma amostra. Os íons são retro-espalhados e detetados en função de sua energia remanescente. Na colisão, certa energiá é transferida do ín incidente para o átomo estacionário (atvo). A taxa de redução da energia do ín espalhado depende da relaçào dás massas do ion incidente e do átomo alvo e permite assim determinar a identidade do átomo alvo. Kentificado o átomo alvo, sua densidade em átomos $/ \mathrm{cm}^{2}$ no filme pode ser determinada a parti da probabilidade de colisão entre os íons incidentes e os átomos do alvo, medindo-se o número de ions detetado $A$, para um certo número $Q$ de íons incidentes. A relação entre $A$ e Q é dada pela secção de choque de espalhanento. Finalmente, a profundidade local (em relação à superfície do material) onde ocorreu a colisấo pode ser inferida a partir da perda de energia do íon em seu percurso no interior da amostra. Quando um ín se move através do material, ele perde energia por meio de inúmeras colisòes com os clétrons no filme (a probabilidade de espalhamento nuclear é muito pequena quando comparada com a interação com os elétrons, devido à reduzidá dimensão do núcleo atômico, podendo, assim, ser desprezada). Sendo a perda de energia proporcional ao comprimento da Lajetória percorrida pelo ion no interior da amostra, é possível estabelecer uma escala de profundidade e associar a energia do íon detetado ao local em que ocorreu a colisão. 
O grande sucesso das análises de RBS com feixes de $H^{+}$e $/ e^{-1}$ com energia da ordem de 2,4 MeV, deve-se entre outras coisas à possibilidade de modelar leoricamente os espectros experimentais com excelente precisão a partir de princípios simples de espallamento clássico ${ }^{52.53}$.

No RBS, a colisão entre os íons do feixe e os átomos do alvo pode ser descrita como um espalhamento clássico entre duas massas puntiformes com carga positiva. A cinemática da colisão independe das ligações cletrônicas e portanto é insensível ao estado químico da amostra. Numa colisão elástica, a conservação da energia e do momento linear permitem calcular a relação entre a energia do ion espalhado, $E_{1}$ e sua energía inicial Eo, dada a $\operatorname{seg} u 10^{54}:$

$$
K_{N}=\frac{E_{1}}{E_{0}}=\left[\frac{\left(1-\left(M_{1} / M_{2}\right)^{2} \cdot \operatorname{sen}^{2} \theta\right)^{2}+\left(M_{1} / M_{2}\right) \cdot \cos \theta}{1+\left(M_{1} / M_{2}\right)}\right]^{2}
$$

onde $K_{N}$ é denominado fator cinemático, sendo que $N$ indica o símbolo do átomo que sofreu colisào com o ín do feixe, $M_{i}=$ massa ( $i=1$, ín do feixe incidente; $i=2$, átomo alvo), e 00 ângulo entre o feixe incidente e o detetor.

Por outro lado, como foi mencionado anteriomente, quando um ion do feixe incidente se move para dentro do filme sem sofrer nenhuma colisão com os átomos alvo, cle perde energia devido às inúmeras colisões com os elétrons do material. Esta perda de encrgia está relacionada com a distância que o ion percorre dentro do material. Assim, a quanticlade de energia (E) perdida por unidade de distância $(x)$ é conhecida como poder de freamento (S) , sendo definida por:

$$
S=-\frac{d E}{d x}[\mathrm{eV} / \text { Angstron }]
$$

onde $x$ é definido como a distância a partir da superfície do material percorrida pelo feixe. Note que o sinal negativo, na definição acima, gera um valor positivo para o poder de freamento, uma vez que a energía diminui à medida que $x$ cresce.

O poder de freamento é considerado constante nas condições em que se realizam análises RBS. Assim, a perda de energia de um feixe de íons em um filme fino com espessura l é dada com boá aproximação por: 


$$
\Delta E(t)=\left.\int^{\prime} \frac{d E}{d x} d x \cong \frac{d E}{d x}\right|_{i n} \cdot
$$

onde $d l: / d x]_{\text {in }}$ é calculado em alguma energia intemediária entre a energia incidente e a energia na profundidade t. E(t). As partículas espalhadas no interior de uma amostra perdem encrgia tanto no caminho de entrada como no caminho de saída, rumo ao detetor. Na Figura 2.1, as particulas de um feixe com energia $E_{0}$ incidem com um ângulo $\theta_{1}$, penetram até a profundidade $x$ e emergem com energía $E_{1}$ e ângulo $O_{2}$.

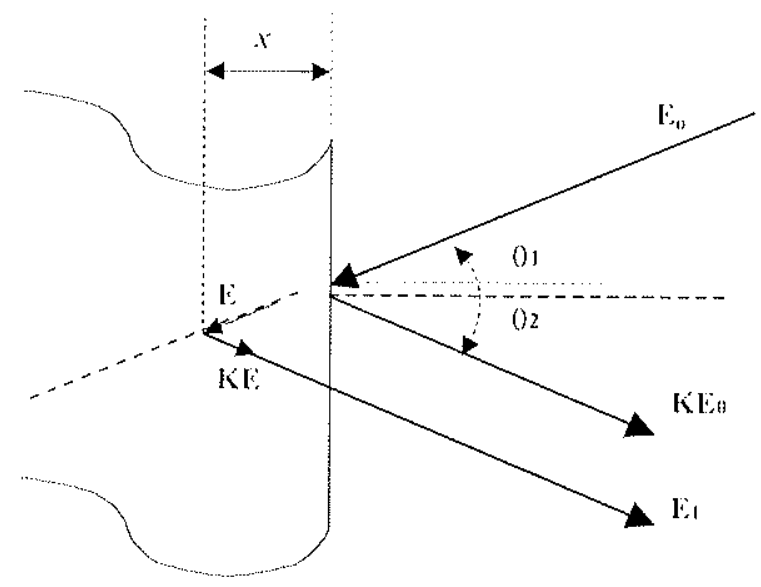

Figura 2.1- Esquema e coordenadas para a definição do fator de perda de energia $|S|$.

Assumindo constante o poder de freamento nos percursos de entrada (c) e saida (s),

Iemos que:

$$
\begin{aligned}
& E=E_{0}-\left.\frac{x}{\cos \theta_{1}} \frac{d E}{d x}\right|_{,} \\
& E_{1}=K E-\left.\frac{x}{\cos \theta_{2}} \frac{d E}{d x}\right|_{s}
\end{aligned}
$$

Fazendo a combinaçào das equações eqs. 2.11 e 2.12 :

$$
\Delta E_{d}=K E_{0}-E_{1}=[S] \cdot x
$$




$$
[S]=\left[\left.\frac{k}{\cos \theta_{1}} \frac{d E}{d x}\right|_{1}+\left.\frac{1}{\cos \theta_{2}} \frac{d E}{d x}\right|_{x}\right]
$$

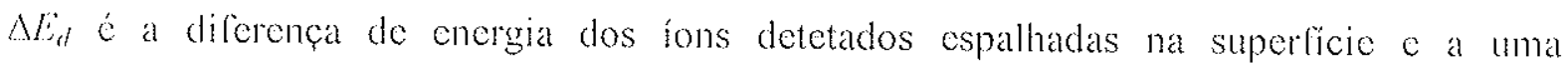
profundidade $x$ no interior da amostra.

Um espectro RBS é un gráfico da intensidade (taxa de contagens) em função da energia das partículas detectadas. Um espectro é na realidade um histograma onde o cixo das cnergias (abscissa) é dividido em 512 ou 1024 canais. Cada canal corresponde a um pequeno intervalo de energia, da orden de $5 \mathrm{KeV} /$ canal. O espectro de uma análise RBS de um lilme lino de $\mathrm{SiO}_{2}$, por excmplo, com espessura $l=300 \mathrm{~mm}$, depositado sobre substrato de UDAC pode ser observado a seguir:

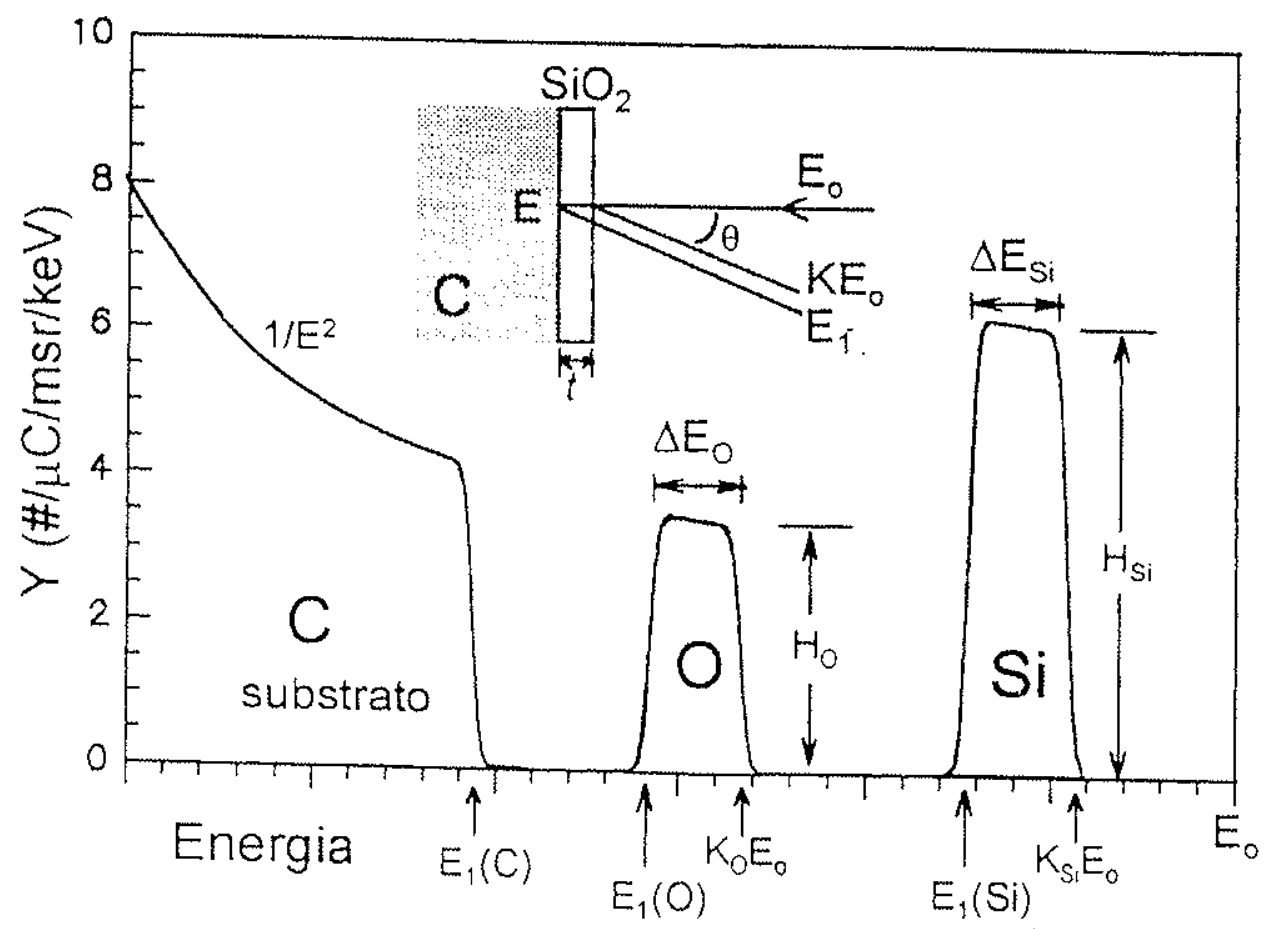

Figura 2.2- Espectro RBS de um filme fino de $\mathrm{SiO}_{2}$ com $300 \mathrm{~nm}$ de espessura sobre substrato de carbono.

Conforme o espectro acima, o feixe de ions que incide na amostra com energia $E_{p}$, é espalhado na superfície com energia $K_{0} E_{0}$ (átomo de O) ou $K_{s i} E_{\theta}$ (átomo de silicio) acpendendo do átomo com que tenha colidido. Ao atingir a interface com o substrato, a chergia do feixe é $E=E_{0}-\Delta E$. O valor de $\triangle E$ pode ser calculado conforme a eq. 2.10 . 
Acontece que para determinar $d E / d x$ do filme é necessário saber sua estequiometria que é em geral, a incógnita do problema. Assim, usam-se métodos iterativos e programas de computador que permitem simular espectros de RBS para uma dada composição/estrutura da amostra $^{55}$. Na interface entre o carbono liso e o SiO $\mathrm{O}_{2}$ as partículas do feixe são espalhadas com energia $K_{C} E$ caso colidam com átomos de carbono, $K_{0} E$ se colidirem com oxigenio e $K_{, y} E$ se colidirem com átomos de silício. As partículas espalhadas, cada qual com sua energia, são, mais uma ve\% freadas em seu caminho de saída através do filme rumo ao delector, cmergindo respectivamente com energias:

$$
E_{1}(C)=K_{c} \cdot E_{0}-[S] \cdot / \quad E_{1}(O)=K_{0} E_{i_{0}}-[S] \cdot / E_{1}(S i)=K_{S i} E_{0}-[S] \cdot t
$$

Num filme fino a largura dos picos elementares no espectro RBS é dada por:

$$
\Delta E_{O}=[S]_{O}^{\text {meios }} \cdot t \quad \Delta E_{S i}=[S]_{S i}^{\text {meio }} \cdot t
$$

onde $[S]_{N}{ }^{m+i o}$ indica que no cálculo de $[S]$ usa-se o fator cinemático $K_{N}$ e o poder de freamento do meio $\left(\mathrm{SiO}_{2}\right)$.

A altura $Y_{k}$ das contagens no canal $k$ num espectro multicanal, é o número de eventos acontecidos com energia entre $E_{k}$ e $E_{k}-\delta$. A eq. 2.13 e sua subseqüente derivação permite associár a cada canal (com largura $\delta$ ) uma "fatia" dá amostra com espessura $x=8 /[S]$. Dessa forma, o número de eventos $Y_{k}$, coletados num canal é função da espessura da fatia ná amostra e do número de unidades espalhadoras (átomos da espécie $i$ ) na fatia:

$$
Y_{k}=\sigma_{i}\left(E_{k}\right) \cdot \Omega \cdot Q \cdot N_{i} \cdot\left(\frac{x_{i}}{\cos \theta_{i}}\right)
$$

onde $N_{i}$ é a densidade total do elemento $i, \sigma_{i}\left(E_{k}\right)$ é a seção de choque de espalhamento diferencial num perfil de profundidade, $\Omega$ é o ângulo sólido de deteção e $Q$ é a quantidade total de particulas incidentes na amostra.

O número de eventos de espalhamento ocorridos num filme com espessura $t$ (área do pico no espectro RBS) pode ser calculado diretamente substituindo $x$ por $t$ :

$$
A=\sigma_{i}\left(E_{0}\right) \cdot \Omega \cdot Q \cdot N_{i} \cdot\left(\frac{t}{\cos \theta_{1}}\right)
$$

Essa expressão pemite determinar $N_{i}$, sem a introdıção do poder de freamento, em geral desconhecido e fonte de considerável incerteza. Conhecidos os parâmetros experimentais $\Omega, Q$ e $\theta_{1}$, pode-se determinar $N_{i}$ de forma absoluta. 


\subsubsection{PROCEDIMENTO EXPERIMENTAL}

No experimento de RBS foram utilizados fulmes com espessura da ordem de 1000 A depositados sobre substrato de UDAC. O experimento foi realizado no Laboratório de Análise Materiais por Feixe lônico (LAMFI) no IFUSP. Foi utilizado um feixe $/ e^{*}$ de energia $E=2,40 \mathrm{MeV}$, com carga $Q=20 \mu \mathrm{C}$, corrente $I=30 \mathrm{nA}$ e ângulo de deteção de $\theta=$ $1)^{\circ} \mathrm{em}$ relação ao feixe incidente. A densidade $\mathrm{em}$ (átomos $/ \mathrm{cm}^{2}$ ) é obtidá utilizando o programa RUMP ${ }^{55}$. Análise de dados foi obtida com supervisão do coordenador do LAMFI, Prol. Dr. Manfredo H. Tabacniks.

\subsubsection{ABSORÇÃO DE RAIOS $X$}

\subsubsection{FUNDAMENTOS BÁSICOS}

A espectroscopia de absorção de raios $X^{56}$ mede o coeficiente de absorçăo de raios $X$ como função da energia (E) incidente no material. A atenuação de raios X pela matéria segue a equação:

$$
I_{1}=I_{0} e^{-\mu t x}
$$

onde $I_{f}$ ć a intensidade total medida após a transmissão pela amostra, $l_{0}$ é a intensidade do reixe incidente, $\mu$ é o coeficiente de absorção da matéria e $x$ é a espessura da matéria a cual o feixe atravessal.

Quando graficamos o coeficiente de absorção como função da energia incidente (E), o espectro experimental (Figura 2.3) pode ser dividido em três regiões distintas en energia:

1. Região de pré-borda: consiste normalmente de um decréscimo monotônico do coeficiente de absorção de raios X com aumento da energia incidente.

2. Região da borda: consiste de um aumento abrupto do coeficiente de absorção numa dada energia $\left(E_{0}\right)$ do fóton incidente, necessária para ejetar um elétron fortemente ligado ao núclco (por exemplo, o elétron Is da camada $K$ ), criando um fotoclétron. 
A transição associada é sempre para estados não ocupados, isto é, paráa estados cm que a energia do fotoelétron é maior que a energia de Fermi ${ }^{57}$. A posiçào $\mathrm{cm}$ cnergia de cada borda de absorção (Figura 2.3) é relacionada a um determinado átomo presente no material, pois a energia de ligação do elétron numa determinada camada intema é associada ao número atômico de cada elemento.

3. Na região pós-borda o coeficiente de absorção exibe pequenas oscilações para valores de energia $E$ maiores que a da borda de absorção $\left(E_{,}\right)$.

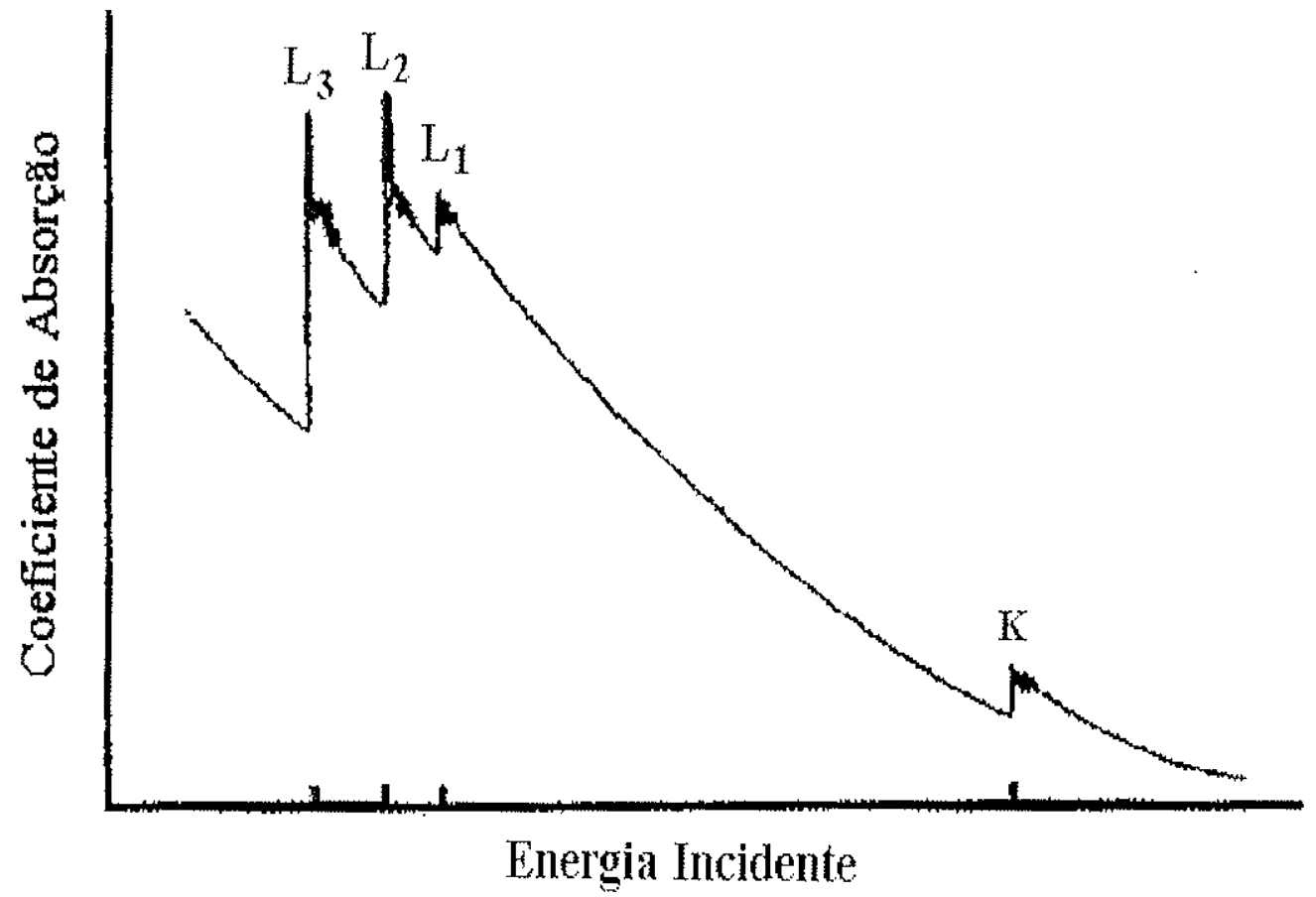

Figura 2.3- Visão esquemática do coeficiente de absorção como função da energia do fóton incidente. Da figura observa-se que o coeficiente para as todas as bordas $L_{3}, L_{2}$, $I_{1}, K$ decrescem como função da energia incidente do fóton.

Em geral, a região pós-borda é conhecida como estrutura fina de absorçào de raios $X$ (XAFS- "X-Ray Absorption Fine Structure"). Nessal região, as oscilações acima da borda de absorção (Figura 2.4) são devidas às interações entre os fotoelétrons com os átomos que circundam o átomo absorvedor. Então, a regiào de XAFS, quando interpretada corretamente, pode ser utilizadá para cxtrair informações estruturais atômicas a respeito do material em 
análise. Devido às contribuições de fenômenos diferentes, a região de XAFS é divididá em oulras duas regiões (Figura 2.4 , por exemplo):

1. Para energias da ordem de $100 \mathrm{eV}$ acima da borda é conhecida como estrutura fina estendida de absorção de raios X ( EXAFS- "Extented X-ray Absorption Fine Structure");

2. A região de energia próxima à bordá é conhecida como estrutura próxima à borda de absorçào de raios X (XANES- "X-ray Absorption Near Edge Structure").

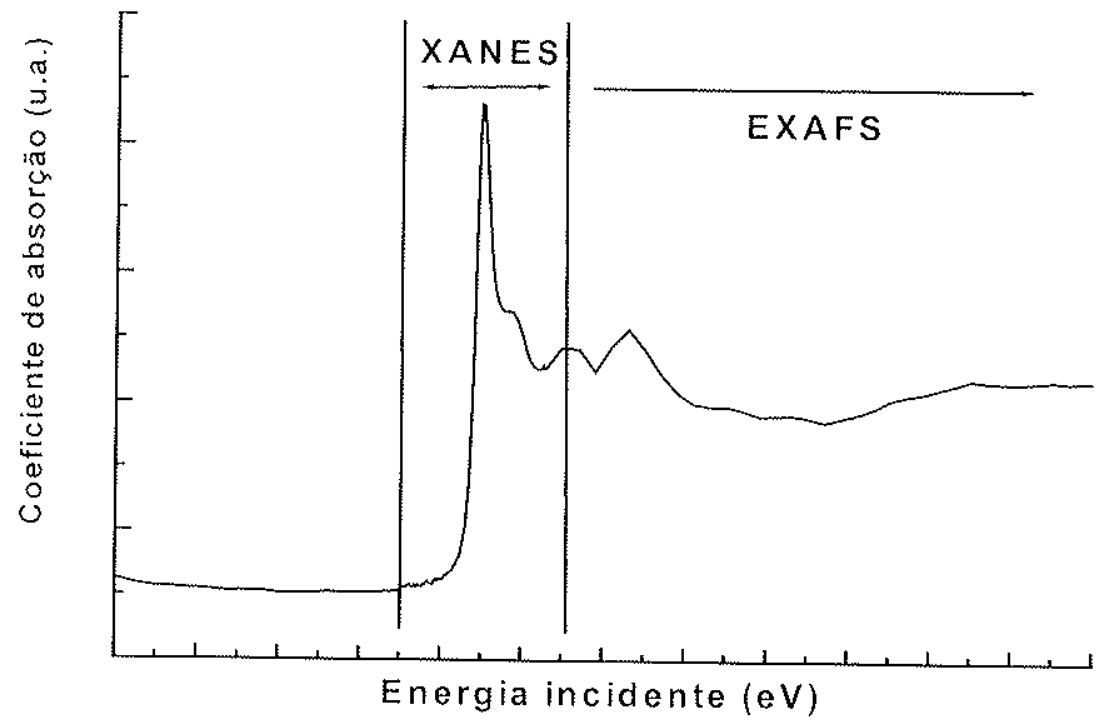

Figura 2.4- Espectro do coeficiente de absorção de raios $\mathrm{X}$ na borda $K$ do Si.

As oscilações presentes no espectro de XAFS (Figura 2.4) são interpretadas como um fenomono de interferênciá quântica. Assim, quando um átomo (absorvedor) é circundado por outros átomos, o fotoctétron que sá do átomo absorvedor pode ser interpretado como uma onda que é espalhada pelos átomos vizinhos. Então, a função de onda do estado final pode ser expressa em termos da onda que é emitida pelo átomo absorvedor mais as ondas que sào retro-espalhadas pelos átomos vizinhos. Essas funções de ondas interferem de forma construtiva ou destrutiva, dependendo do comprimento de onda do fotoelétron e da distancia aos átomos espalhadores. Esse efeito de interferência dá origem a oscilaçòes que aparecen no coeficiente de ábsorçăo. Considerando a aproximação de dipolo, o coeficiente de absorção pode ser tratado pela teoria de perturbação de primeira ordem ${ }^{58}$ e então, pela regla de ouro de Fermi, temos que: 


$$
\mu(E) \propto \sum_{r}\left|\left\langle f\left|H^{\prime}\right| i\right\rangle\right|^{2} \delta\left(E_{i}-E_{i}-h v\right)
$$

onde If'é hamiltoniana que expressa a interação fóton (incidente)-elétron, $/ y$ ć a energia do fóton incidente, $E_{f} \mathrm{e} E_{i}$ as energias do elétron nos estados final (estado final da funçĩo de onda do fotoctétron) e inicial (estado inicial da função de onda do elétron excitado, por exemplo, is da camada $K)$, respectivamente.

O coeficiente total de absorção de um átomo especifico na matéria é estimado experimentalmente como sendo:

$$
\chi(E)=\frac{\mu(E)-\mu_{0}(E)}{\Delta \mu_{0}}
$$

onde $\mu_{0}(E)$ ć o coeficiente de absorção do átomo de interesse isolado estimado através de um ajuste polinomial da parte oscilatória acima da borda de interesse(Figura 2.5). Por outro lado, $\Delta \mu_{0}$ ć o làtor de nomalização obtido pela diferença entre $\mu_{0}(E)$ e a absorção de fundo. Esta é obtida ajustando-se normalmente uma reta na pré-borda, e extrapolando-se a mesma além da borda de absorção (indicado pela linha traço ponto). O termo $\chi(E)$ é a mudança induzida no coeficiente de absorção devida áos átomos vizinhos que circundan o átomo de interesse.

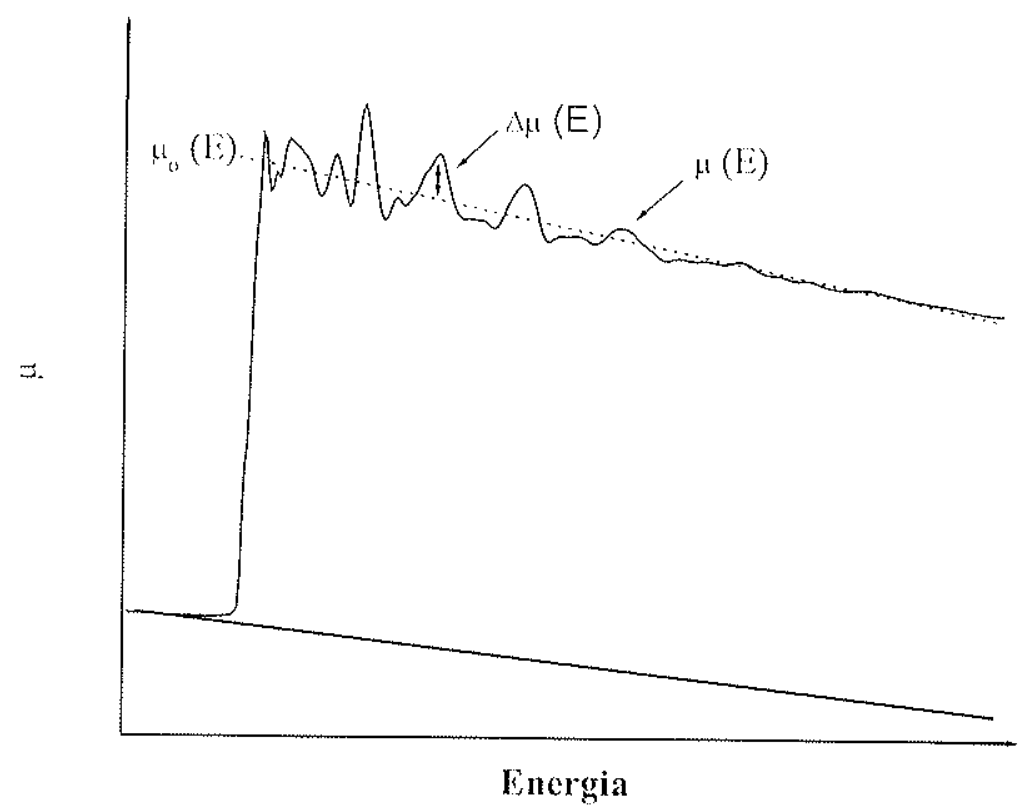

Figura 2.5- Coeficiente de absorção na borda $K$, como função da energia do fóton incidente. 
Dentro do contexto de espalhamento ánico e aproximação de ondas planas Stern, Sayers e Lytle ${ }^{59}$ propuseram uma expressão para $\chi(k)$ a partir dá eq. (2.17) conhecida como equação de EXAFS, dada por:

$$
\chi(k)=\sum_{i} \frac{N_{i} A_{i}(\pi, k)}{k R^{2} i} \exp \left(-2 \sigma_{i}^{2} k^{2}-\frac{2 R_{i}}{\lambda(k)}\right) \operatorname{sen}\left(2 k R_{i}+\phi(k)\right)
$$

onde a somatória é estendida sobre todas as esferas de átomos retro-espathados, j, cada esfera contendo $N_{j}$ átomos dispostos a distâncias $R_{j}$ do átomo absorvedor.

A magnitude do sinal de EXAFS é dada pela equação (2.18) que é proporcional a $N_{j}$ átomos, inversamente proporcional a $R_{j}^{2}$ e proporcional à amplitude retro-espathada $\left(A_{j}\right)$ dos átomos da j-ésima esfera. A amplitude do sinal de EXAFS é atenuado por causá do livre caminho médio dos életrons $\left(\lambda_{e}\right)$ no material e pelo termo de Debye-Waller envolvendo os deslocamentos médios $\sigma_{j}$ (térmico ou estático) sobre a posição de equilíbrio a longo do comprimento da ligação entre o átomo absorvedor e os átomos retro-espalhadores. Por fim, a amplitude é senoidalmente modulada por uma função envolvendo a mudança de fase $(\phi(k))$ sofrida pelo fotoclétron durante seu trajeto entre os átomos absorvedor-(retro-espalhador)absorvedor e o termo $2 k R_{j}$ que é adicionado para que a onda retome ao átomo absorvedor. $O$ módulo do vetor de onda do fotoelétron, $k$, é dado por

$$
k=\sqrt{\frac{2 m}{h}\left(h v-E_{o}-\Delta E_{o}\right)}
$$

onde $h v$ é a energia do feixe de raios $\mathrm{X}$ incidente, $E_{0}$ é a energía da borda de absorção e $\triangle E_{0}$ ć o desvio em energia do sinal de absorção referente a umá deteminada camada atômica com relaçào à amostra de referência, originado a partir da diferença de configuração química entre a amostra de referencia c a estudada.

Em resumo, as informações estruturais obtidas do experimento de EXAFS são a princípio, o número de coordenação, $N_{j}$, a distância interatômica, $R_{j}$. e o desvio quadrático médio, $\sigma_{j}$ (desordem témica c estática), para cada esfera de átomos vizinhos que circunda o átomo absorvedor. 


\subsubsection{PROCEDIMENTO EXPERIMENTAL}

Para o experimento de XAFS filmes de $a-\mathrm{SiO}_{x} \mathrm{~N}_{y}$ com espessuras da orden de $1000 \AA$ foram depositados sobre substrato de UDAC e Si (100). As medidas foram realizadas on energia variável, na borda $\mathrm{K}$ de absorção do $\mathrm{Si}(1,839 \mathrm{keV})$ ná linha $\mathrm{SXS} \mathrm{S}^{(0)}$ do LNLS. Os espectros XANES $(1,800$ a $1,870 \mathrm{keV})$ foram obtidos com passos em energia de $0,5 \mathrm{cV}$ c os espectros EXAFS $(1,800$ a $2,300 \mathrm{keV})$ com passos em energia de $1 \mathrm{cV}$, utilizando um monocromador de lnSb (111). O método de deteção foi por corrente total elctrônica (TEY -" Total ElectronYicld"). As amostras de referências $a-\mathrm{SiO}_{2}$ (crescido termicamentc), $a-\mathrm{Si}_{3} \mathrm{~N}_{4}$ (depositada por PECVD), $\beta-\mathrm{Si}_{3} \mathrm{~N}_{4}$ e e-Si (100) foram utilizadas neste experimento. O estudo da estrutura de filmes desconhecidos por esta técnica exige o conhecimento de alguns parâmetro eletrônicos que são extraídos das amostras de referência.

Os dados de EXAFS obtidos experimentalmente foram tratados e simulados utilizando o programa desenvolvido por Michalowicz". A parte oscilatória do espectro de EXAFS foi extraida usando un ajuste polinomial de grau 5 e normalizado pela aproximaçào de leitler, atribuindo peso $K^{2}$ ao sinal (para compensar o decaimento das ondas, isto é, hazer os dados serem o mais próximo possível de ondas senoidais monocromáticas no intervalo de dados). Fe\%-se uso de uma jancla delimitadora ("apodization window") gaussiana (tipo Káiser) num determinado intervalo em $\AA^{-1}$, utilizando o parâmetro $\tau$ ( minimizar o efeito de truncamento (levido ao intervalo finito utilizado na obtenção da transformada de Fourier) constante e igual 2,50 para todas as amostras e referencias.

Os parâmetros eletrônicos (amplitude da fase retro-espalhada do fotoclétron, mudança de fase sofrida pelo fotoclétron, e o livre caminho médio) utilizados na simulação foram extrádos das amostras de referências $a-\mathrm{SiO}_{2}, a-\mathrm{Si}_{3} \mathrm{~N}_{4}, \beta-\mathrm{Si}_{3} \mathrm{~N}_{4}$ e c-Si (100). Entletanto, para obtençào desses parâmetros eletrônicos experimentais é necessário ter uma estimativa do fator de Deybe Waller associado a cada referencia. O fator de Deybe Waller das referencias foi deteminado atilizando o seguinte procedimento. Inicialmente, fez-se o tratamento de dados do sinal de EXAFS das referências como descrito no parágrafo anterior. Em seguida, cxtraimos do programa McKale ${ }^{62}$ a fase e amplitude teóricas associadas a cada amostra de referência. Estes parâmetros eletrônicos obtidos teoricamente foram utilizados para simular o 
sinal de EXAFS das referencias, e assim estimar experimentalmente o fator de Deybe Waller correspondente a cada padrão. Com esses fatores de Debye Waller obtivemos os parânetros elctrônicos experimentais das referências, para então, simularmos as amostras desconhecidas.

\subsubsection{ESPECTROSCOPIA DE ABSORÇÃO NA REGIÃO DO INFRAVERMELHO}

\subsubsection{FUNDAMENTOS BÁSICOS}

A espectroscopia de absorção na regiăo do infravermelho é uma técnica analitica que pode ser utilizada para investigar a estrutura de ordem local de um material amorfo. Entretanto, unidades estruturais devem estar presentes nesse material de forma que sejam capazes de serem excitadas vibracionalmente, independentemente da matriz amorfa vizinha.

Esta técnica consiste na incidência de uma determinadá radiação sobre uma anostra produzindo mudanças no estado vibracional das moléculas que compõem o material. A freqüiencia de radiaçào necessária para mudar o estado vibracional da molécula está geralmente comprendida na regiăo de infravermelho $(0,77 \mu m \sim 1000 \mu m)$. Durante a vibraçào de uma molécula, devida por exemplo a una radiação infravermelha, a distribuiçào de cargáa sofre uma mudança periódica e, em geral, como conseqüiência, o momento dipolar muda também periodicamente. As vibraçòes moleculares que estão relacionadas com uma mudança no momento dipolar são chamadas de "infravermelho ativo", enquanto que vibraçòes para as quais a distribuiçào da carga muda e não altera o momento dipolar, sào chamadas de "infravermelho inativo".

Quando a lreqüência de radiação incidindo sobre umá molécula coincide com a frequiência de ressonância natual da molécula, ocorrerá umá mudança no estado vibracional, que se for acompanhada por uma mudança no momento dipolar (infravermelho ativo) c, portanto, na energía da molécula, uma banda de absorção associada com este estado vibracional será observada no espectro de absorção. A intensidade desta absorção dependerá (a magnitude da transição do momento dipolar enquanto que a freqüência da absorção dependerá das massas dos átomos envolvidos e suas posições relativas para a deteminada ligaçào 63.04 . 
É mais conveniente fazer o tratamento do problema vibracional em função de coordenadas internas que descrevam os movimentos dos átomos, tais como: mudanças no comprimento e ângalo das ligações, e nos ângulos de torção. Assim, as bandas no espectro de infravernelho podem ser relacionadas a vibrações longitudinais (stretching) ou a vibrações angulares (bending) de uma ligação química particular, É importante destacar, porém, que o problema é raramente simples, pois as freqüiências das vibrações não dependem somente da natureza das ligações particulares entre dois átomos, mas também da própria molécula e de sua vizinhança. Muitas bandas de absorção no infravermeiho são devidas a vibraçòes acopladas; isto é, vibraçòes que envolvem mais de um tipo de movimento ocorrendo à mesma frequiência.

Apesar de toda a complexidade, pode-se pensar em primeira aproximação que grupos de frequiencias de absorção podem estar relacionados aos movimentos dos átomos individuais que compõem a molécula. Se tivermos um movimento complexo de átomos, este pode ser considerado como uma agregação de um pequeno número de movimentos básicos, os quais são delinidos como vibrações fundamentais da molécula. Estas podem ser:

1. Vibrações conhecidas como stretching (ou de valência) que são movimentos vibracionais periódicos de estiramento e relaxamento, produzindo una banda de absorçào no infravermetho observada para todas as moléculas contidas dentro de um mesmo grupo. Podemos distinguir duas classes de movimentos: a)"movimento simétrico", onde os dois átomos extremos movimentam-se para dentro e fora em fase; b) "movimento assimétrico", onde um movimenta-se para dentro e o outro para fora em forma altemada (Figura 2.6).

2. Vibrações conhecidas como bending, onde o movimento vibracional ocorre na direçào perpendicular à ligação entre os átomos. Este grupo é freqülentemente subdividido $\mathrm{cm}$ quatro tipos: a) scissor (ou bending propriamente dito) onde os movimentos dos átomos estão na direção da mudança do ângulo entre os átomos que formam o grupo; b) waggring na qual nầo há mudança no ângulo entre as ligações do grupo vibrando, isto porque a vibração toma fugar para cima e para baixo do plano, e seus movimentos estão cm fase; c) rocking onde o ângulo entre os átomos mudá en relação ao movimento no plano dos átomos extremos em fase; e d) twisting onde os átomos do 
mesmo grupo movimentam-se no mesmo plano, mas em direções opostas de um em relaçào ao outro (Figula 2.6 ).
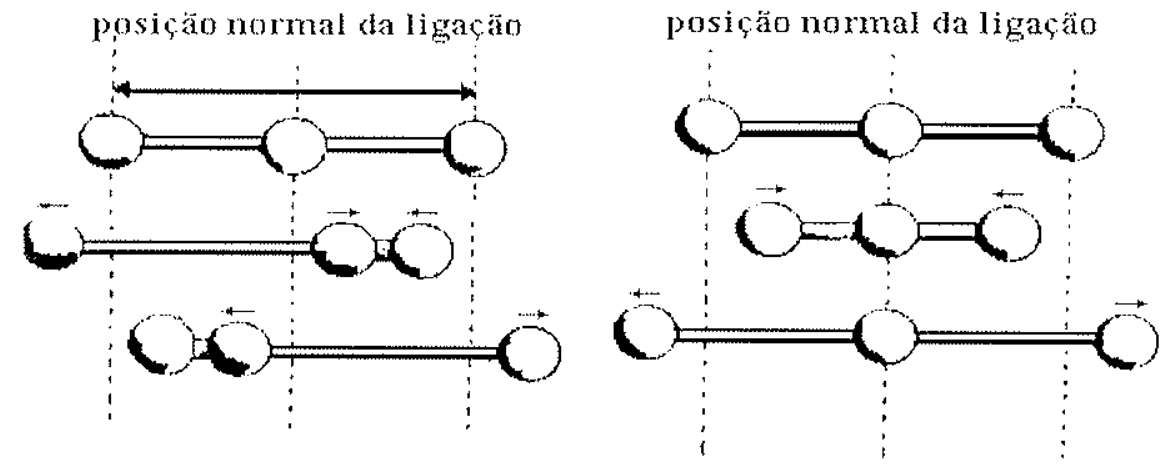

stretching assimétrico

stretching simetrico
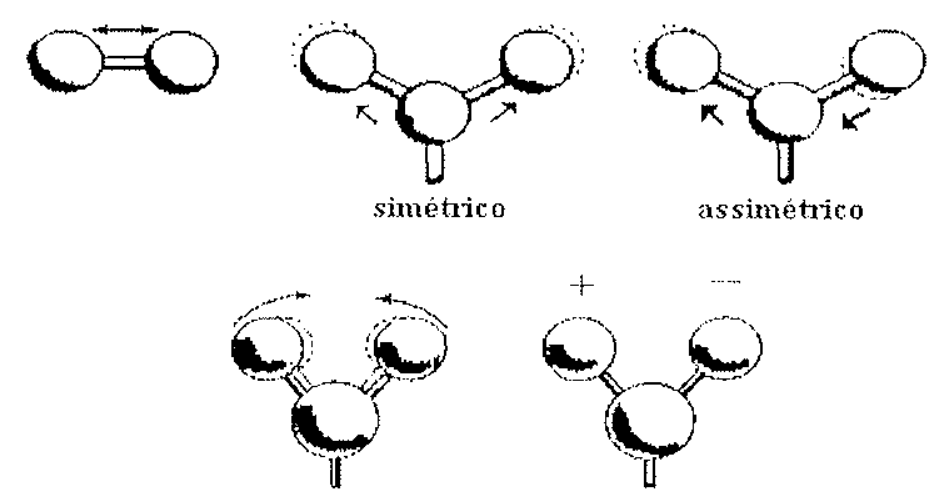

tesourat (scissoring)

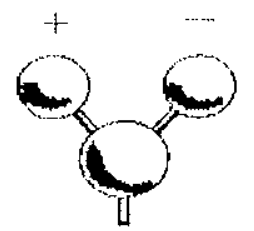

torçăo (Twisting)

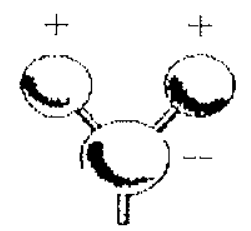

balanço (wagging)

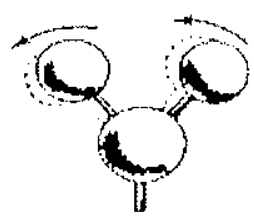

oscilaçäo (rocking)

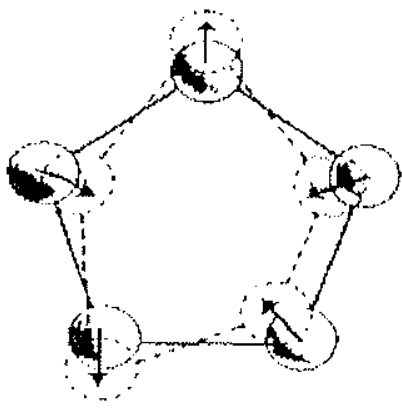

deformaçáo no plano

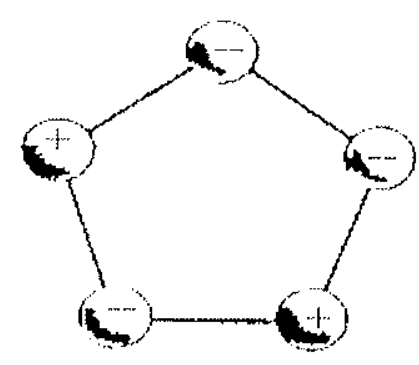

deformaçăo fora do plano

Figura 2.6 - Representação esquemática dos diferentes tipos de vibrações fundamentais stretching e bending. 
As descrições apresentadas na página anterior sobre a espectroscopia de infravermelho são corretas somente para moléculas totalmente isoladas. Nos materiais reais, raramente ocorrem estas situações. Para materiais sólidos, as moléculas interagem e esta interaçào influi no espectro de infravermelho. Isto é manifestado como um alargamento ou un deslocamento das bandas ou, eventualmente, com o surgimento de novas bandas.

Considerando o caso de materiais amorfos, a espectroscopia de infravermetho destes [ilmes pode ser descrita, também, da mesma forma que para um material cristalino. No entanto, se comparados localmente com os materiais cristalinos, mesmo tendo um arranjo de primeiros vizinhos muito similar, estes materiais apresentam dispersão tanto na distância da ligação dos elementos presentes, quanto no ângulo das ligações. Isto provoca, basicamente, um alargamento das bandas de absorção. Isto é, o incremento na desordem de um material amorlo originará mudanças nas ligações químicas dos elementos componentes (variação na distância e ângulo das ligaçooes), causando um deslocamento da frequência de ressonância daquelas estruturas desordenadas dentro do material amorfo, alargando a banda de absorção. Finalmente, uma outra diferença no espectro na região de infravermetho destas amostras pode incluir deslocamentos das freqüências de absorção devido à influência de grupos de átomos próximos.

\subsubsection{PROCEDIMENTO EXPERIMENTAL}

No experimento de FTIR, foram medidas filmes depositados sobre substrato de Si(100). Esse experimento foi realizado no DEE-POLLUSP, utilizando $\mathrm{m}$ espectrofotometro por transformada de Fourier, FTS-40 da marca BIO-RAD, com faixá de comprimento de onda no espectro de absorção de $400 \mathrm{~cm}^{-1}$ até $4000 \mathrm{~cm}^{-1}$, com resolução de até $2 \mathrm{~cm}^{-1}$, medida a temperatura ambiente $\mathrm{cm}$ uma atmosfera de $\mathrm{N}_{2}$. 


\section{RESULTADOS EXPERIMENTAIS}

\subsection{PROPRIEDADES QUÍMICAS E MORFOLÓGICAS DOS FILMES}

A composição química dos filmes estudados foi determinada através da densidade atômica (átomos $/ \mathrm{cm}^{3}$ ) por RBS e FTIR. A título de ilustração, o espectro de RBS para as amostras com $R e=5,00,2,00$ e 0,50 é mostrado a seguir.

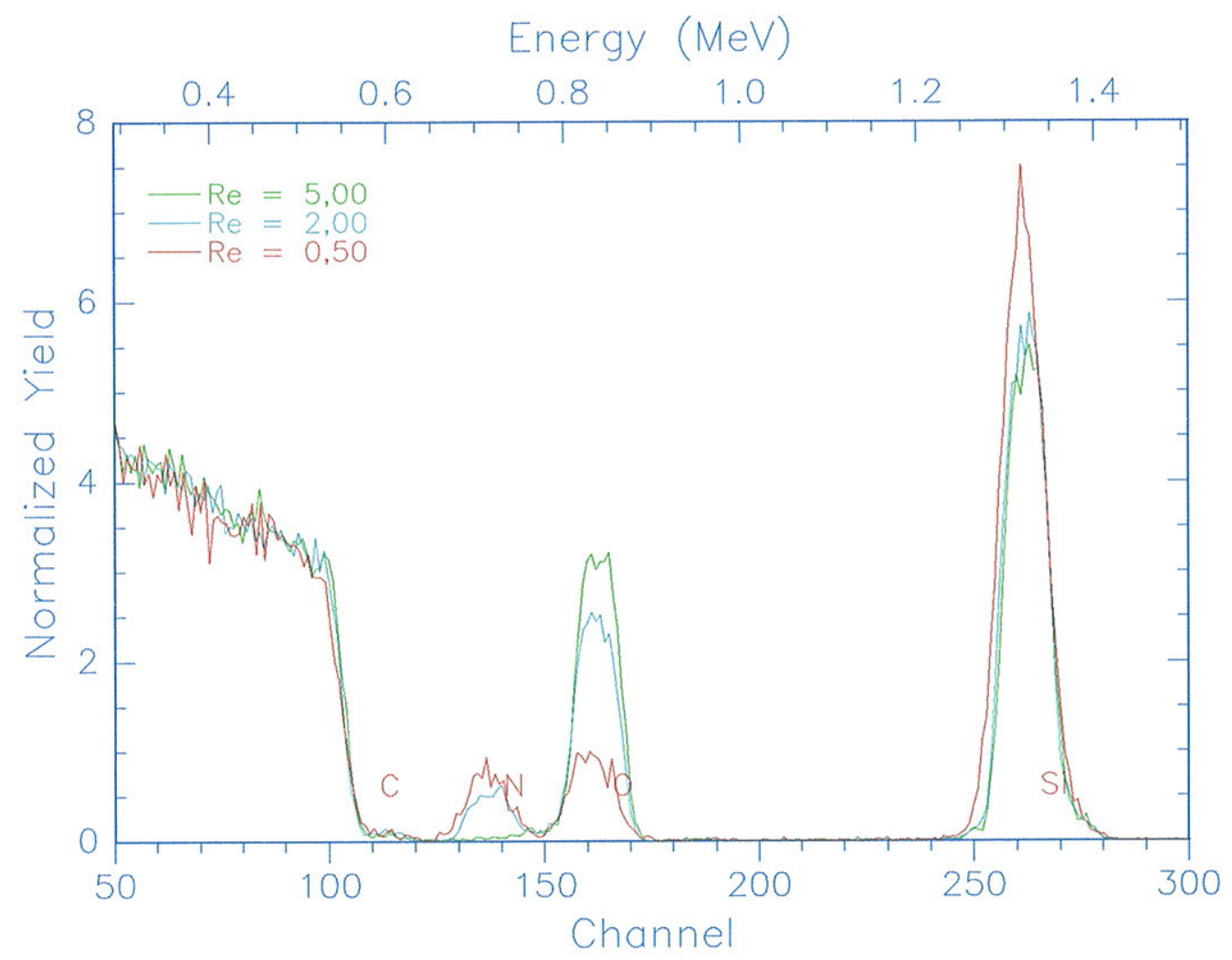

Figura 3.7-Espectro de RBS obtido para as amostras com $R e=5,00,2,00$ e 0,50. Sendo C (Carbono) do substrato e os elementos Si (silício), $\mathrm{O}$ (oxigênio) e $\mathbf{N}$ (nitrogênio) do filme.

As densidades do silício, oxigênio e nitrogênio foram determinadas por RBS. Por outro lado, a densidade de hidrogênio foi estimada convertendo a absorbância medida em átomos $/ \mathrm{cm}^{3}$, seguindo o procedimento descrito por Lanford e Rand ${ }^{65}$, que consiste basicamente em integrar a área sob a banda de vibração Si-H e N-H dos espectros de FTIR, 
utilizando suas respectivas seções de choque de absorção. A densidade atômica estimada para o $\mathrm{Si}, \mathrm{O}, \mathrm{N}$ e H são mostradas na Figura 3.8 a seguir.

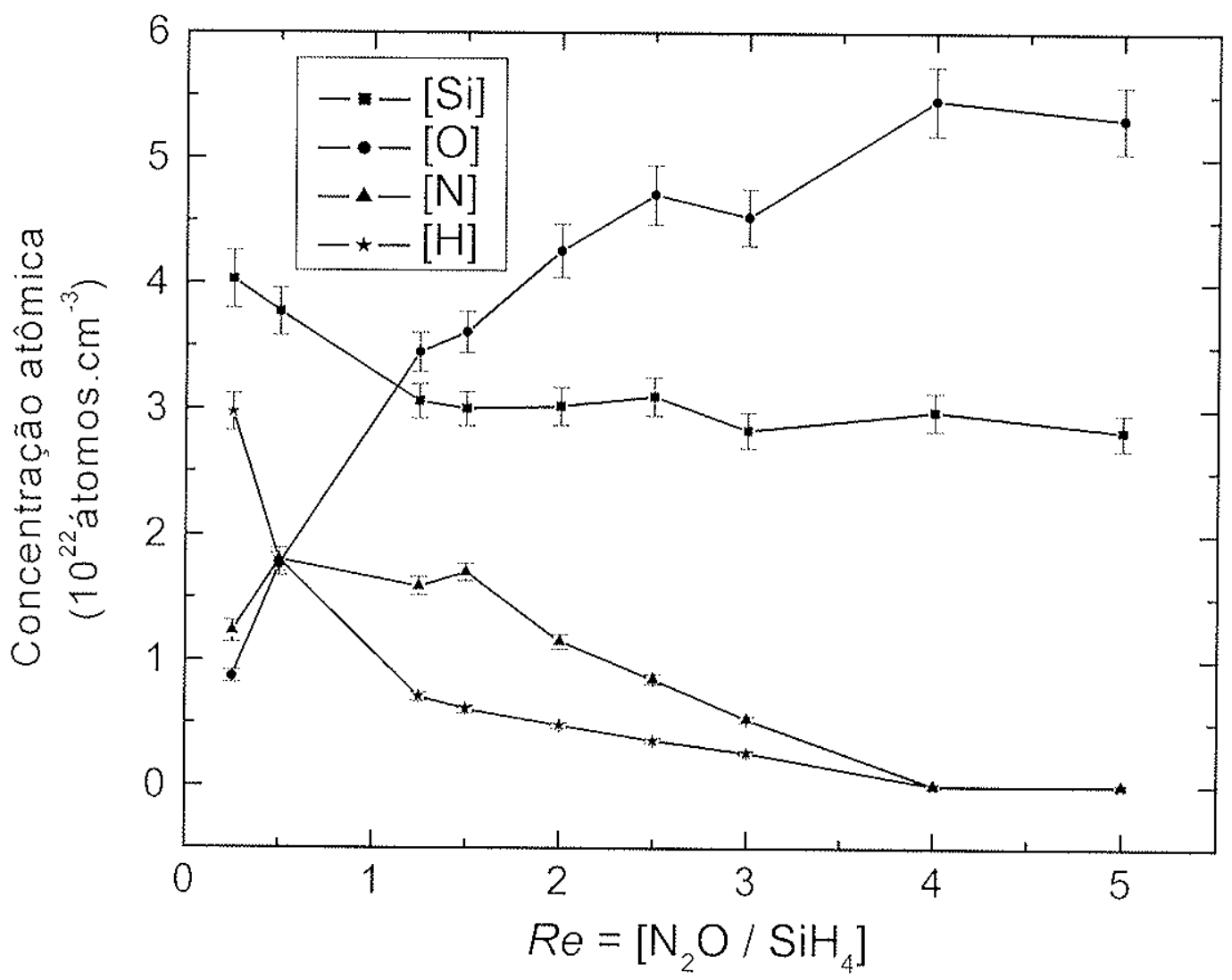

Figura 3.8-Densidade atômica do Si, O e $\mathrm{N}$ determinadas por RBS, e H por FTIR.

A Fïgura 3.8 mostra que a variação na razão de fluxos $\left[\mathrm{N}_{2} \mathrm{O} / \mathrm{SiH}_{4}\right]$ permite obter filmes com diferentes composições químicas. Observa-se também que o decréscimo de Re induz um aumento na concentraçào atômica de Si e H, enquanto que a quantidade de O ciecresce. A densidade atômica de $N$ é relativamente baixá, quando comparáa com a quantidade de Si e O para valores de Re $>0,50$, mas igual à quantidade de O para a amostra com Re $=0,50$. O comportamento da composição química nos filmes pode ser interpretado em termos das reaçòes químicas que ocorrem no plasma. Utilizando a mistura gasosa $\left[\mathrm{N}_{2} \mathrm{O} /\right.$ $\left.\mathrm{SiH}_{4}\right]$ o plasma conterá radicais $\mathrm{SiH}_{n}, \mathrm{O}$ e $\mathrm{N}$, sendo as reações químicas mais favoráveis entre os radicais $\mathrm{SiH}_{1} / \mathrm{O}$. Desta forma, para razões de fuxos grandes existe muito monos radicais $\mathrm{SiH}_{n}$ do que $\mathrm{O}$ e $\mathrm{N}$ c, assim, os poucos radicais de $\mathrm{SiH}_{n}$ irão reagir com $\mathrm{O}$ e nenhuma ligação do tipo Si-N e Si-Si será formada. Entretanto, para un decréscimo da razào dos fluxos, o número de radicalis de Sit 
Assim, reações SiH $_{n} / \mathrm{N}$ irão ocorrer lazendo surgir ligações tipo Si-N e N-H. Por outro lado, ao se reduzir a razào de gases $\mathrm{N}_{2} \mathrm{O} / \mathrm{SiH}_{4}$ até termos defieiência de ambos $\mathrm{N}$ e O, se favorece as reaçòes homonucleares $\mathrm{SiH}_{n}$, resultando num material amorfo rico em silício.

Filmes com Re $<2,00$ possuem uma baixa taxa de deposição $(\sim 0,30 \mu \mathrm{m} / \mathrm{h})($ tabela 2.1). Essa baixa taxa de deposição limita experimentalmente a espessura dos filmes a valores $\ll 5 \mu \mathrm{m}$, uma vez que para a obtenção de filmes espessos é necessário um tempo muito longo. Longos tempos de deposição tornam os lilmes quebradiços, que se desprendem dos substratos. Assim, o estudo morfológico limitou-se somente às amostras com Re $>1,50$ ). A morfologia dessas amostras foi estudada por SAXS, TEM e por medida de densidade através (io método de Mutuação. As curvas de SAXS são apresentadas na Figura 3.9 a seguir.

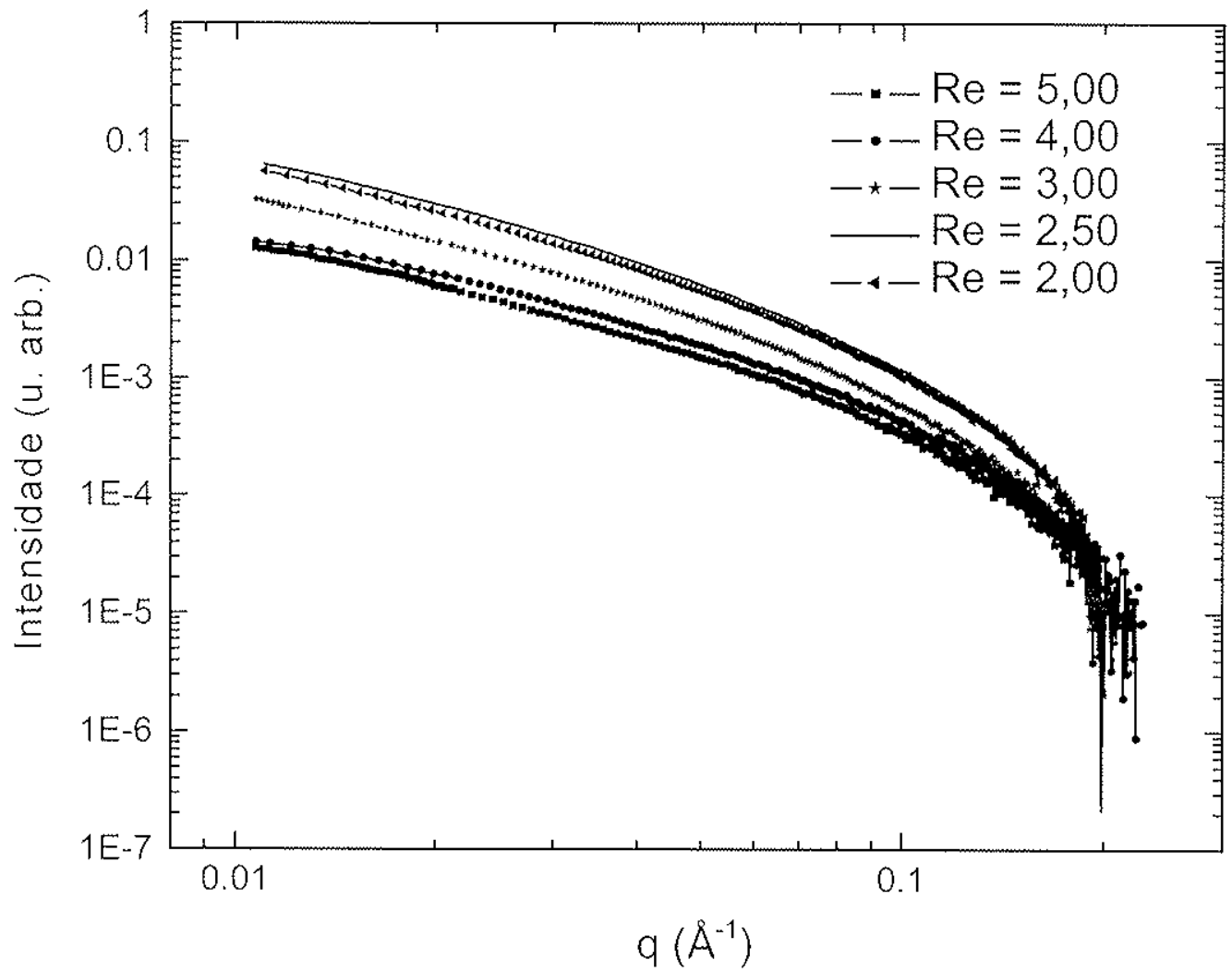

Figura 3.9- Intensidade de espahamento de raios $X$ a baixo ângulo das amostras $2,00 \leq$ Re $\leq 5,00$.

A Figura 3.9 mostra o comportamento de $I(q)$ como função da razão de fluxos, e evidencia um decréscimo na intensidade espalhada com o aumento do fluxo de $\mathrm{N}_{2} \mathrm{O}$ no processo de deposição, exceto para a amostra com Re $=2,50$. Contudo, o perfül das curvas 
são similares para valores pequenos de $q, q<0,1 \AA^{-1}$. Os dados de intensidade para $q>0,1$ $\AA^{-1}$ apresentam uma maior dispersão, devido à baixa intensidade espalhada nesta região. Com objetivo de complementar a análise de SAXS foi feita na amostra com $R e=5,00$ (composição química similar à do $\mathrm{SiO}_{2}$ ) medida de TEM, cujos resultados são apresentados na Figura 3.10 e Figura 3.11.

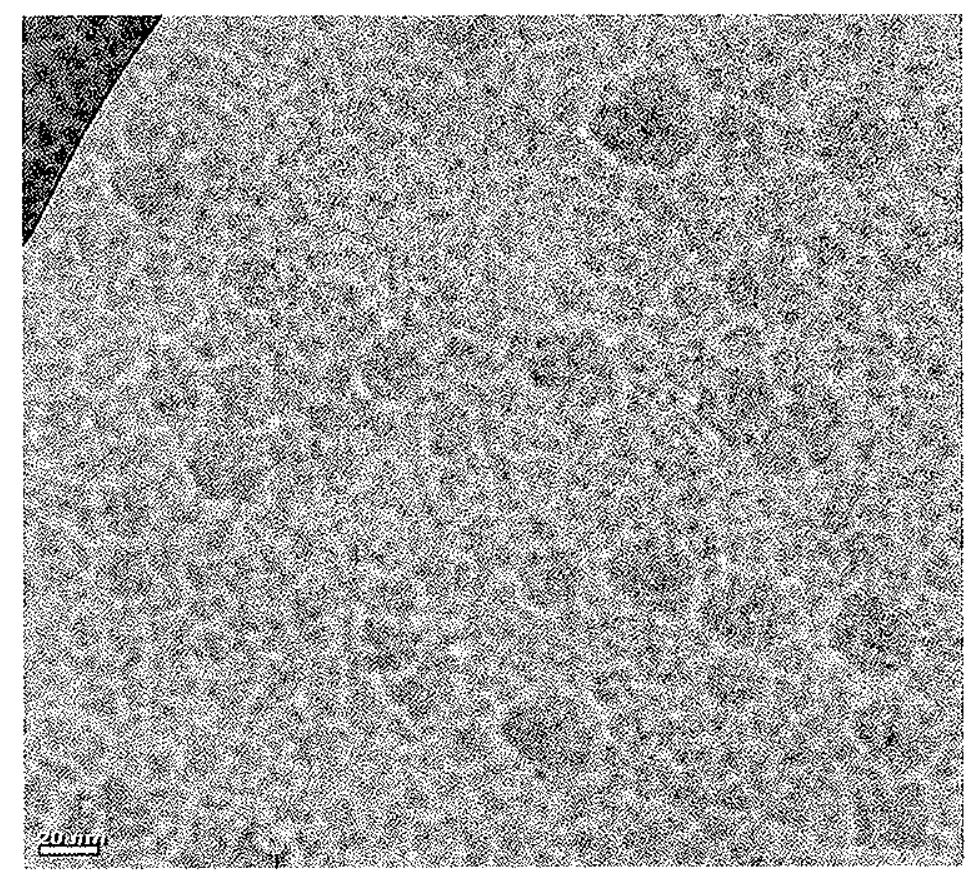

Figura 3.10- Imagem de TEM da amostra $R e=5,00$.

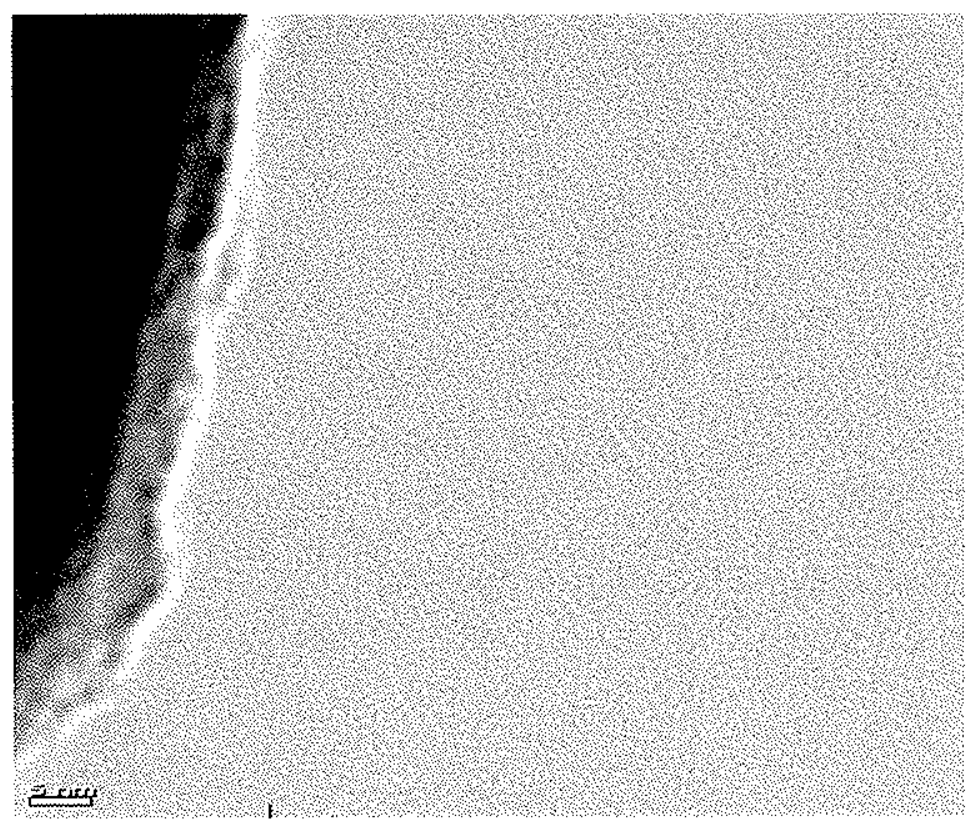

Figura 3.11- Imagem de TEM da amostra $R e=5,00$. 
Da Figura 3.10 podemos evidenciar uma distribuição de partículas com tamanhos entre $40 \AA$ A a $200 \hat{A}$, cuja forma geométrica pode ser aproximada por de uma esfera. Uma micro análise química dessas partículas mostrou que elas são compostas das mesmas espécies atômicas da matriz onde elas estão dispersas, porém com uma densidade diferente.

A partir dos resultados de TEM, a análise de SAXS foi feita utilizando o programa GNOM $^{66}$, considerando un sistema composto por partículas esféricas de diferentes tamanhos e não interagentes (conforme observado por TEM), determinando a distribuição de volumes $D_{r}(R)$ dos objetos espalhadores, mostrada na Figura 3.12 a seguir:

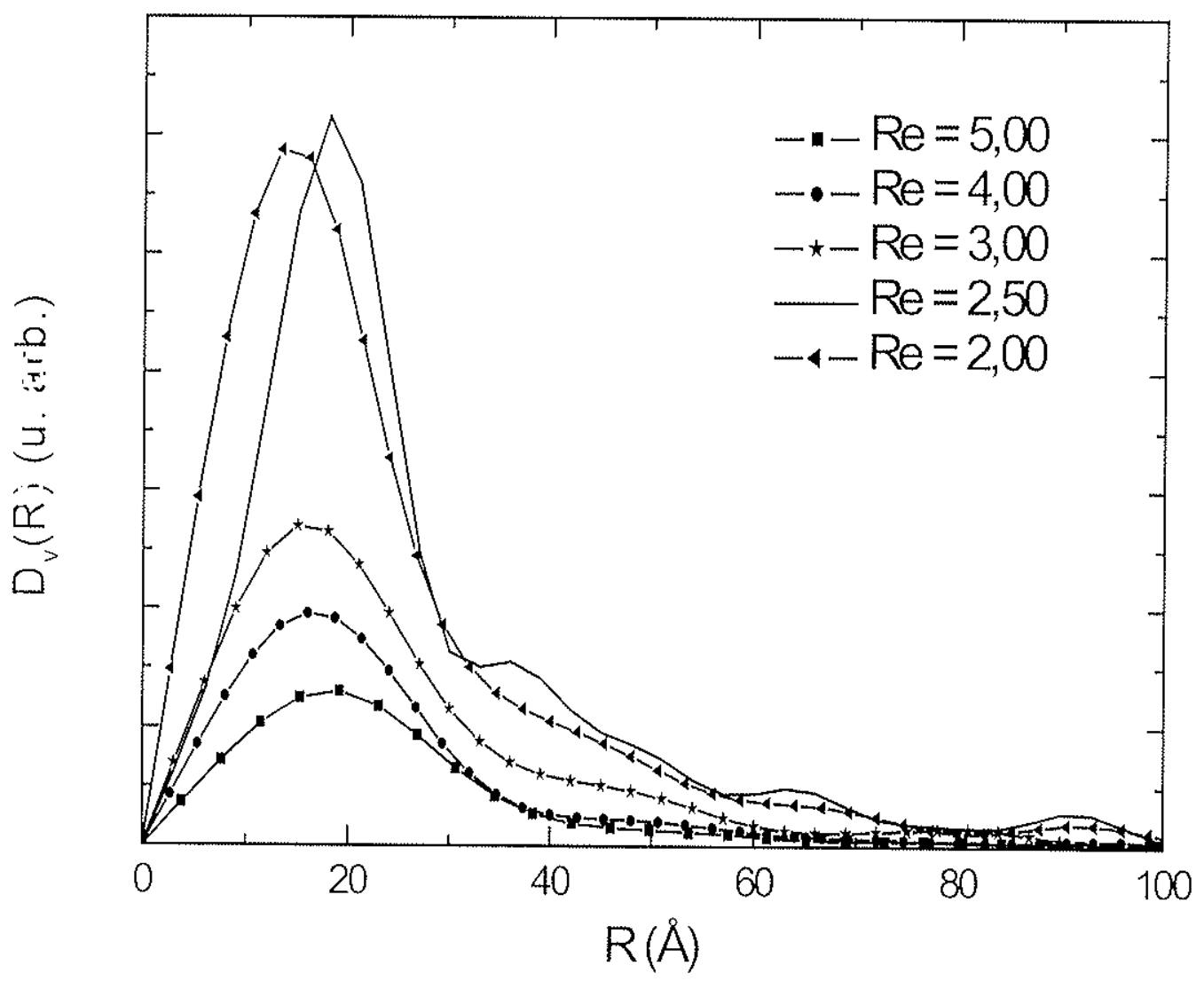

Figura 3.12- Funções distribuição de volumes das amostras $2,00 \leq R e \leq 5,00$, obtidos pelo programa GNOM das curvas de SAXS.

As curvas de $D,(R)$ evidenciam um número grande de espalhadores pequenos, isto é,

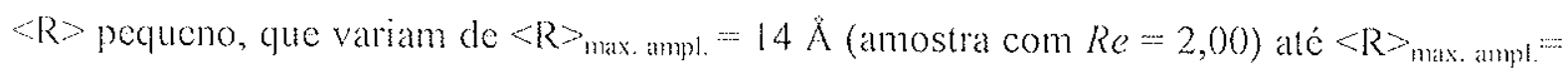
19 $A$ (amostra com $R e=5,00)$. Essas pequenas inomogeneidades são responsáveis pela 
maior parte da intensidade espalhada, embora sua presença não pode ser detetada por micrografia eletrônica, pois a rugosidade dos filmes é da mesma orden de grandeza. Partículas com tamanhos médios maiores que $40 \AA$ são observados por TEM, porém suas contribuições são pequenas nas curvas de SAXS. Esse resultado é atribuído a um baixo contraste de densidade eletrônica entre as partículas e matriz, uma vez que possuem composição química semelhante. Assim, as inomogeneidades menores (tamanhos entre 14 a 20 A), que são responsáveis pela maior parte da intensidade espallhada, são atribuídas a poros (vazios), normalmente formados en fïlmes depositados por PECVD ${ }^{67,68}$. É sabido da litcratura que filmes amorfos crescidos por PECVD geralmente possuem pequenos poros (da ordem de algumas dezenas de Angstrom), decorrentes de descontinuidades da rede amorfa.

A qualidade dos ajustes teóricos, associada às distribuições de tamanhos dadas ná Figura 3.12, às curvas de espalhamento experimentais, é mostrada a seguir.

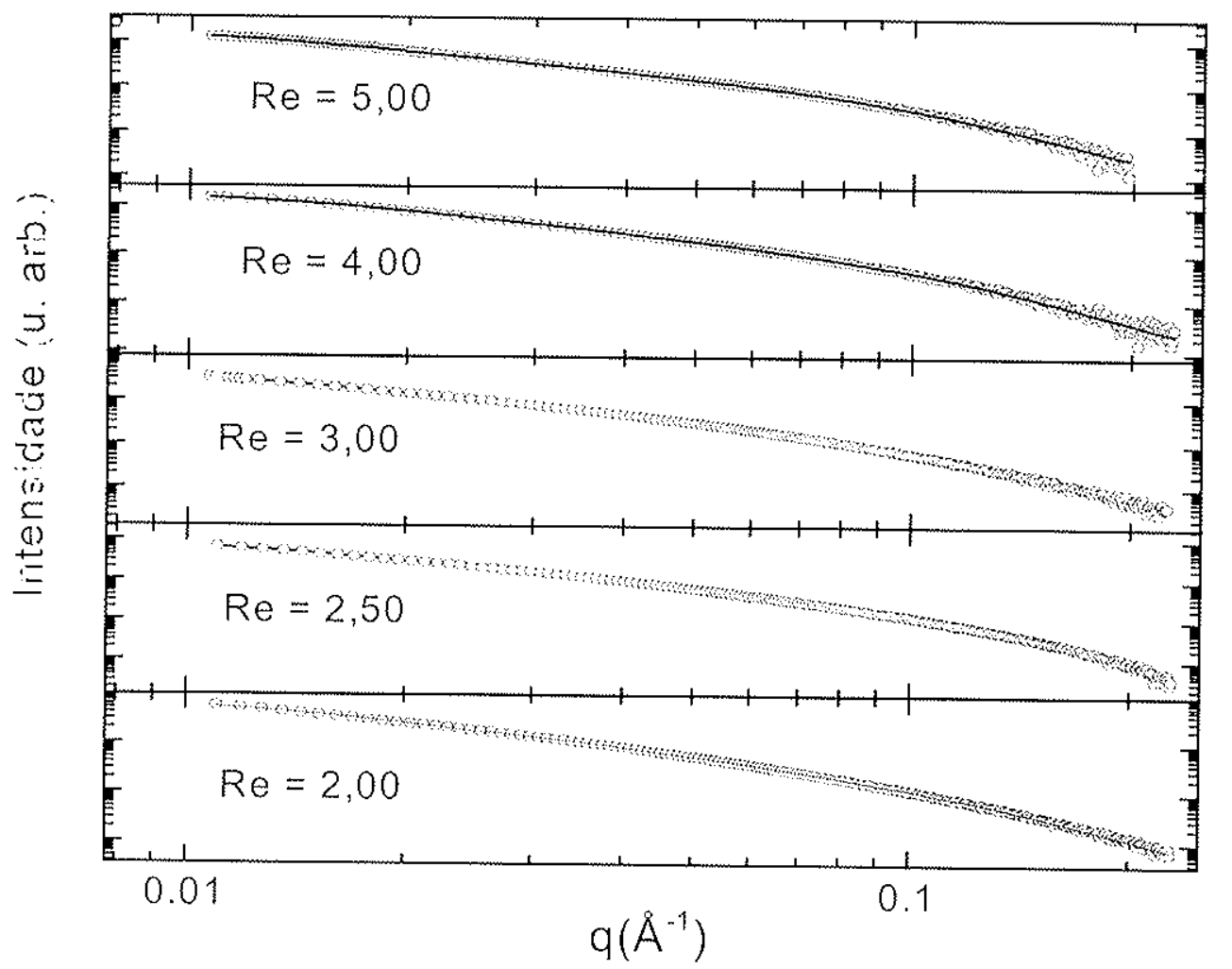

Figura 3.13- Comparação entre a curva experimental (símbolos abertos) e a teórica (linha cheia) calculada pelo programa GNOM.

Na Figura 3.13 conforme podemos observar, temos uma boa concordância entre os dados experimentais e as curvas de espalhamento associadas às $D_{v}(R)$. 
O valor da densidade obtido pelo método de flutuação para a amostra com $R e=2,50$ (auto-sustentada) foi de $(2,19 \pm 0,03) \mathrm{g}_{\mathrm{cm}} \mathrm{cm}^{-3}$. O filme medido tem uma fórmula química de $\mathrm{SiO}_{1,57} \mathrm{~N}_{0,57}$. O quartzo $\mathrm{SiO}_{2}$ tem uma densidade de $2,66 \mathrm{~g} . \mathrm{cm}^{-3}$, calculada pela dimensão da cela unitária c composição ${ }^{64}$. Considerando a mesma cela unitária e a composição atômica do filme medido, determinou-se que a sua densidade na forma cristalina seria de $2,57 \mathrm{~g} . \mathrm{cm}^{-3}$. Por outro lado, materiais amorfos apresentam ama densidade menor. Por exemplo, da literatura $^{70}$ temos que o $\mathrm{SiO}_{2}$ amorfo tem uma densidade de $2,20 \mathrm{~g} \mathrm{~cm}^{-3}$. A presença do nitrogênio na composição dos filmes aumenta sua densidade. Portanto, tanto a composição quanto a estrutura afeta o valor da densidade. Valores variando de 2,20 (a-SiO 2$)$ até 3,20 $g^{\prime} \mathrm{cm}^{-3}\left(a-\mathrm{Si}_{3} \mathrm{~N}_{A}\right)$ são encontrados na literatura". No caso particular de nossos filmes, estimamos a densidade do material sem poros usando o desvio experimental observado na posição da banda associada a ligação de "stretching "Si-O $O^{72,73} \mathrm{~cm} 1044 \mathrm{~cm}^{-1}($ Re $=2,50)$, obtido das medidas de FTIR (Figura 3.15 a seguir). Neste caso o valor calculado foi de 2,39 g. $\mathrm{cm}^{-3}$, considerando a densidade do $a-\mathrm{SiO}_{2}\left(2,20 \mathrm{~g}_{\mathrm{g}} \mathrm{cm}^{-3}\right)$ igual à densidade do nosso filme com maior concentração de oxigênio. Assumindo que a amplitude de SAXS é devidà à presença de poros, como já discutido anteriormente, a amostra com $R e=2,50$ (autosustentada) tem uma fração em volume de poros de $8,5 \%$.

Para o cálculo da fração volume de poros dos vários filmes, utilizamos a informaçào das intensidades das curvas de SAXS tal que ${ }^{74}$

$$
\int q^{2} I(q) d q=K(\Delta \rho)^{2} v_{f}\left(1-v_{f}\right)
$$

onde $\Delta \rho=\left(\rho-\rho_{0}\right)$ é a diferença de densidade eletrônica sendo, $\rho_{0}=0$ (poros) e $\rho$ (matriz) obtida da fórmula química de cada amostra, $K$ é um fator que depende dos fatores geométricos. No caso, cle foi calculado dos dados de SAXS, utilizando a fração volume de poros c o valor da densidade obtidos para a amostra $R e=2,50$. O resultado é apresentado na Figura 3.14 como função da razão dos fluxos $\left[\mathrm{N}_{2} \mathrm{O} / \mathrm{SiH}_{4}\right]$. 


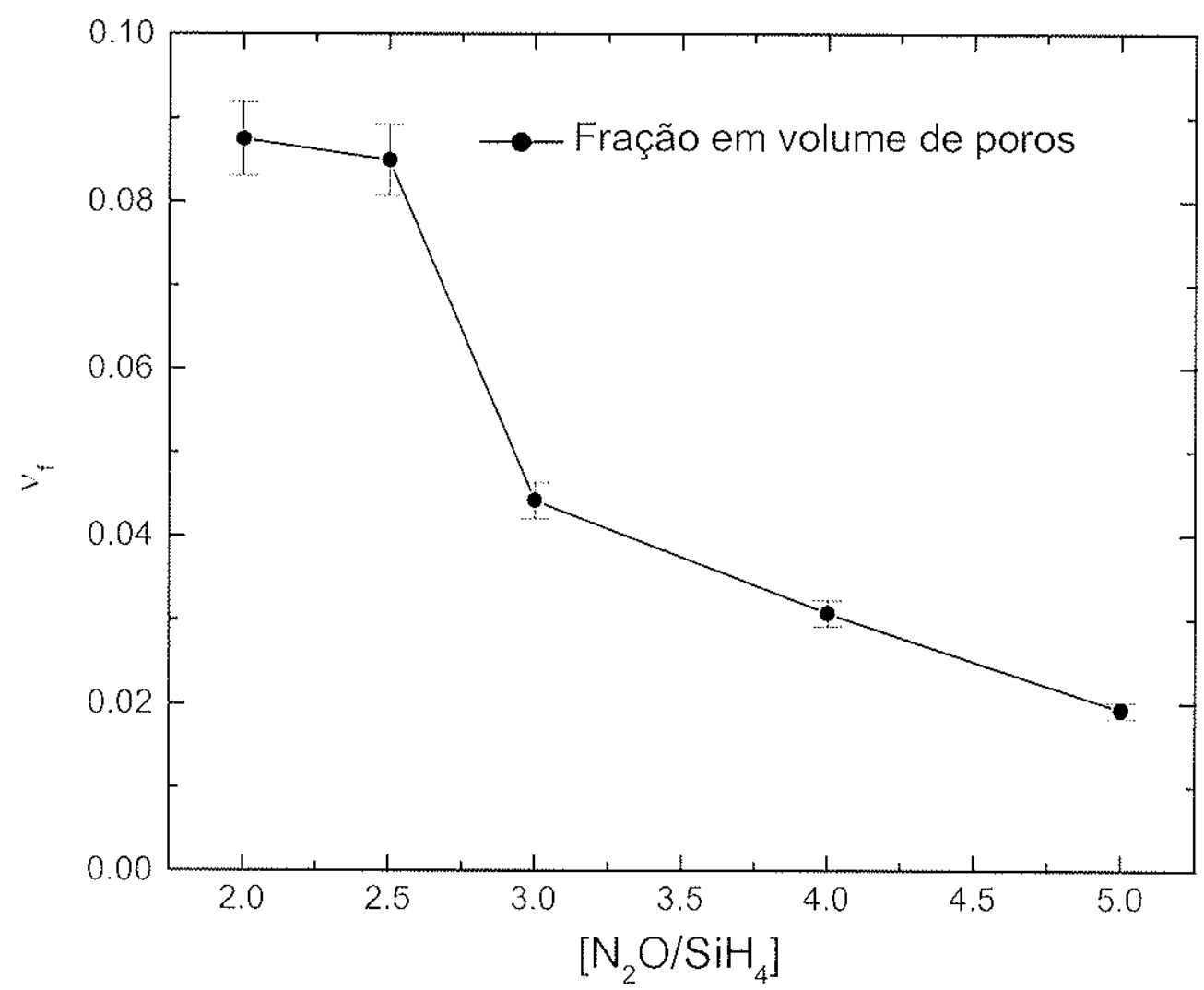

Figura 3.14- Fração volume de poros dos filmes estudados com $2,00 \leq R e \leq 5,00$.

Da Figutál 3.14 observamos que a fraçào $\mathrm{cm}$ volume de poros possui comportamento não linear com a razăo de fluxos $\left[\mathrm{N}_{2} \mathrm{O} / \mathrm{SiH}_{4}\right]$. Assim, notamos que o aumento gradativo de $\mathrm{N}_{2} \mathrm{O}$ na mistura gasosa induz à formação de fílmes mais homogêneos. A fração volume de poros da amostra com $R e=5,00$ (composição similar ao do $\mathrm{SiO}_{2}$ ) concorda com os dados da literatura ${ }^{75}$.

Em resumo, o estudo da morfologia dos filmes revela que o material é composto de uma matriz contendo Si, O e $\mathrm{N}$ com poros e particulas. Os poros possuem diferentes tamanhos, porém menores que $40 \AA$, e sua grande maioria com raio médio de $20 \AA$. As partículas com ráos cntre 40 c 200 A são de mesma espécic atômica da matriz, porém com diferentes densidades. A fração em volume de poros é menor que $10 \%$ e decresce com o aumento da concentraçào de $\mathrm{O}$ e decréscimo de $\mathrm{N}$ nos filmes, indicando que é possivel obter filmes homogeneos de $a-\mathrm{SiO}_{2}$ a baixa temperatura. 


\subsection{PROPRIEDADES ESTRUTURAIS DOS FILMES}

\subsubsection{AMOSTRAS SEM TRATAMENTO TÉRMICO}

As propriedades das ligações quimicas dos fĭlmes depositados (Figura 3.8) foram estudadas por FTIR, cujos espectros podem ser apreciados na Figura 3.15 e Figura 3.16 para amostras com $R e \geq 2,00$ e $R e \leq 1,50$, respectivamente. A intensidade do espectro de FTtR das amostras estudadas foi normalizada pela espessura de cada amostra. Além disto, foi feito também uma ampliação (5 vezes) na escala de comprimento de onda na região $\lambda>1500 \mathrm{~cm}^{-1}$ para melhor visualizarmos os modos de vibração das ligações $\mathrm{N}-\mathrm{H}\left(-3400 \mathrm{~cm}^{-1}\right)$ e Si-H $\left(2100 \mathrm{~cm}^{-1}\right)$.

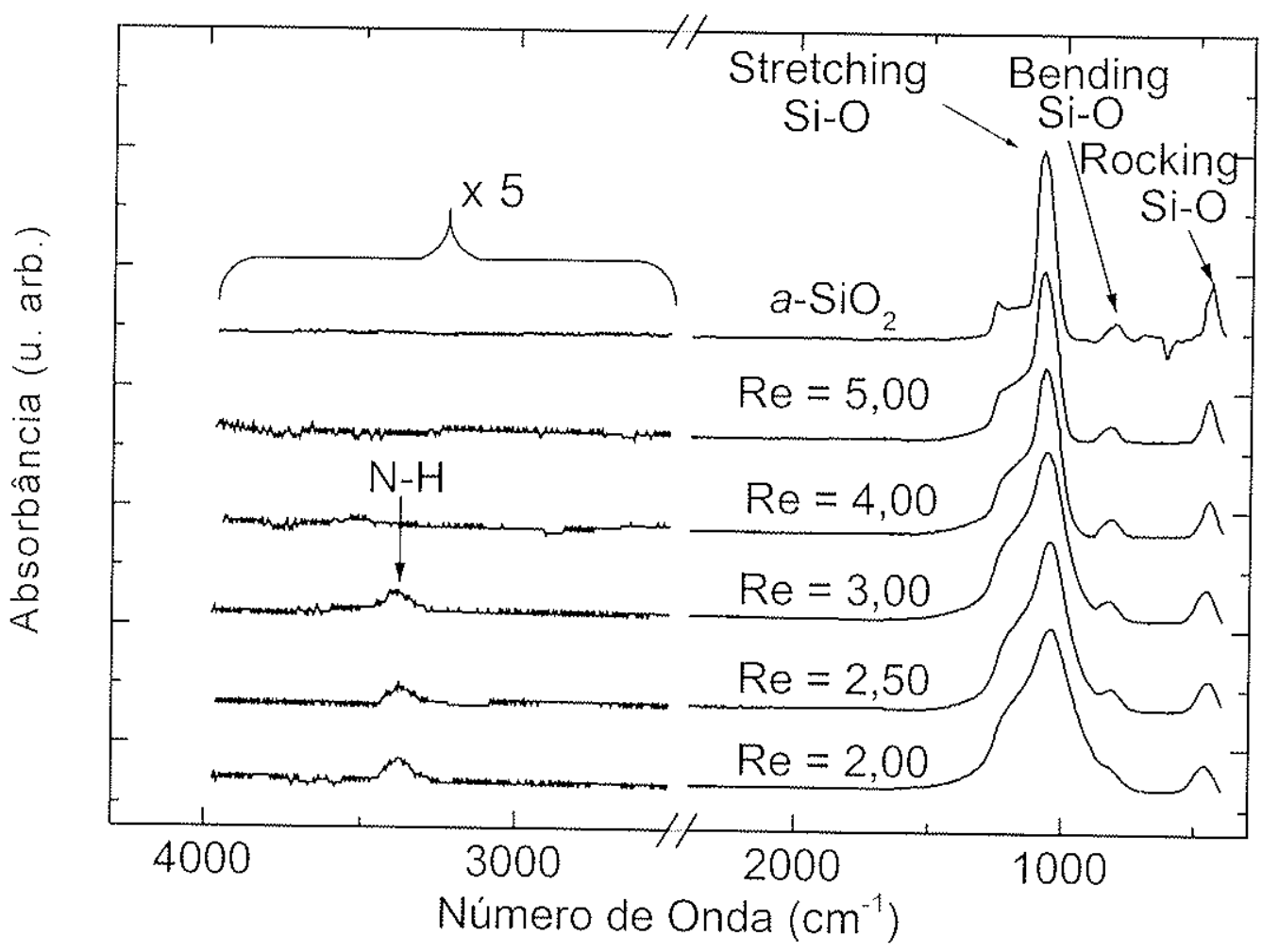

Figura 3.15- Espectro de FTIR das amostras estudadas com $2,00 \leq R e \leq 5,00$.

Na Figura 3.15 observa-se que a amostra com $R e=5,00$ apresenta um espectro bem similar ao do $a-\mathrm{SiO}_{2}$ crescido temicamente, isto é, mostrando só picos característicos de 
"stretching $\left(\sim 1070 \mathrm{~cm}^{-1}\right)$, bending $\left(\sim 800 \mathrm{~cm}^{-1}\right)$ e rocking $\left(\sim 440 \mathrm{~cm}^{-1}\right)$ " da ligação Si-O. Por outro lado, uma banda na região entre 1100 e $1250 \mathrm{~cm}^{-1}$, correspondente à vibração de "stretching" do Si-O fora de fase ${ }^{70}$, torna-se menos definida, ao mesmo tempo que observase um aumento na intensidade da banda centrada $\mathrm{cm} \sim 3400 \mathrm{~cm}^{-1}$, associada ao modo de vibração da ligação N-H, com o decréscimo de Re. Este último resultado é uma indicação da incorporação de He $\mathrm{N}$ nos fílmes de óxido.

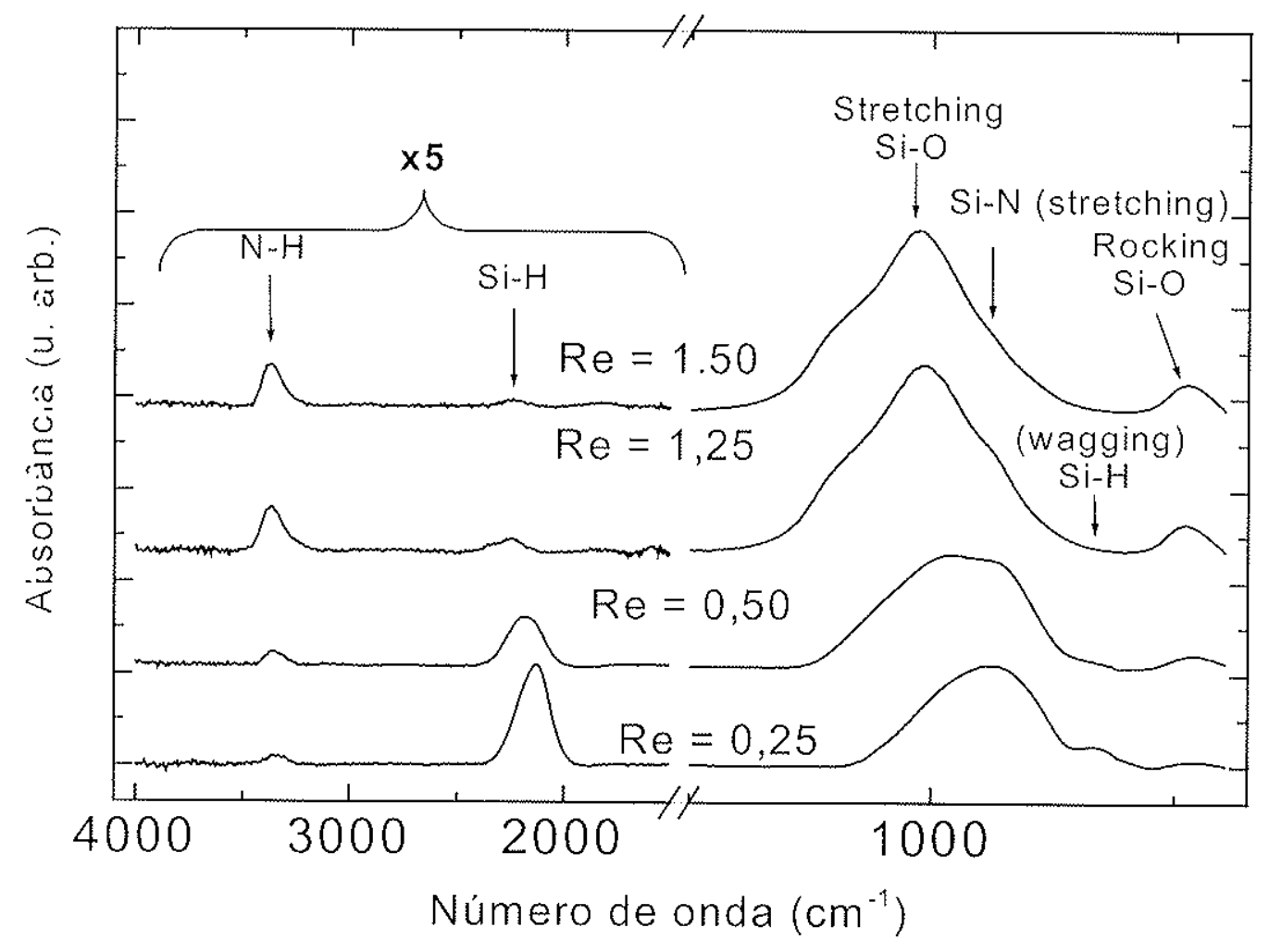

Figura 3.16 - Espectros de FTIR das amostras estudadas com $R e \leq 1,50$.

Na Figura 3.16 observa-se una banda centrada em $3400 \mathrm{~cm}^{-1}$ correspondente à vibração de "stretching" da ligação N-H, cuja intensidade decresce com o decréscimo de Re. A banda associada à vibração de "stretching" da ligação Si-N" ${ }^{77} 78$ (845 $\left.\mathrm{cm}^{-1}\right)$, também aparece no espectro. Observa-se ainda que com o decréscimo de Re, a intensidade da bandas associadas ao modo de vibração "stretching" da ligação Si-H $\left(\sim 2300 \mathrm{~cm}^{-1}\right)$ e "wagging" ( $680 \mathrm{~cm}^{-1}$ ) aumentam. A Figura 3.16 também mostra que a banda centrada $\mathrm{cm} 2300 \mathrm{~cm}^{-1}$, correspondente à vibraçào de "stretching" da ligação Si-H, desloca-se para um valor de número de onda menor, $\sim 2100 \mathrm{~cm}^{-1}$, característico do $a-\mathrm{Si}: \mathrm{H}^{79,80,81}$, com o decréscimo da razào $\left[\mathrm{N}_{2} \mathrm{O} / \mathrm{SiH}_{4}\right]$. 
Em resumo, os resultados de FTIR evidenciam aumento da incorporação de $\mathrm{N}$, He Si nos fílmes estudados, com decréscimo de Re. Um outro resultado importante é a possivel formaçầo de agregados de Si, para os filmes mais ricos em Si (amostra com Re $=0,25$ ). É apropriado ressaltar ainda que os dados de FTIR são complementares aos dados de composição química obtidos por RBS.

As propriedades estruturais dos filmes foram investigadas por XAFS. Os espectros de absorção na região de XANES são mostrados na Figura 3.17 e Figura 3.18 , referentes à borda $K$ de absorção do $\mathrm{Si}$ das referências, das amostras com $2,00 \leq R e \leq 5,(0)$, c clas amostras com $R e \leq 1,50$, respectivamente.

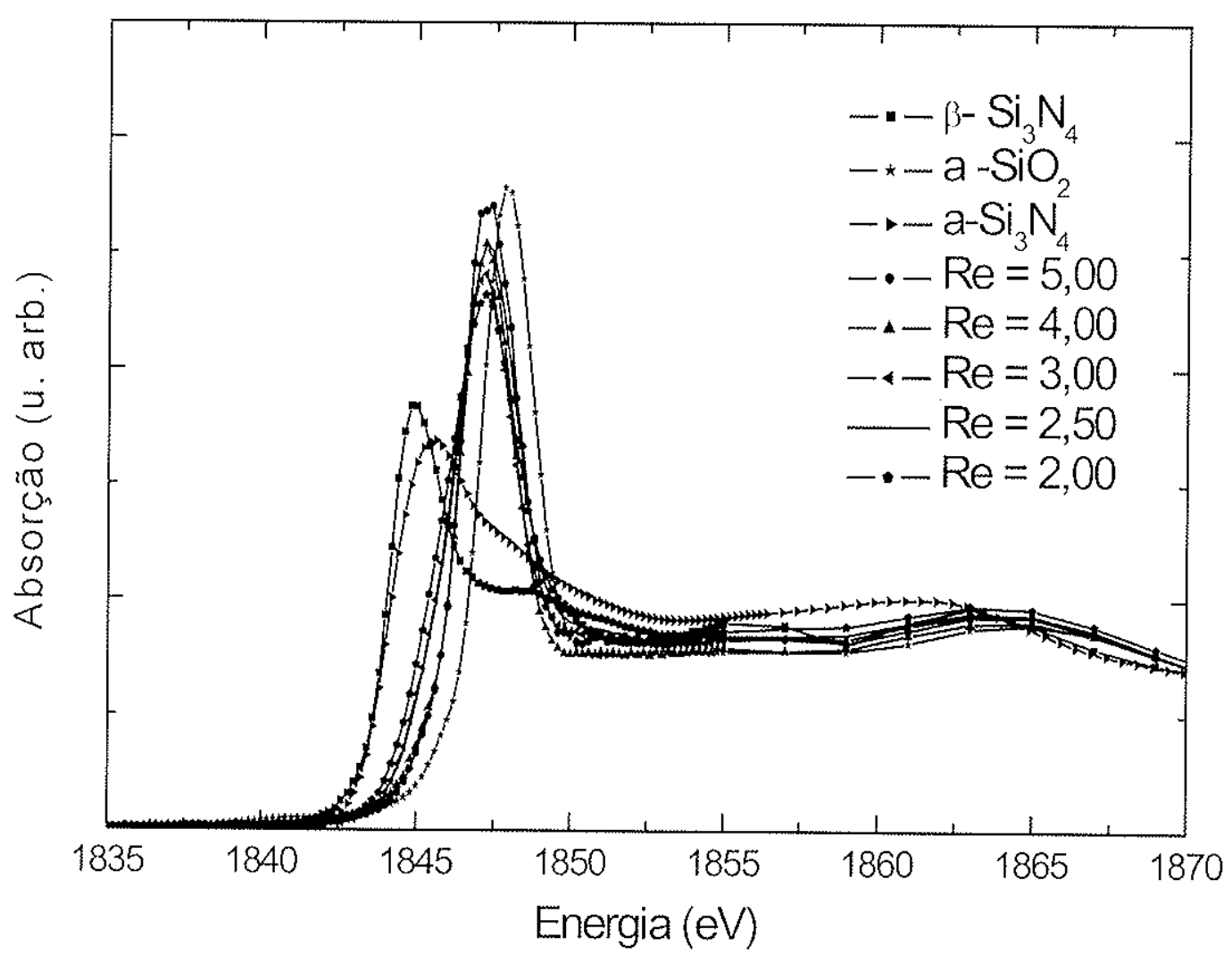

Figura 3.17- Espectros de absorção na borda $K$ do Si na região de XANES das amostras estudadas $(R e \geq 2,00)$ e das amostras referências.

Dá Figura 3.17 pudemos constatar que os espectros de absorção do $\beta-\mathrm{Si}_{3} \mathrm{~N}_{4}, a-\mathrm{Si}_{3} \mathrm{~N}_{4} \mathrm{C}$ $a_{-\mathrm{SiO}_{2}}$ não apresentam qualquer mudança quando comparados aos da litcratura ${ }^{22}$.3. As posições em energia da borda $K$ de absorção dos filmes aqui estudados estão localizadas na escala de energia entre o padrão $\beta-\mathrm{Si}_{3} \mathrm{~N}_{4}$ e o $a-\mathrm{SiO}_{2}$, porém mais próxima da referência $a$ - 
$\mathrm{SiO}_{2}$. A energia da borda $K$ de absorção depende da natureza e da eletronegativadade dos átomos ao redor do Si. Assim, o resultado de XANES é consistente com os dados de RBS, pois o último evidencia uma maior concentração relativa de oxigênio para os filmes com Re $\geq 2,00$. Outro resulado importante é que as posições da borda $K$ de absorção mudam continuamente, apontando para a formação de material homogêneo, isto é, com umá única fase ${ }^{83}$. Os espectros de XANES das amostras apresentam também una banda larga no intervalo de 1860 a $1870 \mathrm{cV}$, característica do $a-\mathrm{SiO}_{2}$. Os dois picos extras que aparecen no intervalo de 1845 a $1865 \mathrm{eV}$ são característicos da amostra referência de $\beta$-Si $\mathrm{N}_{4}$, indicando ordem estrutural de médio alcance, o que não é visto para o a-Si3 $\mathrm{N}_{4}$. Assim, para cste conjunto de amostras com $R e \geq 2,00$ os nossos resultados apontam para o crescimento de um material homogêneo, amorfo e similar à referência a-SiO 2 (crescido termicamente).

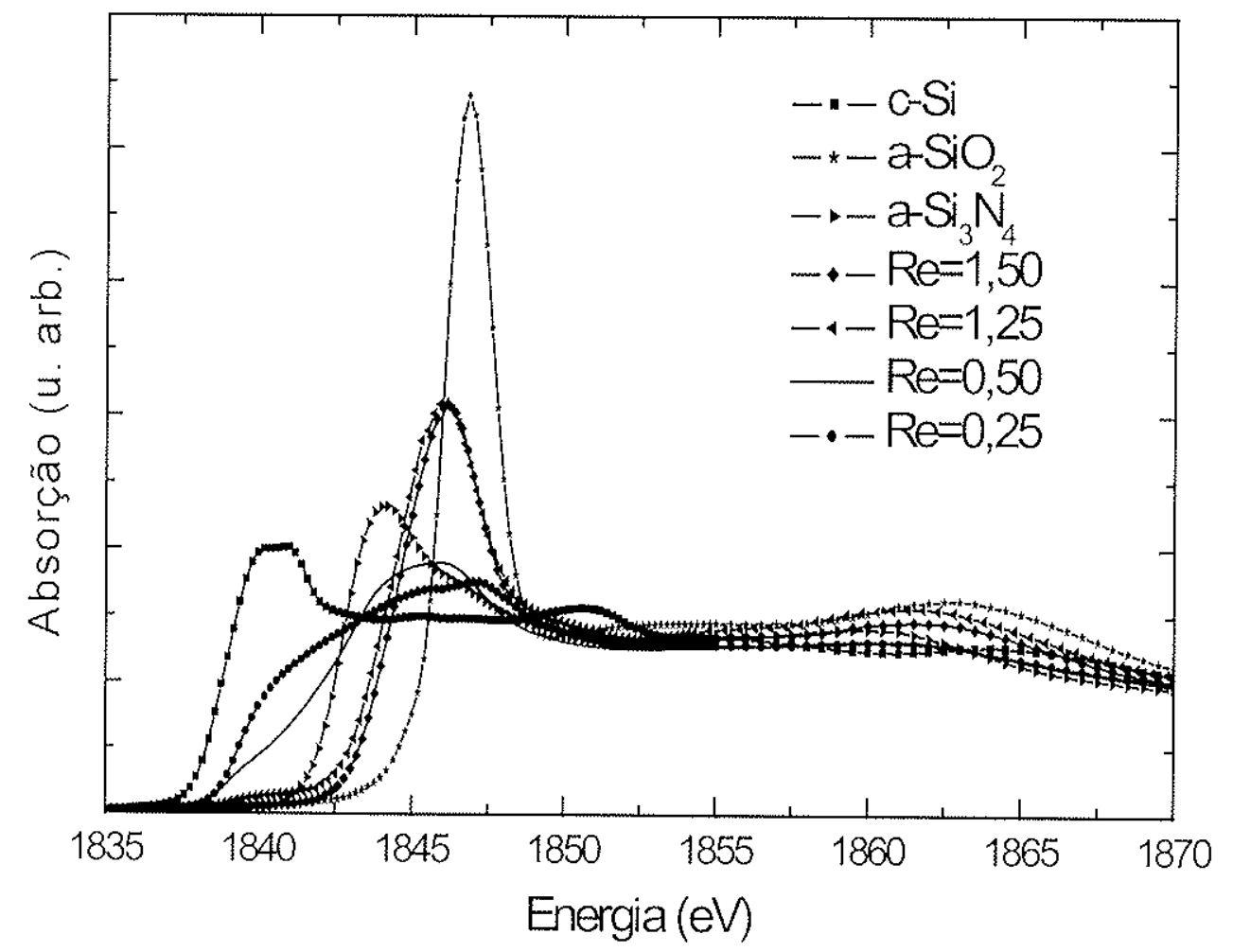

Figura 3.18- Espectro de absorção da borda $K$ do Si na região de XANES para as amostras estudadas $(R e \leq 1,50)$ e para as referências.

Na Figura 3.18 verifica-se que a borda de absorção das amostras desloca-se para valores de energia menores com o decréscimo de Re. A borda de absorção das amostras com $R e=1,50$ e 1,25 encontram-se entre as bordas das referencias $a-\mathrm{SiO}_{2}$ e $a-\mathrm{Si}_{3} \mathrm{~N}_{4}$, enquanto 
que para as amostras com $R e=0,50$ e 0,25 as bordas encontram-se entre as referencias $a-$ $\mathrm{Si}_{3} \mathrm{~N}_{4}$ e o $c-\mathrm{Si}(100)$. Os espectros das amostras com $R e=1,50$ e 1,25, apresentam um aumento abrupto do coeficiente de absorção no intervalo de energia entre 1845,0 e 1847,5 $\mathrm{cV}$. O deslocamento observado na borda de absorção é devido principalmente à variação de composição química ao redor do átomo absorvedor (Si). Entretanto, os espectros das amostras com $R e=0,50$ e 0,25 , possuem um perfil de absorção da borda que pode ser interpretado como uma convolução de dois tipos de átomos vizinhos ao absorvedor (Si), isto é, Si-(O-N) e Si-Si. Em particular, a contribuição de Si-Si na borda de absorção para a amostra mais rica em Si é evidenciada pela presença de um ombro, localizado no intervalo de energia próximo da referênciá c-Si (100).

Em resumo, os dados de XANES das amostras com $R e \geq 2,00$ apontam para o crescimento de materiais homogêneos e com estruturas locais de curto alcance, isto é, um material amorfo e similar à referência $a-\mathrm{SiO}_{2}$ (crescido termicamente). Por outro lado, os resultados para as amostras com Re $\leq 1,50$ evidenciam a formação de agregados de Si ná matriz $\mathrm{SiO}_{x} \mathrm{~N}_{y}$, comoborando assim com os dados FTIR.

O tratamento de dados na região de EXAFS para as amostras com Re $\geq 2,00 \mathrm{e}$ referências $\left(a-\mathrm{SiO}_{2}, a-\mathrm{Si}_{3} \mathrm{~N}_{4}\right)$, coi feito no intervalo de 1,5 a $9,0 \AA^{-1}$, do qual obtivemos a transformada de Fourier no espaço real. A transformada de Fourier (T.F.) do sinal de EXAFS nos dá uma informação qualitativa a respeito da estrutura de ordem local ao redor do átomo absorvedor (Si), como pode ser apreciado na Figura 3.19. 


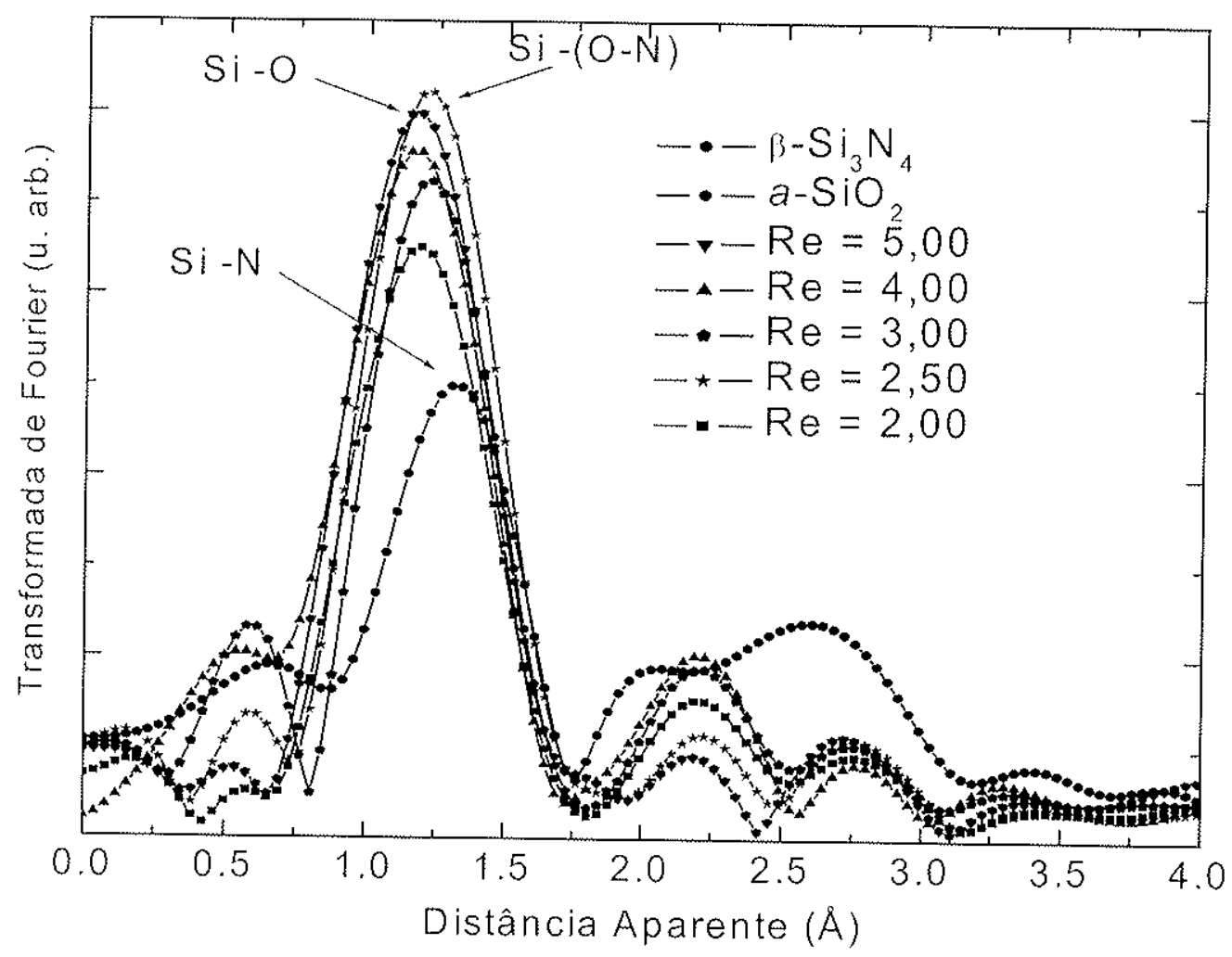

Figura 3.19 - Transformada de Fourier do sinal de EXAFS das amostras $(2,00 \leq R e \leq$ $5,00)$ e referências.

Da Figura 3.19 observa-se que a ordem de curto alcance é fracamente dependente da composição, como pode ser visto pelá magnitude do primeiro pico da transformada de Fourier, pelo menos para amostras ricas en oxigenio $($ Re $\geq 2,(0))$. Por outro lado, observa-se lambém que a posição do primeiro pico da transformada de Fourier das amostras está localizado entre as posições dos picos das referências. Assim, esse resultado sugere que a primeira esfera de coordenação seja composta por dois tipos de átomos diferentes, isto é, átomos de Si ligados a N e O.

A partir dos dados de EXAFS tratados, foi feita uma simulação utilizando o programa do Michalowicz." (a qualidade do ajuste da simulação é mostrada na Figura 3.22). Na análise dos dados consideramos o número de coordenação total do Si líxo em 4, isto é, todos os átomos de silício possuem sua primeira esfera de coordenação completa. Uma outra consideração que fizemos na análise dos dados de EXAFS é que a primeira esfera de coordenação é parcialmente preenchida por átomos de $\mathrm{O}$ e $\mathrm{N}$ (Figura 3.19). O número de coordenação associado a cada ligação $\mathrm{cm}$ relação ao átomo de Si, foi inicialmente estimado 
por RBS. Durante a simulação foi permitido variar a distância interatômica, o fator de Deybe Waller e a variável associada ao deslocamento de energía em relação à borda $K$ de absorção. Antes de finalizarmos a simulação, era permitido variar o número de coordenação. O número de coordenação, comprimento das ligações, assim como o fator de Deybe Waller obtidos da simulação de EXAFS para este conjunto de amostras é mostrado na Tabela 3.2 a seguir.

Tabela 3.2- $\mathrm{N}_{\mathrm{Si}-i}( \pm 10 \%), \sigma_{S i-i}( \pm 15 \%), \mathrm{N}_{\mathrm{total}}$ e $\mathbf{R}_{S i-i}( \pm 1 \%)$ correspondem ao número de coordenação, fator de Debye-Waller, número de coordenação total e distância interatômica média das ligações químicas em $\AA$, respectivamente, $(i=1$, oxigênio $i=2$, nitrogênio).

$\begin{array}{cccccccc}\text { Re } & N_{\text {Si- })} & \sigma_{\text {Si- }()} & R_{\text {Si-O }} & N_{\text {Si-N }} & \sigma_{\text {Si-N }} & R_{\text {Si-N }} & N_{\text {lotal }} \\ 5,00 & 4,01 & 0,00 & 1,60 & - & - & - & 4,01 \\ 4,00 & 4,04 & 0,00 & 1,60 & - & - & - & 4,04 \\ 3,00 & 3,20 & 0,00 & 1,63 & 0,80 & 0,00 & 1,60 & 4,00 \\ 2,50 & 3,33 & 0,00 & 1,60 & 0.72 & 0,00 & 1,73 & 4,05 \\ 2,00 & 2,75 & 0,04 & 1,60 & 1,25 & 0,00 & 1,70 & 4,00\end{array}$

Da Tabela 3.2 verifica-se que as amostras com $R e=5,00$ e 4,00 năo possuem contribuição de $\mathrm{N}$ em torno dos átomos de Si. Na primeira esfera de coordenação observamos também que o comprimento da ligação Si-O não varia como função de Re, e este é similar ao da referência $\mathrm{SiO}_{2}(\sim 1,61 \AA)$. Por outro lado, o comprimento da ligação Si$\mathrm{N}$ é menor do que o da refência $\mathrm{Si}_{3} \mathrm{~N}_{4}(\sim 1,73 \AA)$ para a amostra com $R e=3,00$. Este úttimo resultado pode ser interpretado pelo modelo de ajuste de eletronegatividade ${ }^{84}$, onde se espera um pequeno descréscimo do comprimento da ligação Si-N devido à grande eletronegatividade do átomo de O. O fator de Deybe Waller é diferente de zero somente para a amostra com maior concentração de $N($ Re $=2,00)$; para todos os outros filmes a desordem nas liggaçòes Si-O e Si-N é zero, isto é, igual a das referências. Essa desordem maior na ligaçào Si-O para a amostra com maior concentração de $N$, pode ser devida à uma maior desordem angular. 
Pelo monos duas estruturas podem ser formadas entre as ligações do Si, O e N. O material pode ser formado por uma estrutura homogênea de Si-O-N ou uma mistura de duas fases, $a-\mathrm{SiO}_{\mathrm{x}}$ and $a-\mathrm{SiN}$. Devido à coordenação 4 do $\mathrm{Si}$, espera-se que os filmes de a$\mathrm{SiO}_{\mathrm{N}} \mathrm{N}_{\mathrm{y}}$ mostrem uma confrguração tetraédrica em torno do átomo de Si. Dois possiveis modelos podem descrever tal estrutura:

1. Modelo de ligações alcatórias (RBM- "Random Bonding Model")" Neste modelo considera-se que os átomo de Si são tetraedricamente coordenados por $\mathrm{O}$ e/ou $\mathrm{N}$, sendo o O bi-coordenado e o $\mathrm{N}$ tri-coordenado, na estrutura do $a-\mathrm{SiO}_{\mathrm{x}} \mathrm{N}_{y}$

2. Modelo de mistura alcatória (RMM-" Random Mixture Model") ${ }^{86}$. Neste modelo considera-se que a estrutura do $a-\mathrm{SiO}_{x} \mathrm{~N}_{\mathrm{y}}$ é uma mistua de fases de $a-\mathrm{SiO}_{2}$ e $a-\mathrm{Si}_{3} \mathrm{~N}_{4}$ distribuidas aleatoriamente.

Os espectros de FTIR (Figura 3.15) das amostras com $\mathrm{Re} \geq 2,00$ evidenciaram um deslocamento contínuo do centro da bandá da vibração de "stretching" do Si-O, com a incorporaçăo do N. Este resultado sugere a formação de um material homogêneo do tipo Si$\mathrm{O}-\mathrm{N}^{\mathrm{8} 7}$, corroborando com os dados de XANES (Figura 3.17), que mostram um deslocamento contínuo da banda de absorção. Portanto, os resultados experimentais são compatíveis com o modelo RBM. Neste modelo, a estrutura de ordem local do filme a-SiO $\mathrm{N}_{y}$ ć composta por 5 tipos de tetraedos diferentes, especificados pela fórmula química $\mathrm{SiO}_{v} \mathrm{~N}_{4-v}$ (onde $v=0,1,2,3$, e 4) com una distribuição descrita por:

$$
W(x, y)=\left(\frac{2 x}{2 x+3 y}\right)^{\prime \prime}\left(\frac{3 x}{2 x+3 y}\right)^{\prime \prime \prime \cdot} \frac{4 !}{y !(4-v) !}
$$

Esta cxpressão propõe uma probabilidade relativa entre os 5 possiveis SiO $N_{\text {: }}$. tretaedros diferentes nos filmes de $a-\mathrm{SiO}_{x} \mathrm{~N}_{y}$. A função de distribuição $W(x, y)$, calculada para cada amostra $(2,00 \leq R e \leq 5,00)$, substituindo as quantidades relativas $x(\mathrm{O} / \mathrm{Si})$ e $y(\mathrm{~N} / \mathrm{Si})$ obtidas por RBS, é mostrada na Figura 3.20 a seguir: 


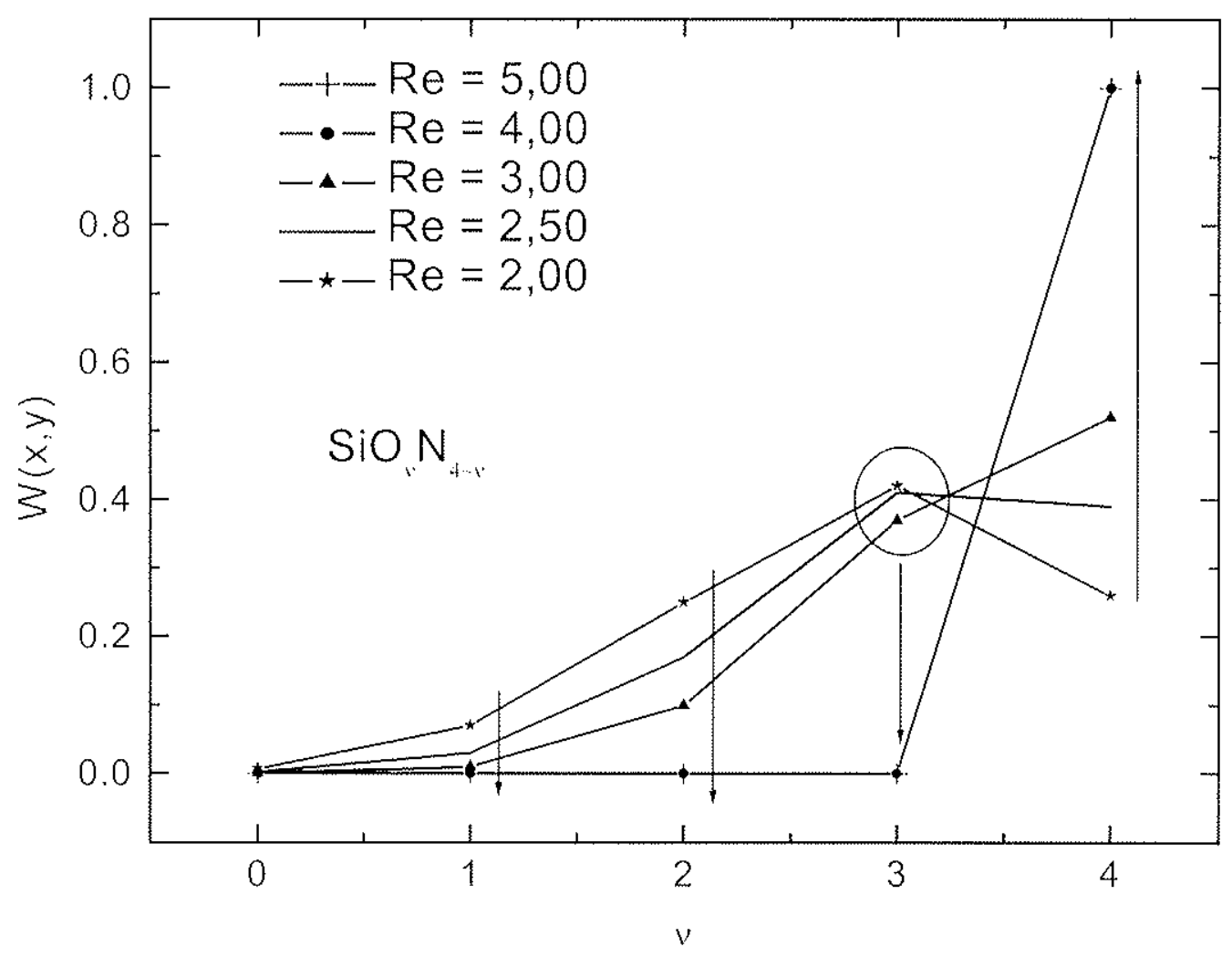

Figura 3.20- Função distribuição de probabilidade $W(x, y)$ como função de $v$ no fïme a$\mathrm{SiO}_{x} \mathrm{~N}_{y}$, onde $v$ está relacionado com os 5 tipos de $\mathrm{SiO}_{v} \mathrm{~N}_{4-v}(v$ variando de 0 a 4$)$ tetraedros diferentes. A seta indica a tendência de $W(x, y)$ com o aumento da quantidade de $\mathrm{O}$ nos filmes.

Os resultados da Figura 3.20 mostram que as amostras com $\mathrm{Re}=3,00,2,50$ e 2,00 são compostas por percentuais de tetraedros diferentes. Por outro lado, amostras com Rc= 4,00 e 5,00 devem ser compostos por tetraedros tipo $\mathrm{SiO}_{4}$, similares ao a-SiO 2 . Estes resultados estão em bom acordo com o número de coordenação obtido dos dados de EXAFS (Tabela 3.2). Esta comparação pode ser feita adicionando o número de átomos de $\mathrm{O} \mathrm{cm}$ cadá tetraedro, com sua respectiva probabilidade (Figura 3.20). Nos filmes que contém N, $40 \%$ dos tetracdrados são formados por $\mathrm{SiO}_{3} \mathrm{~N}$. Com o decréscimo de $\mathrm{N}$ o número de tetracdrados $\mathrm{SiON}_{3}$ e SiO${ }_{2} \mathrm{~N}_{2}$ também decrescem, seguido por um aumento da quantidade de tetraedros do tipo $\mathrm{SiO}_{4}$. A transição ocorre para a amostra com menor quantidade de $\mathrm{N}$ detetável, Re::: 3,00 , a qual possui um percentual grande de tetraedos do tipo $\mathrm{SiO}_{4}$ comparados ao $\mathrm{SiO}_{3} \mathrm{~N}$ (Figura 3.20). 
Para as amostras com maior conteúdo de Si $(0,25 \leq R e \leq 1,50)$ e as referências (a$\mathrm{SiO}_{2}$, a-Si $\mathrm{S}_{3}$ e e-Si), o tratamento de dados na região de EXAFS foi feito no intervalo de $(2,0 \cdots 9,0) \AA^{1}$. A partir dos dados tratados, obtivemos a transformada de Fourier no espaço real Figura 3.21 .

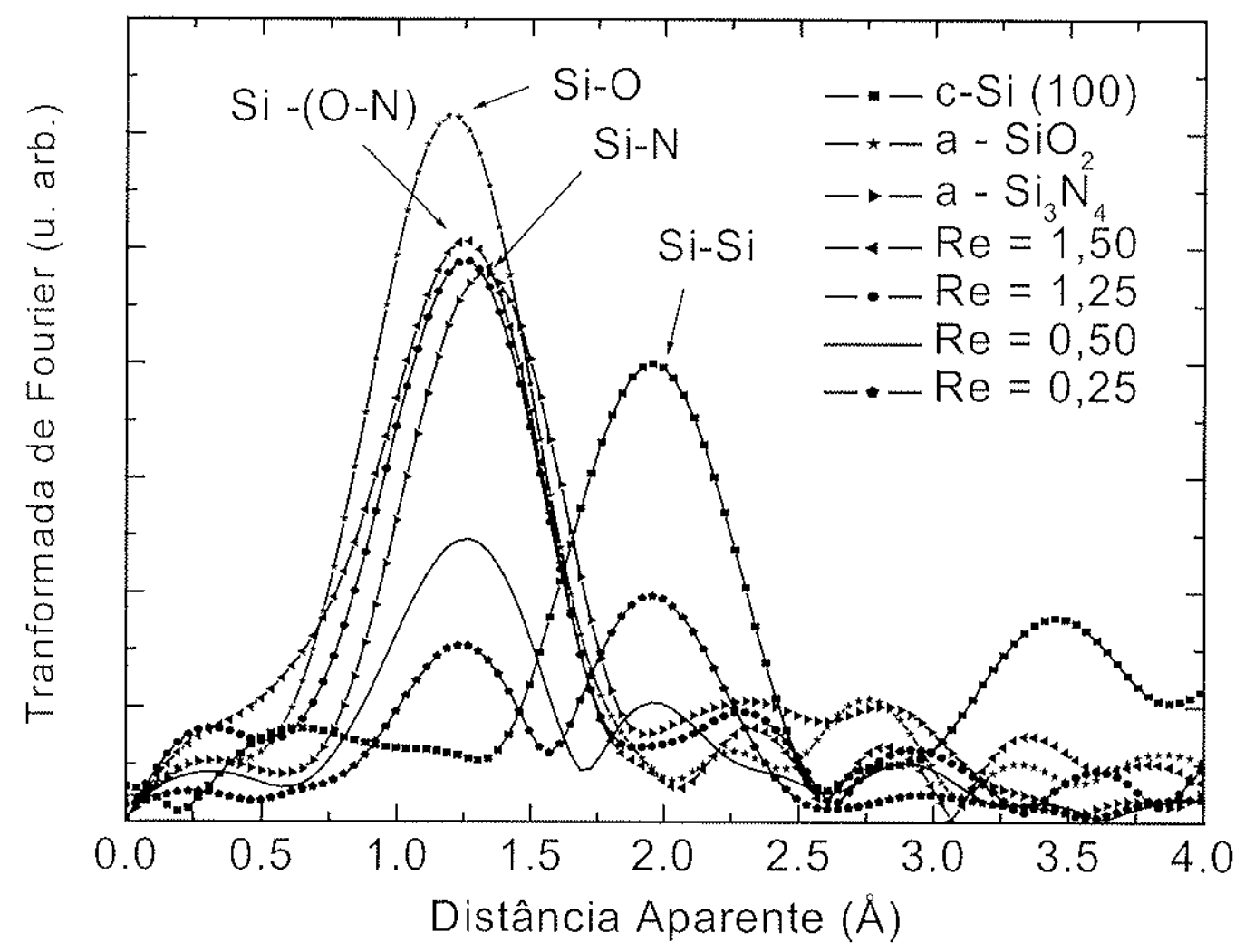

Figura 3.21- Transformada de Fourier do sinal de EXAFS das amostras com $0,25 \leq R e$ $\leq 1,50$ e referências.

Da figura Figura 3.21 observa-se que todas as amostras apresentam un primeiro pico localizado entre os picos das referências $a-\mathrm{SiO}_{2}$ e $a-\mathrm{Si}_{3} \mathrm{~N}_{4}$, que correspondem às ligações SiO e Si-N, respectivamente. Entretanto, somente nas amostras com Re $\leq 0,50$ existe evidencia de un segundo pico localizado na posição da ligação Si-Si da referência $c$-Si. É evidente uma dependencia da composição com a magnitude do primeiro pico da transformada de Fourier, pelos menos para as amostras ricas em silício (Re $\leq 0,50)$.

A análise de EXAFS foi feita considerando un modelo $\mathrm{em}$ que os átomos de silício estão ligados tetraedricamente com átomos de Si, N e O (Figura 3.21). Entretanto, as amostras com $R e \geq 1,25$ não apresentaram qualquer melhora significativa no ajuste com a 
inclusão da ligação Si-Si. O número de coordenação associado a cada ligação em relação ao átomo de Si foi inicialmente estimado por RBS. Durante a simulação foi permitido variar a distância interatômica, o fator de Deybe Waller e a variável associada ao deslocamento de energia em relação à borda $K$ de absorção. Antes de se finalizar a simulação, permitiu-se variar o número de coordenação associado a cada tipo de ligação.

A Tabela 3.3 apresenta os resultados obtidos dos dados de EXAFS, tal como número de coordenação, fator de Debye Waller e distância média interatômica das ligações químicas.

Tabela 3.3- $\mathrm{N}_{S i-i}( \pm 10 \%), \sigma_{S i-i}( \pm 15 \%), \mathrm{R}_{S i-i}( \pm 1 \%)$ e Re correspondem ao número de coordenação, fator de Debye-Waller, número de coordenação total e distância interatômica média das ligações químicas em $\AA$, razão de fluxos $\left[\mathrm{N}_{2} \mathrm{O} / \mathrm{SiH}_{4} \mid\right.$, respectivamente, $(i=1$, oxigênio; $i=2$, nitrogênio e $i=3$, silício).

\begin{tabular}{ccccccccccc} 
Re & $N_{\text {Si- } O}$ & $\sigma_{\text {Si- })}$ & $R_{\text {Si-O }}$ & $N_{\text {Si-N }}$ & $\sigma_{\text {Si-N }}$ & $R_{\text {Si-N }}$ & $N_{\text {Si-Si }}$ & $\sigma_{\text {Si-Si }}$ & $R_{\text {Si-Si }}$ & $N_{\text {toral }}$ \\
\hline 1,50 & 2,04 & 0,00 & 1,60 & 1,96 & 0,00 & 1,73 & - & - & - & 4,00 \\
1,25 & 1,96 & 0,00 & 1,64 & 1,84 & 0,00 & 1,69 & - & - & - & 3,80 \\
0,50 & 0,90 & 0,00 & 1,65 & 1,00 & 0,00 & 1,66 & 1,82 & 0,10 & 2,34 & 3,72 \\
0,25 & 0,49 & 0,02 & 1,66 & 0,84 & 0,02 & 1,73 & 2,28 & 0,05 & 2,38 & 3,61
\end{tabular}

Na T'abela 3.3 observa-se que o comprimento da ligação Si-O tende para o valor de $\sim$ $1,61 \AA\left(\mathrm{SiO}_{2}\right)$ com o aumento do conteúdo de oxigenio, sendo consistente com o crescimento de filmes oxidados. O comprimento da ligação Si-N é diferente de $\sim 1,73 \AA$ $\left(\mathrm{Si}_{3} \mathrm{~N}_{4}\right)$, somente para a amostra com Re $=0,50$. Este comportamento é atribuido alo alo de que esta amostra possui o mesmo conteúdo de O e N (Figura 3.8). Portanto, o comprimento das ligações Si-O e Si-N são iguais, e estão entre os valores das referências ${ }^{88,89}, 90$. O número de coordenação do Si aumenta, enquanto que o de O e N decresce com o decréscimo de Re. Ao mesmo tempo, o número total de coordenação decresce como conseqüiencia do aumento do conteúdo de hidrogênio nos filmes. O fator de Deybe Waller não nulo para as ligaçòes Si$\mathrm{Si}$, indicam uma desordem estática, quando comparada com a amostra de referencia cristalina, e-Si. Esta desordem depende da coordenação relativa dos diferentes átomos presentes na primeira esfera de coordenação ( $\mathrm{Si}, \mathrm{O}$ e N) e de suas respectivas ligações. O comprimento das ligações Si-O e Si-N são próximas, porém muito diferentes da distância Si- 
$\mathrm{Si}$; portanto, esperamse uma maior desordem na ligaçĩo $\mathrm{Si}-\mathrm{Si}$, para os filmes com maior conteúdo de Si (veja Tabela 3.3 para $R e=0,50$ ). Entretanto, com o aumento da quantidade de Si $(R e=0,25)$, a desordem deve decrescer devido à maior infuência das ligações Si-Si, na ordem local do Si. Por outro lado, o fator de Debye Waller associado às ligações Si-O c Si-N são maiores do que as referencias somente para a amostra com $R e=0,25$. Isto é devido à presença de três tipos de átomos diferentes na primeira esfera de coordenação do Si, sendo pelo menos $50 \%$ das ligações feitas com átomos de Si.

O átomo de hidrogênio com seu único elétron não contribui para o espálhamento, e seus efeitos estruturais podem somente ser detetados quando estes estão localizados em sítios bem definidos entre o átomo absorvedor e o espalhador, como mostrado por Lengeler ${ }^{21}$. Em una estrutura desordenada como a desse sistema estudado, o principal efeito da presença de hidrogênio é a redução do número total de coordenação $\mathrm{cm}$ torno do Si. Como mostrado na Figura 3.8, o conteúdo de hidrogênio aumenta com o decréscimo de Re. Este cleito é obscrvado no número total de coordenação em torno dos átomos de $\mathrm{Si}$, isto é, ele decresce com o decréscimo de Re (Tabela 3.3).

Em resumo, os dados de EXAFS mostram que nossos filmes possuem apenas uma estrutura de ordem local ao redor do átomo de $\mathrm{Si}$, que é basicamente composta de ligações Si-O e Si-N para filmes com maior conteúdo de oxigênio. Por outro lado, para as amostras com maior concentração de Si $(R e \leq 0,50)$, a ligação Si-Si também está presente na estrutura local. 

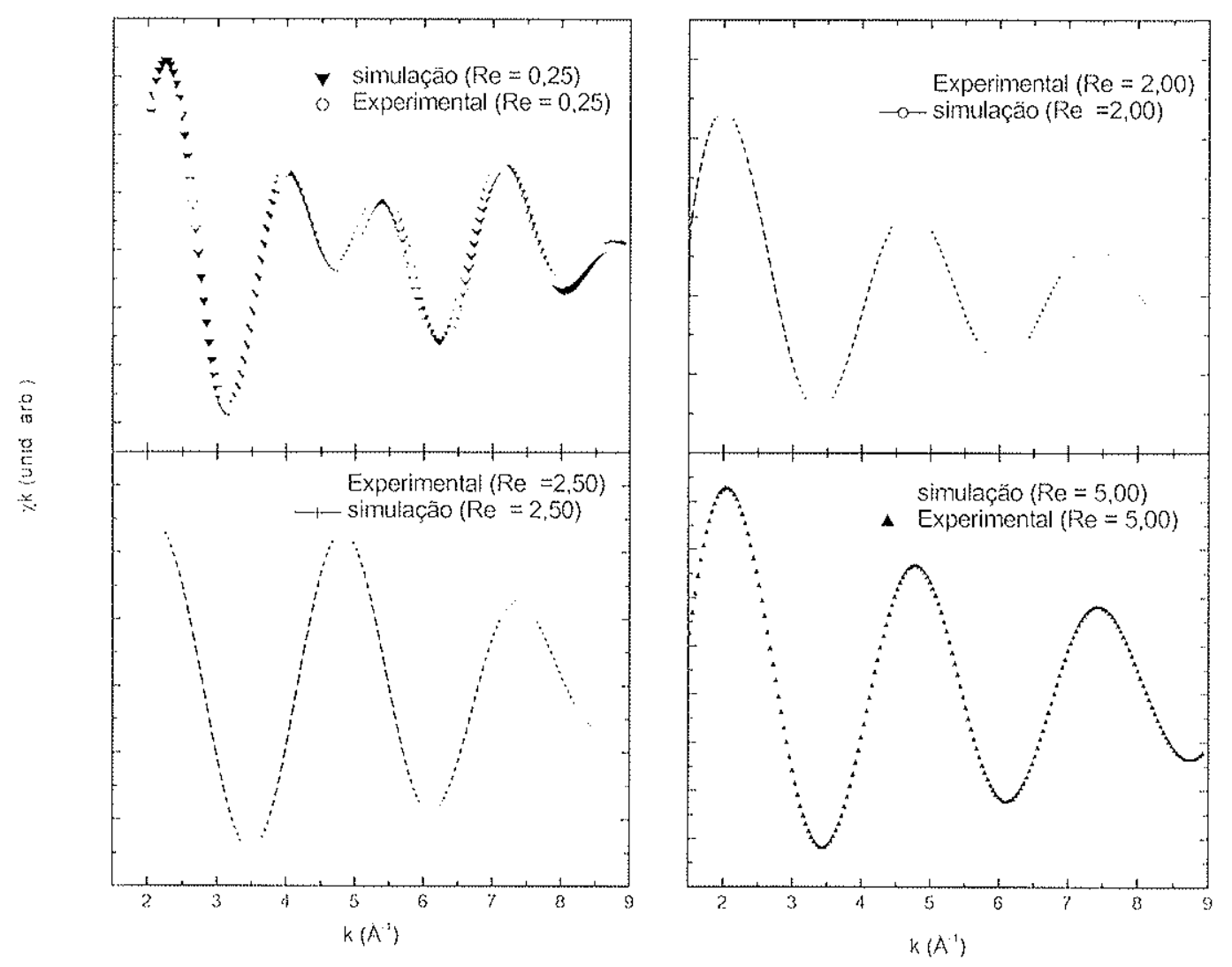

Figura 3.22- Espectro de EXAFS experimental e ajuste para as amostras $R e=0,25$, $2,00,2,50$ e 5,00 .

\subsubsection{AMOSTRAS TRATADAS TERMICAMENTE}

Com objetivo de verificar a cstabilidade das propriedades estrutuats e ligaçòes químicas, foi realizado tratamento térmico nos filmes. As amostras crescidas com Re $=0,25$ e 2,50 foram submetidas a um processo de tratamento térmico a vácuo nas seguintes temperaturas, 550,750 e $1000^{\circ} \mathrm{C}$. Essas duas amostras foram escolhidas pois a primeira (rica em Si) apresentou fotoluminescência, a cual foi associada à presença de aglomerados de silício c a segunda (rica em $\mathrm{O}$ ), devido ao fato de ter apresentado propriedade mecânical diferenciada, isto é, foi o único filme auto-sustentado obtido da série de amostras ricas em oxigênio. liizomos o tratamento témico na amostra com $\mathrm{Re}=0,25$ devido à possibilidade de densificarmos os aglomerados de silício, umá vez que a quebra das ligações Si-H, induzida pelo tratamento térmico, propiciaria a formação de novas ligações Si-Si. Por outro lado, 
fizemos também o tratamento térmico na amostra $\mathrm{com} R \mathrm{Re}=2,50$ para estudarmos os efeitos da temperatura sobre as ligaçòes N-H e sobre as suas propriedades estruturais.

Os cspectros de FTIR da amostra rica em silício $(R e=0,25)$ sem tratamento e com tratamento nas três temperaturas diferentes são mostrados na Figura 3.23.

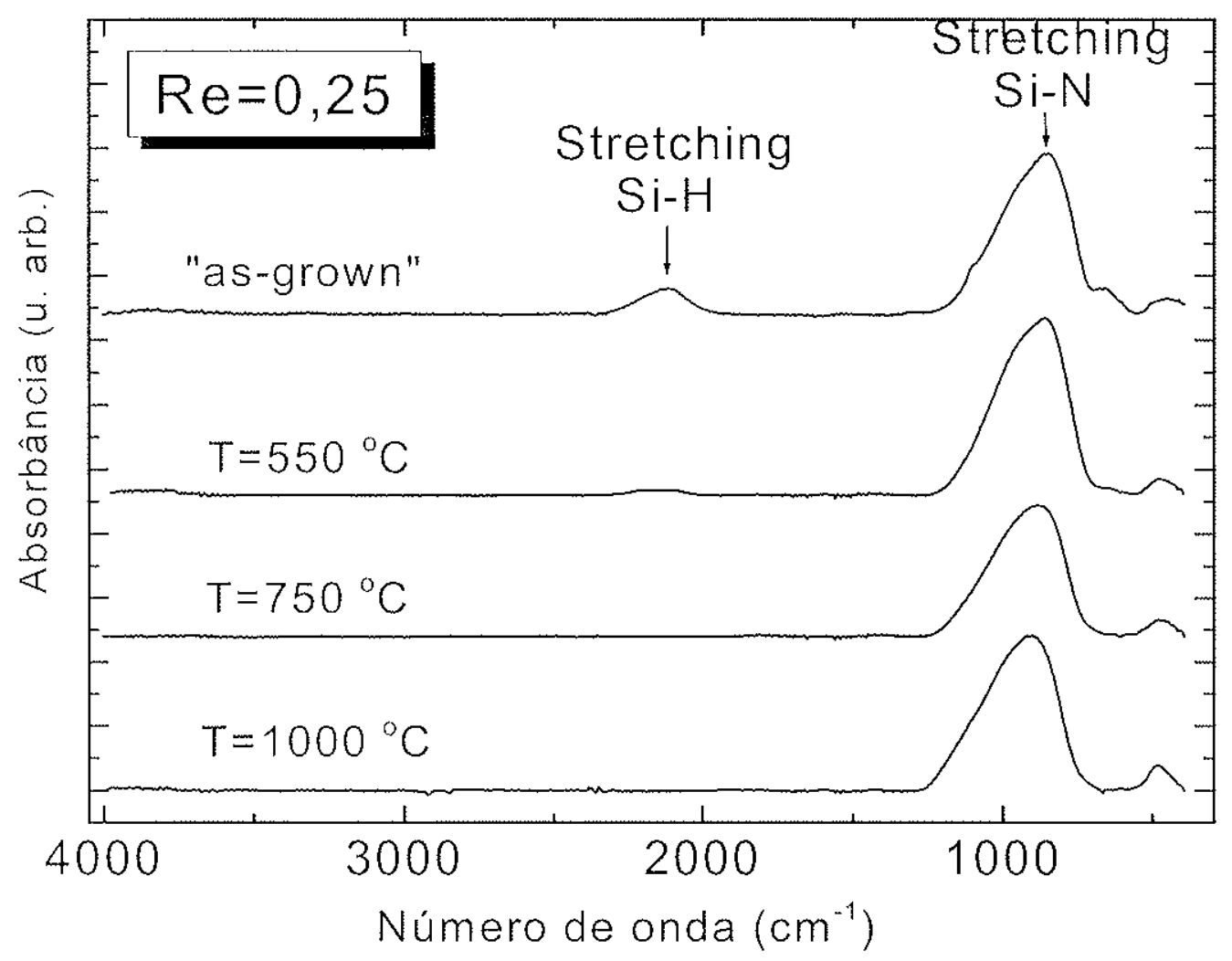

Figura 3.23 - Espectro de FTIR da amostra $(R e=0,25)$, com e sem tratamento térmico.

Da ligura Figura 3.23 observa-se que o aumento da temperatura no tratamento tćmico induz um pequeno deslocamento na posição da vibraçăo de "stretching" da ligação Si-N $\left(\cdots 845 \mathrm{~cm}^{-1}\right)$ para valores de frequiencias maiores $\left(\sim 920 \mathrm{~cm}^{-1}\right)$. Observanse também um decréscimo na intensidade do modo Si-H $\left(\sim 2100 \mathrm{e} 680 \mathrm{~cm}^{-1}\right)$ que desaparece para tomperaluras $\mathrm{T}>550^{\circ} \mathrm{C}$. Este resultado indica que as ligações Si-H são quebradas e os átomos de hidrogênio deixam o filme a partir de temperaturas maiores que $\sim 550^{\circ} \mathrm{C}$, como reportado na literatura"2, "3. Com a quebra das ligações $\mathrm{N}-\mathrm{H}$ (embora não evidente neste espectro) e SinH, os átomos de N e Si tornam-se disponiveis para fazer novas ligaçoos.

Os cspetros de FTIR da amostra rica em oxigenio $($ Re $=2,50)$ com e sem tratamento foram também analisados, como mostra a Figura 3.24. 


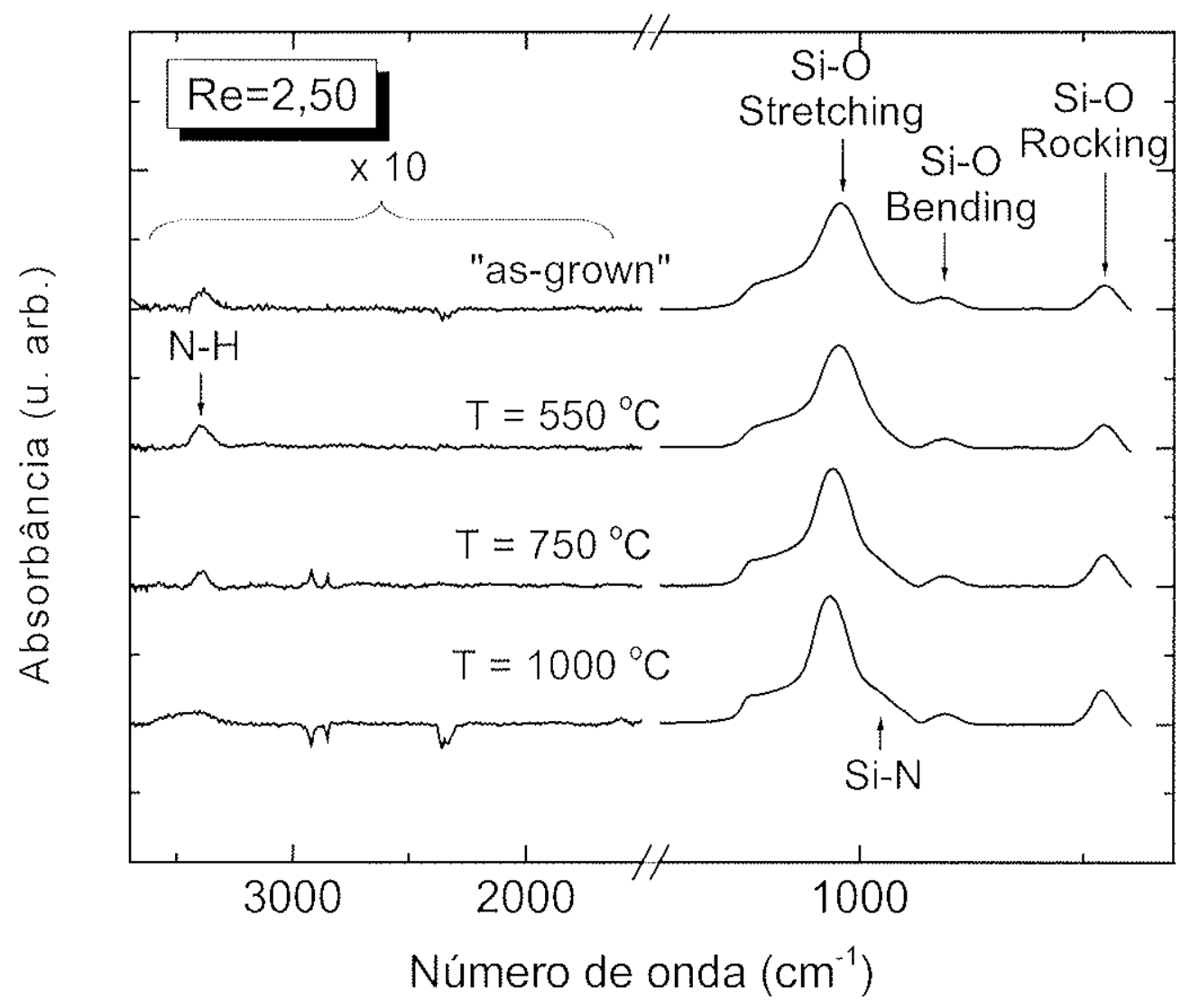

Figura 3.24- Espectro de FTIR da amostra $(R e=2,50)$, com e sem tratamento térmico.

Da ligura Figura 3.24 observamos uma banda centrada $\mathrm{em} 3400 \mathrm{~cm}^{-1}$ correspondente à vibração de "stretching" da liggaçào N-H que reduz sua amplitude com o aumento dá tempcratura de tratamento térmico. Também observamos uma banda centrada em $1060 \mathrm{~cm}^{-1}$ correspondente à vibração Si-O de "stretching" que torna-se estreita, assim como ocorre o aparecimento de uma banda fraca centrada em $835 \mathrm{~cm}^{-1}$ correspondente à vibração dá ligação Si-N de "stretching", com o aumento da temperatura do tratamento térmico.

Para uma interpretação quantitativa do deslocamento das bandas das ligações Si-O e Si-N observadas na Figura 3.24, fizemos uma deconvolução dos picos no intervalo de 800 a $1300 \mathrm{~cm}^{-1}$. Esta deconvolução foi feita através de um ajuste por 3 funções Gaussianas. O resultado da deconvolução referente à ligação SimO é mostrado na Figura 3.25. 


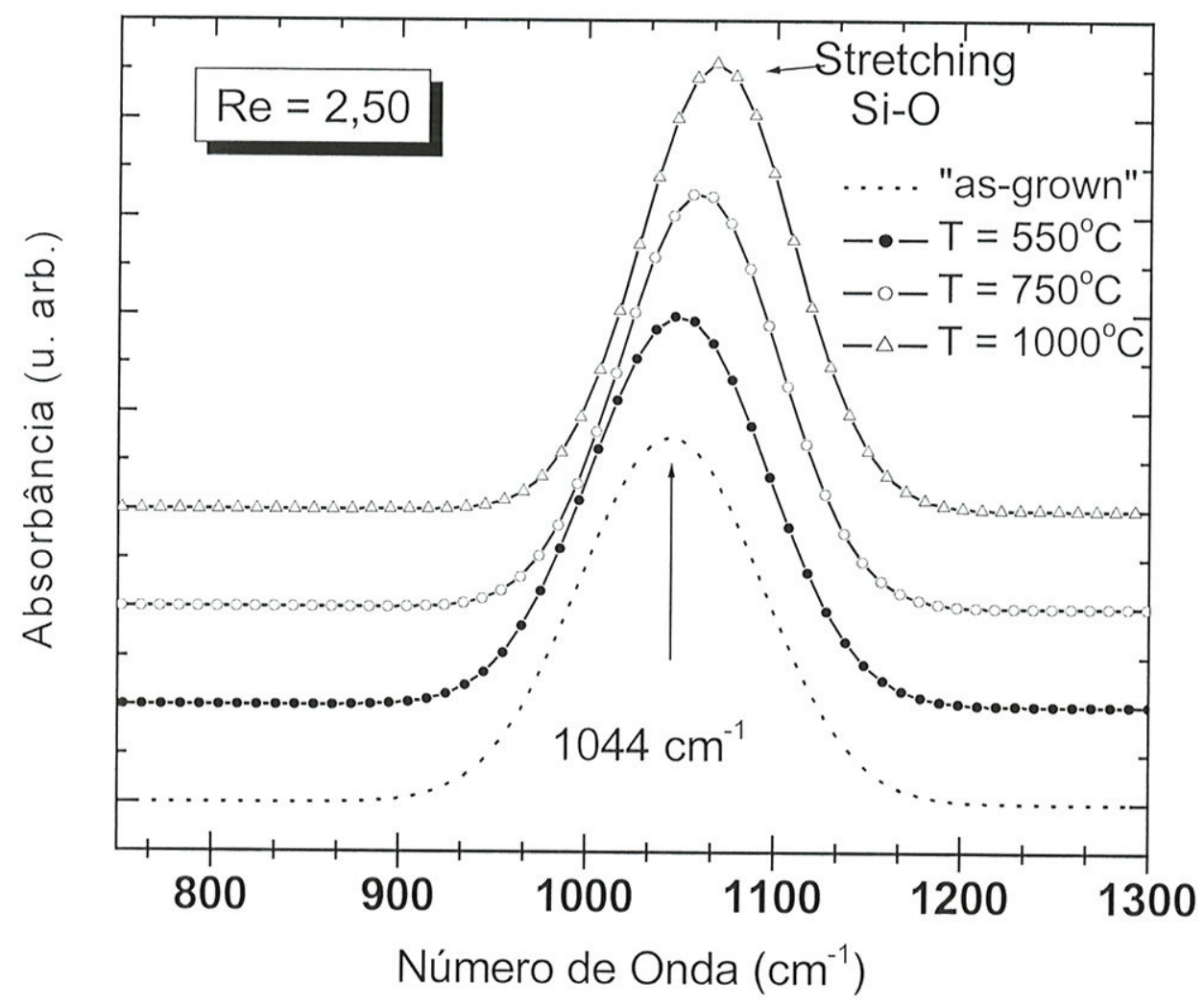

Figura 3.25- Banda de vibração de "streching" da ligação Si-O para a amostra $(R e=$ 2,50; as-grown e com tratamento térmico).

Na Figura 3.25 observa-se que a banda centrada em $1044 \mathrm{~cm}^{-1}$, correspondente à vibração de "stretching" da ligação Si-O, se desloca continuamente para valores de número de onda maiores, com o aumento da temperatura de tratamento térmico. A $1000{ }^{\circ} \mathrm{C}$, a banda associada à ligação Si-O está centrada em $1067 \mathrm{~cm}^{-1}$, mais próximo ao valor relatado para o $\mathrm{SiO}_{2}$, que é de $1070 \mathrm{~cm}^{-1}$.

O mesmo procedimento da deconvolução foi adotado para a banda associada à ligação Si-N. Esta banda centrada em $865 \mathrm{~cm}^{-1}$, correspondente à vibração de "stretching" da ligação Si-N, desloca-se continuamente para o valor de número de onda menores, com o aumento da temperatura de tratamento térmico. A $1000^{\circ} \mathrm{C}$, a banda associada à ligação Si-N está centrada em $842 \mathrm{~cm}^{-1}$, mais próxima ao valor relatado para o $\mathrm{Si}_{3} \mathrm{~N}_{4}{ }^{94}\left(845 \mathrm{~cm}^{-1}\right)$. Os resultados indicam que o efeito do aumento da temperatura de tratamento térmico é a formação de um material composto por duas fases distintas, $\mathrm{SiO}_{2}$ e $\mathrm{Si}_{3} \mathrm{~N}_{4}$, pelo menos para a amostra rica em oxigênio, depositada com $R e=2,50$.

Tombo: 36.98 
Além disso, os resultados de FTIR das amostras tratadas termicamente apontam paráa uma maior estabilidade das ligações tipo N-H, do que para Si-H, uma vez que a partir da temperatura de $\sim 550^{\circ} \mathrm{C}$ todas as ligações Si-H são quebradas ${ }^{95, \% 6}$.

Os espectros de XANES da amostra rica em oxigênio (Re $=0,25$ ) tratada termicamente em três temperaturas em comparação com a não tratada e as referencias são mostrados na Figura 3.26.

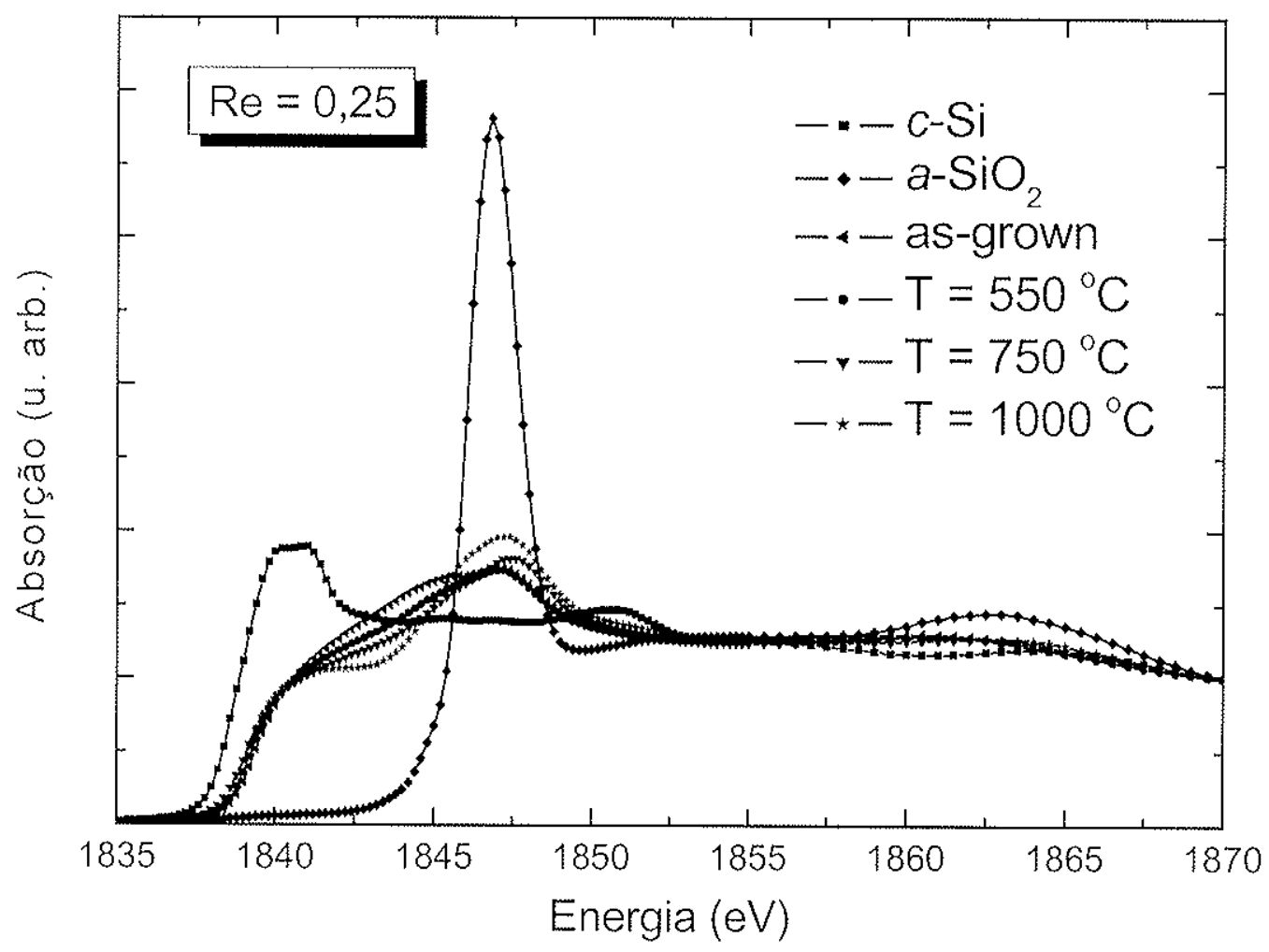

Figura 3.26- Espectro de absorção da borda $K$ do Si na região de XANES para as amostras estudadas $(R e=0,25$; com e sem tratamento térmico) e para as referências.

Na Figura 3.26 observa-se que o perfil da borda de absorção é formado pela convoluçào de vizinhos diferentes ( $\mathrm{Si}-(\mathrm{O}-\mathrm{N})$ e Si-Si) em torno do átomo de Si, mesmo para a amostra não tratada termicamente. O ombro que aparece para valores de energia menores se localiza entre as referencias $6-\mathrm{Si}$ e $a-\mathrm{SiO}_{2}$, porem mais próxima da referência $c-\mathrm{Si}$. Este ombro torna-se mais evidente e similar à referencia c-Si com o aumento da temperatura de fratamento témico. Assim, os resultados indicam que o tratamento térmico define morfologicamente os agregados de Si, pelos menos para os filmes ricos em Silício. 
O espectro de XANES da amostra rica em oxigênio $(R e=2,50)$ tratada termicamente em três temperaturas em comparação com a não tratada e as referências, são mostrados na Figura 3.27.

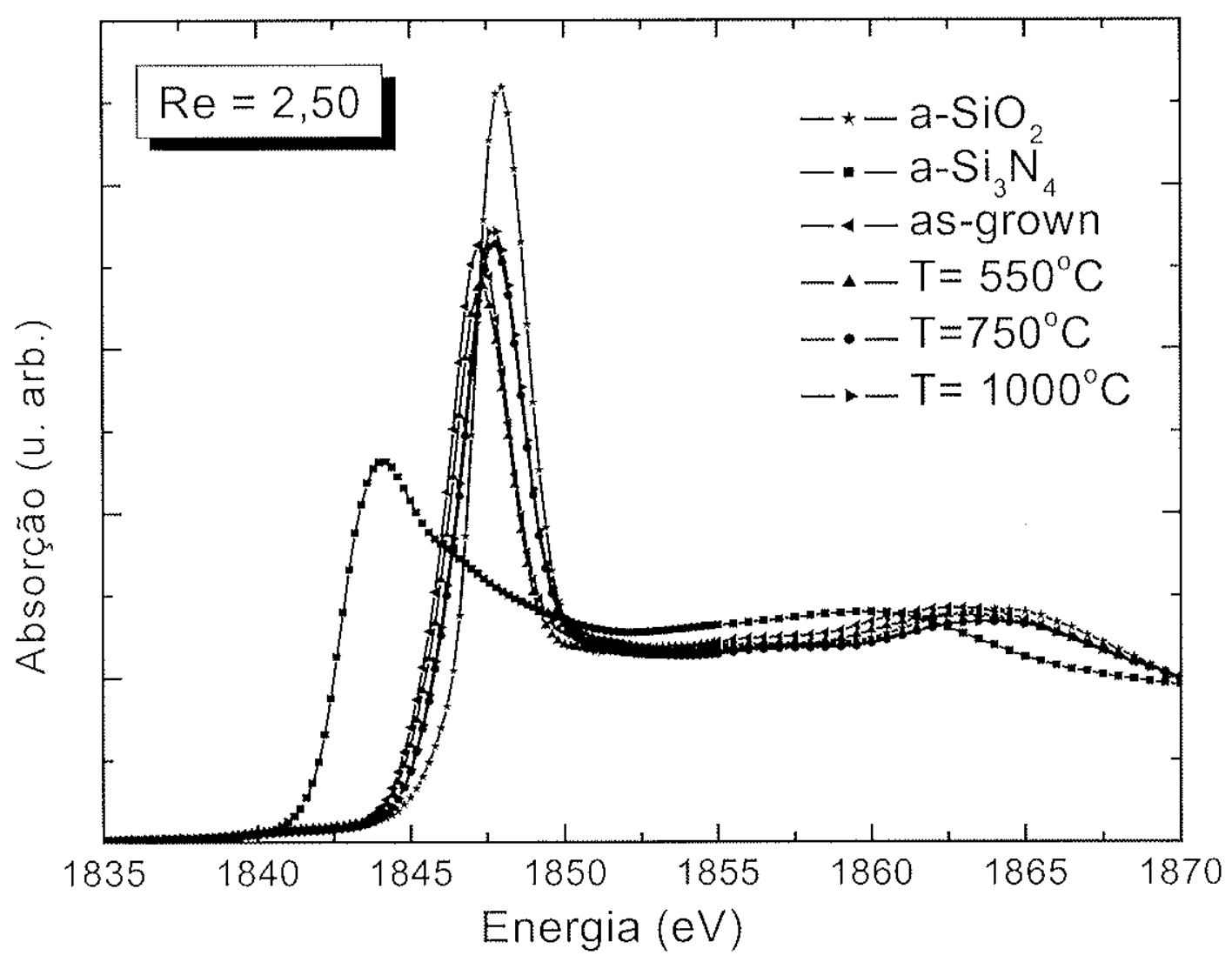

Figura 3.27- Espectro de absorção da borda $K$ do Si ma região de XANES para as amostras estudadas ( $R e=2,50 \mathrm{com}$ e sem tratamento térmico) e para as referências.

Da Figura 3.27 observa-se que a posição em energia da borda de absorção das amostras está localizada mais próxima à referencia $a-\mathrm{SiO}_{2}$. Este resultado corrobora com os dados obtidos por RBS. Tanto a amostra sem tratamento témico quanto as tratadas termicamente apresentam uma estrutura no intervalo de energia entre 1860 e $1870 \mathrm{cV}$, característico do $a-\mathrm{SiO}_{2}$.

No intuito de consolidar os resultados obtidos por FTIR, que apontam para uma separação de fases, para a amostra com $R e=2,50$ tratada temicamente, fizcmos uma combinaçào linear do sinal de EXAFS das referências $a-\mathrm{Si}_{3} \mathrm{~N}_{4}$ e $a-\mathrm{SiO}_{2}$. O percentual relativo de cada padrẽo foi estimado utilizando as concentrações atômicas relativas obtidas por RBS da amostra com Re $=2,50$. O sinal de EXAFS obtido da combinação linear das 
referências comparado ao sinal de EXAFS da amostra tratada termicamente a $10000^{\circ} \mathrm{C}$ pode ser apreciado na Figura 3.28, onde observamos uma boa concordância. Dessa forma, este resultado mostra que pode ocorrer uma segregação de fases a $1000^{\circ} \mathrm{C}$.

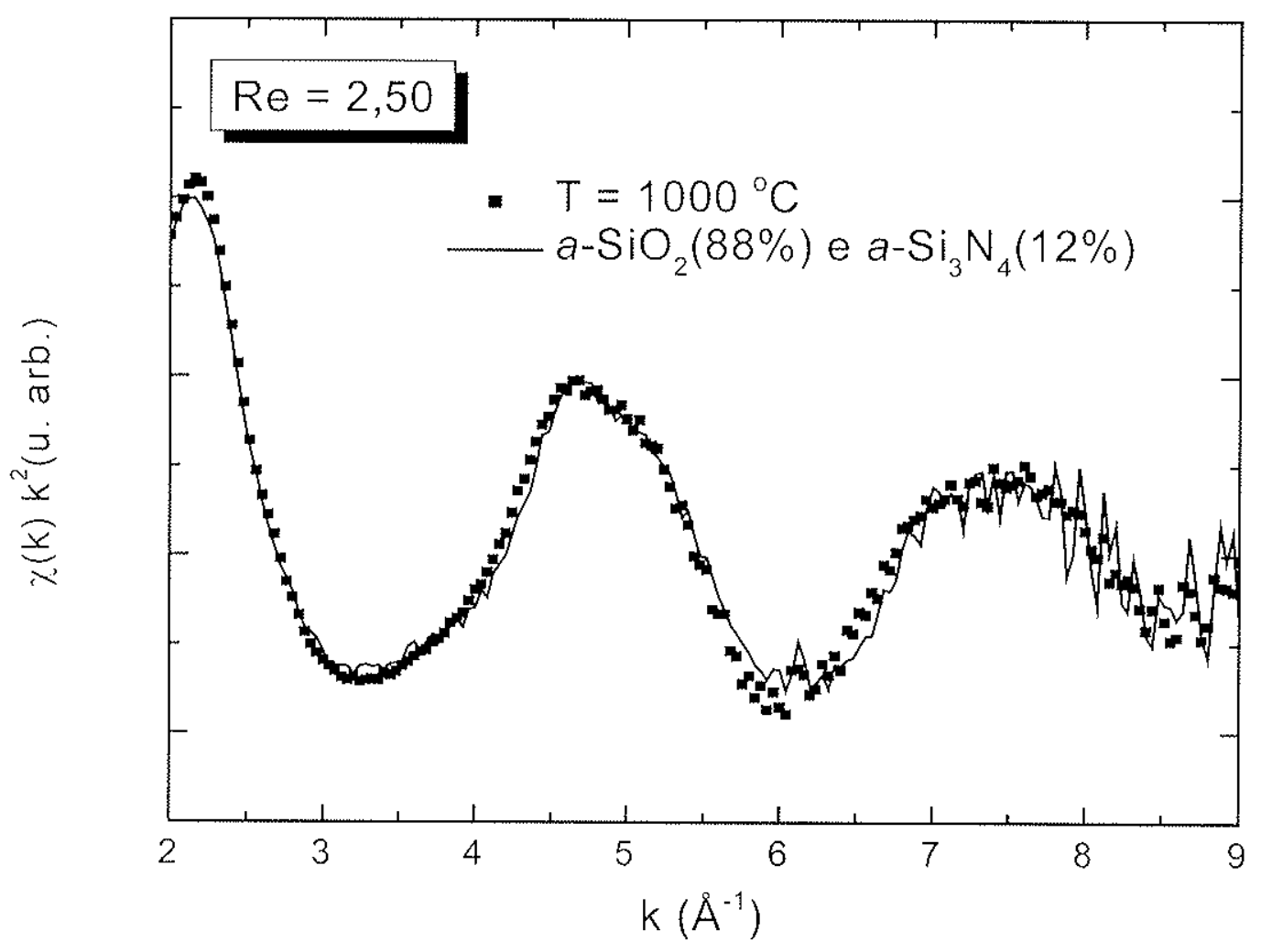

Figura 3.28- Combinação linear do sinal de EXAFS das referências $a-\mathrm{Si}_{3} \mathrm{~N}_{4}$ e $a-\mathrm{SiO}_{2}$ comparada ao sinal da amostra tratada termicamente a $1000^{\circ} \mathrm{C}$.

As transformadas de Fourier do sinal de EXAFS para a amostra rica em silício (Re = $0,25)$ c da amostra rica em oxigênio $(R e=2,50)$, e das amostras de referências comparadas às tratadas termicamente em três temperaturas diferentes, respectivamente, podem ser apreciadas nas Figura 3.29 e Figura 3.30 a seguir 


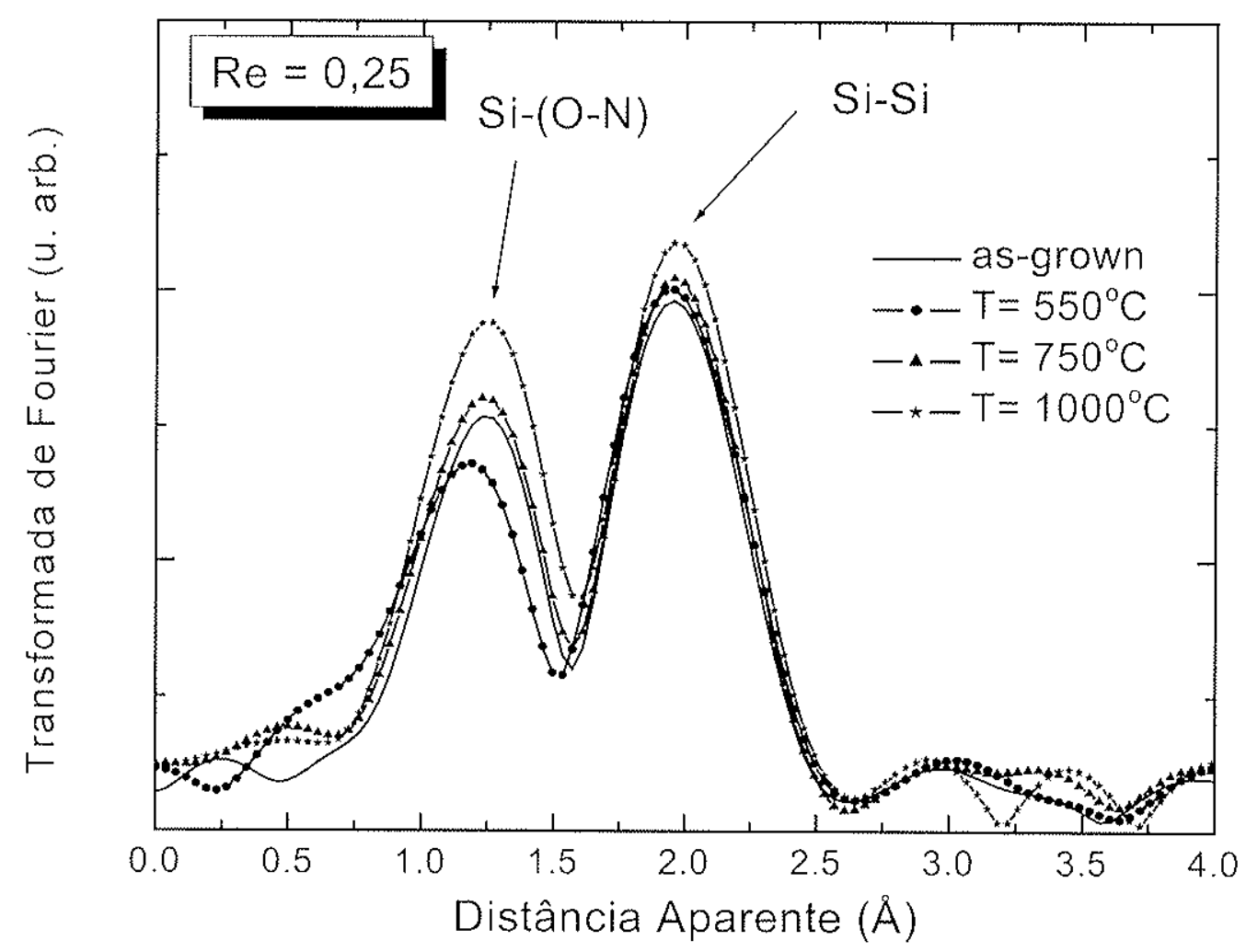

Figura 3.29- Transformada de Fourier do sinal de EXAFS da amostra $R e=0,25 \mathrm{com}$ e sem tratamento térmico, assim como as amostras de referências.

Na Figura 3.29 observa-se que para todas as temperaturas do tratamento témico existe um primeiro pico associado a ligação Si- $(\mathrm{O} N)$ e um segundo associado a ligação SiSi. Assim, como já mencionado anteriormente, para a amostra sem tratamento térmico (Re:-:$0,25)$, este resultado indica que a primeira esfera de coordenação em tomo do Si, tem contribuição de átomos de $\mathrm{O}, \mathrm{N}$ e Si. A amplitude desses picos aumenta com o aumento da temperatura de tratamento témico, indicando um material mais ordenado. 


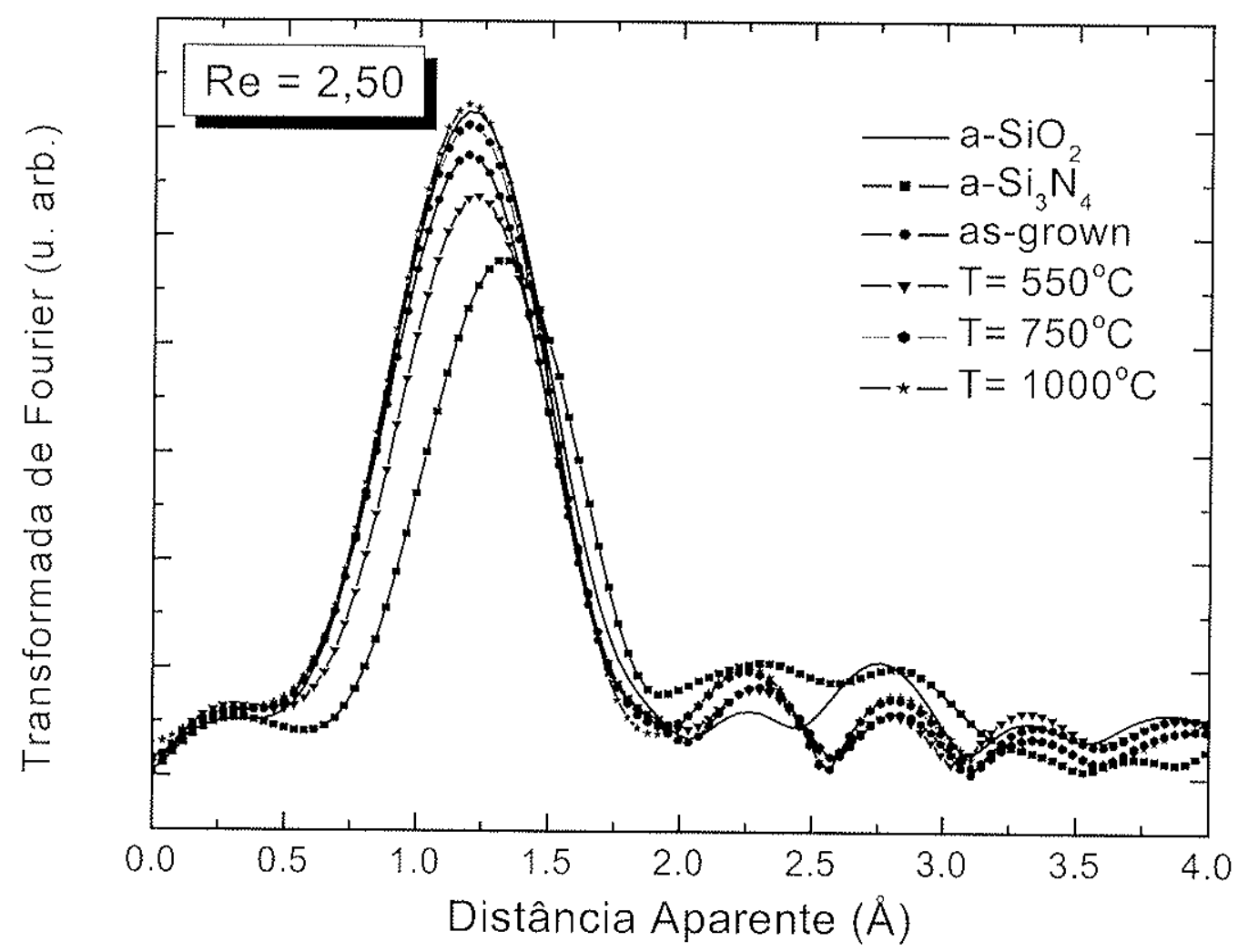

Figura 3.30- Transformada de Fourier do sinal de EXAFS da amostra $R e=2,50 \mathrm{com} \mathrm{e}$ sem tratamento térmico, assim como as amostras de referências.

Na Figura 3.30 observa-se a existência de picos, não corrigidos pelo deslocamento de lase, localizados entre $(1,10-1,30) \AA$ quue estão associados à ligação tipo Si-O (referência (1- $\mathrm{SiO}_{2}$, em $R=1,10 \AA$ ) e à ligação tipo Si-N (referência $\beta-\mathrm{Si}_{3} \mathrm{~N}_{4}$ em $R=1,30 \AA$ ). Um aumento da amplitude do pico ć observado como função do aumento da temperatura de laatamento térmico, exceto para a amostra tratada a $550{ }^{\circ} \mathrm{C}$, que é mais desordenada. Em resumo, esses resultados indicam que a primeira esfera de coordenação em torno do Si, é preenchida parcialmente por átomos de $\mathrm{O} e \mathrm{~N}$.

A análise dos dados de EXAFS para as amostras tratadas termicamente seguiram o mesmo procedimento já descrito anteriormente tanto para as amostras com $R e=0,25$, quanto para as amostras com $R e=2,50$, respectivamente. O efeito do aumento da temperatura de tratamento térmico na distância média interatômica, fator de Deybe-Waller e no número de coordenação en comparação com a amostra sem tratamento é apresentado nas Tabela 3.4 ( $R e=(), 25)$ e Tabela $3.5(R e=2,50)$, a seguir. 
Tabela 3.4- $\mathrm{N}_{S i-i}( \pm 10 \%), \sigma_{S i-i}( \pm 15 \%), \mathbf{R}_{S i-i}( \pm 1 \%)$ correspondem ao número de coordenação, fator de Debye-Waller e distância interatômica média das ligações químicas em $\AA$, respectivamente, $(i=1$ é oxigênio, $i=2$ é nitrogênio e $i=3$ é silício $)$.

\begin{tabular}{ccccccccccc} 
T ("C) & $N_{\text {Si- }()}$ & $\sigma_{\text {Si- })}$ & $R_{\text {Si-O }}$ & $N_{\text {Si-N }}$ & $\sigma_{\text {Si-N }}$ & $R_{\text {Si-N }}$ & $N_{\text {Si-Si }}$ & $\sigma_{\text {Si-Si }}$ & $R_{\text {Si-Si }}$ \\
\hline- & 0,49 & 0,020 & 1,66 & 0,84 & 0,020 & 1,73 & 2,28 & 0,050 & 2,38 \\
550 & 0,49 & 0,030 & 1,60 & 0,84 & 0,030 & 1,73 & 2,28 & 0,050 & 2,38 \\
750 & 0,49 & 0,020 & 1,61 & 1,00 & 0,020 & 1,71 & 2,18 & 0,050 & 2,37 \\
1000 & 0,49 & 0,020 & 1,62 & 1,12 & 0,020 & 1,71 & 2,50 & 0,050 & 2,37 \\
\hline
\end{tabular}

A Tabela 3.4 mostra que a desordem estática associada às ligações químicas não são afetadas pelo tratamento térmico. Somente observa-se um decréscimo no comprimento da ligação Si-O entre a amostra sem tratamento térmico comparada à tratada a $550^{\circ} \mathrm{C}$. Este resultado é interpretado como a formação de um arranjo atômico mais estável, fazendo com que o comprimento da ligaçào Si-O se tome similar ao da referência $\left(\mathrm{SiO}_{2}\right)$. Por outro lado, o número de coordenação de $N_{S i-N}$ aumenta com o aumento da temperatura de tratamento térmico. Estc resultado indica que os átomos de $\mathrm{N}$ e Si tornam-se disponíveis para novas ligações, após a perda de hidrogênio dos filmes. Isto também está em acordo com o modelo de estrutura local, que considera que os átomos de Si sempre tenden a ter coordenação quatro. Os resultados de EXAFS mostram que, como conseqüencia do tratamento térmico, as ligaçồes pendentes são eliminadas para a lormação de Sim N. 
Tabela 3.5- $\mathrm{N}_{S i-i}( \pm 10 \%), \sigma_{S i-i}( \pm 15 \%), \mathbf{R}_{S i-i}( \pm 1 \%)$ correspondem ao número de coordenação, fator de Debye-Waller e distância interatômica média das ligações químicas em $\AA$, respectivamente, $(i=1$ é oxigênio, $i=2$ é nitrogênio).

\begin{tabular}{ccccccc}
\hline $\mathrm{T}\left({ }^{\circ} \mathrm{C}\right)$ & $\mathrm{N}_{\text {Si-O }}$ & $\sigma_{\text {Si-O }}$ & $\mathrm{R}_{\text {Si-O }}$ & $\mathrm{N}_{\text {Si-N }}$ & $\sigma_{\text {Si-N }}$ & $R_{\text {Si-N }}$ \\
\hline- & 3,33 & 0,000 & 1,60 & 0,72 & 0,000 & 1,73 \\
550 & 3,33 & 0,032 & 1,61 & 0,80 & 0,032 & 1,73 \\
750 & 3,33 & 0,000 & 1,61 & 0,85 & 0,000 & 1,70 \\
1000 & 3,33 & 0,000 & 1,61 & 0,85 & 0,000 & 1,70 \\
\hline
\end{tabular}

Na Tabela 3.5 observa-se que o tratamento térmico não altera o comprimento das ligaçòes, se consideramos o erro associado. O número de coordenação permanece constante dentro da faixa de erro. Por outro lado, o fator de Debye Waller é zero para todas as amostras, isto é, igual ao das referencias. Entretanto, a amostra tratada a $550{ }^{\circ} \mathrm{C}$ apresenta una maior desordem do que nas demais temperaturas e nas referencias. Este resultado indica que a estrutura local em torno do Si, formada pelas ligações Si-O e Si-N, assumiu uma configuração mais desordenada, em termos de ângulo de ligação, nesta temperatura de fratamento térmico. Este resultado se deve ao fato de se liberar hidrogênio a essá temperatura, a qual ainda não é suficiente para reordenar as ligações. 


\section{SIMULAÇÕES COMPUTACIONAIS}

\subsection{INTRODUÇÃO}

Existe hoje uma variedade de técnicas experimentais disponíveis que podem ser tlilizadas para obtenção de informações estruturais dos sólidos amorfos. Entretanto, as técnicas experimentais apresentam certas limitações como por exemplo, diffeuldade de montagem do experimento devido as espécies alômicas presentes no sistema estudado ou até mesmo dificuldade na interpretaçào dos dados. No caso particular de nosso trabalho, por exemplo, não é óbvio a priori identificar qual correlação ou quais as correlações de pares que contribuem para a formação do primeiro pico da T.F. (transformada de Fourier) do sinal EXAFS obtida na borda $K$ do Si. Neste sentido, a construção de modelos teóricos para simular computacionalmente a estrutura destes materiais é uma boa ferramenta para ajudar a entender stáa estrutura atômicá.

Do ponto de vista computacional a descrição de um sistema de milhares de átomos tomase menos custosa, cm termos de tempo, utilizando-se potenciais modelos com parânetros empíricos. Na literatura são reportados vários potenciais modelos que tentam descrever as propricdades estruturais de materiais semicondutores $a-\mathrm{SiO}_{2}{ }^{9 \%}{ }^{9 \%}, a-\mathrm{Si}_{3} \mathrm{~N}_{4}{ }^{9 \%}, 100,101 \mathrm{c}$ aSiN $: H^{102}$. Entretanto, não conhecemos da literatura nenhum potencial modelo que descreva a liga ternária $a-\mathrm{SiO}_{\mathrm{x}} \mathrm{N}_{\mathrm{y}}$. O que existe são cálculos $a b$ initio, que investigam a estrutura na regiào de interface entre o Si e $\mathrm{SiO}_{\mathrm{x}} \mathrm{N}_{\mathrm{y}}{ }^{103}$. Uma das aproximações utilizadas neste modelo é cue os fillmes de $\mathrm{SiO}_{x} \mathrm{~N}_{y}$ são nanocristalinos.

Em colaboração com o Prof. Dr. Adalberto Fazzio e Prof. Dr. Antônio J.R. da Silvá, ambos do IFUSP (Grupo de Simulação Computacional de Materiais, SIMCOMAT) descnvolvenos um potencial modelo para descrever a estrutura dos filmes $a-S_{1} O_{x} N_{y}$ O polencial desenvolvido consiste basicamente em termos de interação de dois e três corpos.

Um dos objetivos deste trabalho teórico ć utilizar as posições atômicas da estrutura obtidas através das simulações para gerar a T.F. através do programa FEFF ${ }^{104}$ e compará-la com a obtida experimentalmente. Desta forma, pretende-se melhor compreender como cada corrclação de pares contribui para a primeira e/ou demais esferas de coordenação, una vez que a estrutura atônica é deteminada pela simulação. A simulação computacional foi 
ralizada para um intervalo de composição quimica equivalente às amostras crescidas com Re $=2,00,3,00$ e 5,00$)\left(a-\mathrm{SiO}_{2}\right)$, ricas em oxigênio.

\subsection{MÉTODO DE MONTE CARLO}

O método computational utilizado para simular a estrutura do sistema estudado foi de Monte Carlo (Metropolis). A opção pelo uso do método Monte Carlo (MC) deve-se ao fato da grande experiência do Grupo SIMCOMAT com este método. O método de Monte Carlo consiste basicamente em escolher átomos aleatoriamente, e movê-los em uma direção arbitrária, segundo o critćrio de Metropolis. O programa computacional ( em código Fortran 77) desenvolvido neste trabalho, baseou-se em parte no código desenvolvido por $P$. Venezucla e A. Fazzio ${ }^{195}$. No nosso caso, desenvolvemos um potencial modelo para tentar estudar os sistemas iônicos tipo a-SiOx $\mathrm{N}_{y}$. A seguir, discutiremos alguns pontos importantes lais como: condições periódicas de contomo; método de Metropolis; o potencial de interação; função distribuição radial.

\subsection{DESCRIÇÃO GERAL DA METODOLOGIA DE CÁLCULO}

Em nosso trabalho iniciamos uma simulação de $\mathrm{MC}$ com uma configuração inicial do sistema bascada nas posiçòes atômicas do a-quartzo, com $\mathrm{N}$ átomos confinados em uma caixa de volume $V$ a uma dada temperatura $T$. A evolução do sistema é conseguida através de sucessivos passos de MC. Considerá-se, neste trabalho, que um passo de MC só é completado após a tentativa de se mover os $\mathrm{N}$ átomos do sistema, sendo que para cadátomo 3 números aleatórios são gerados para permitir os deslocamentos $\delta x, \delta y, \delta z$. A cvoluçào do deslocamento, de um dado átomo, depende da regra de aceitação da técnica de amostragem que está sendo utilizada. Neste trabalho, o método de Metropolis foi empregado, como descrito abaixo.

Para evitar efeitos de superfície utiliza-se o método das réplicas ou imagens, juntamente com condições periódicas de contomo (Bom e von Karman, 1912). Una cáxa com simetria aproprialá é repetida no espaço para uma rede infinita. Assim, durante a simulaçào as 
moléculas ou átomos presentes na caixa original ou central se movem, sendo que suas imagens periódicas nas caixas vizinhas movimentam-se exatamente da mesma forma. Quando um átomo deixa a caixa original, um de seus átomos-imagem irá entrar na face oposta.

Um sistema periódico bidimensional é mostrado na Figura 4.31. As caixas duplicadas a partir da caixa original são identificadas como A, B, C, D, E, F, G e H. Se um átomo move na caixa central, suas imagens $3 \mathrm{~B}, 3 \mathrm{G}$, etc... apresentam o mesmo movimento. Quando um átomo deixa a caixa original através de um contomo (ver Figura 4.31), sua imagem entrará no lado oposto.

Neste sistema periódico a densidade na caixa original é conservada. B́ importante ressaltar que, independentemente do uso do método das réplicas, somente as coordenadas dos átomos presentes na caixa original são necessárias para a definição da confinguração do sistema. Durante a simulação não é necessário, portanto, guardar as coordenadas de todas as imagens.

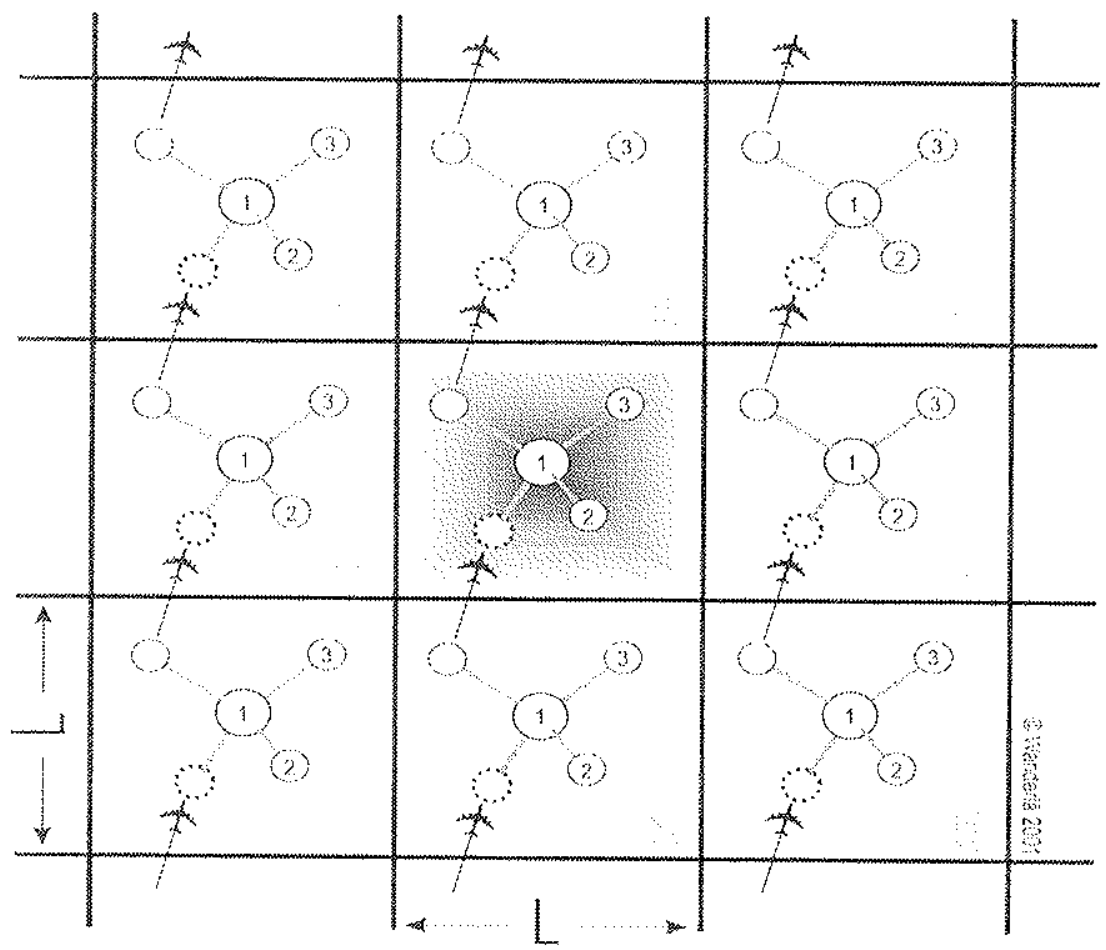

Figura 4.31 - Sistema periódico bidimensional. Os índices A, B, C, D, F, F, G, e H referem-se às caixas duplicadas a partir da caixa central. 
Em resumo, iniciamos a simulação com uma certa configuração, selecionamos um átomo j. lazemos um movimento aleatório neste átomo, e verificamos pela técnica de amostragem (Mctropolis ${ }^{106}$ ) a sua aceitação ou não parà esta nova posição. En seguida, sclecionamos um outro átomo $K$, e o mesmo procedimento anterior é aplicado ao átomo $K$, sendo este ciclo repelido para todos os $\mathrm{N}$ átomos. Ao fim deste processo um passo de $\mathrm{MC}$ foi realizado. Esta nova configuração dos átomos é gravada e reiniciamos um outro passo de MC. Ao final da simulação temos uma sequência de configurações que representam a evolução deste nosso sistemà.

\subsection{MÉTODO DE METROPOLIS}

Considere um sistema tridimensional com $\mathrm{N}$ átomos, cujas posições atômicas são representadas pelas variáveis $r_{1}, r_{2}, \ldots . ., r_{k}$. Considere agora um caminho neste espaço de configurações. Seja $u(t)$ uma certa lista de $r_{1}, r_{2}, \ldots . ., r_{N^{\prime}}$ num tésimo passo do caminho. A funçào $u(t)$ define então uma trajetória como mostrada na Figura 4.32. Ná Figura 4.32, observamos os 9 primeiros passos em uma trajetória do sistema, onde as letras A, B, C C D representam diferentes configurações do sistema. 


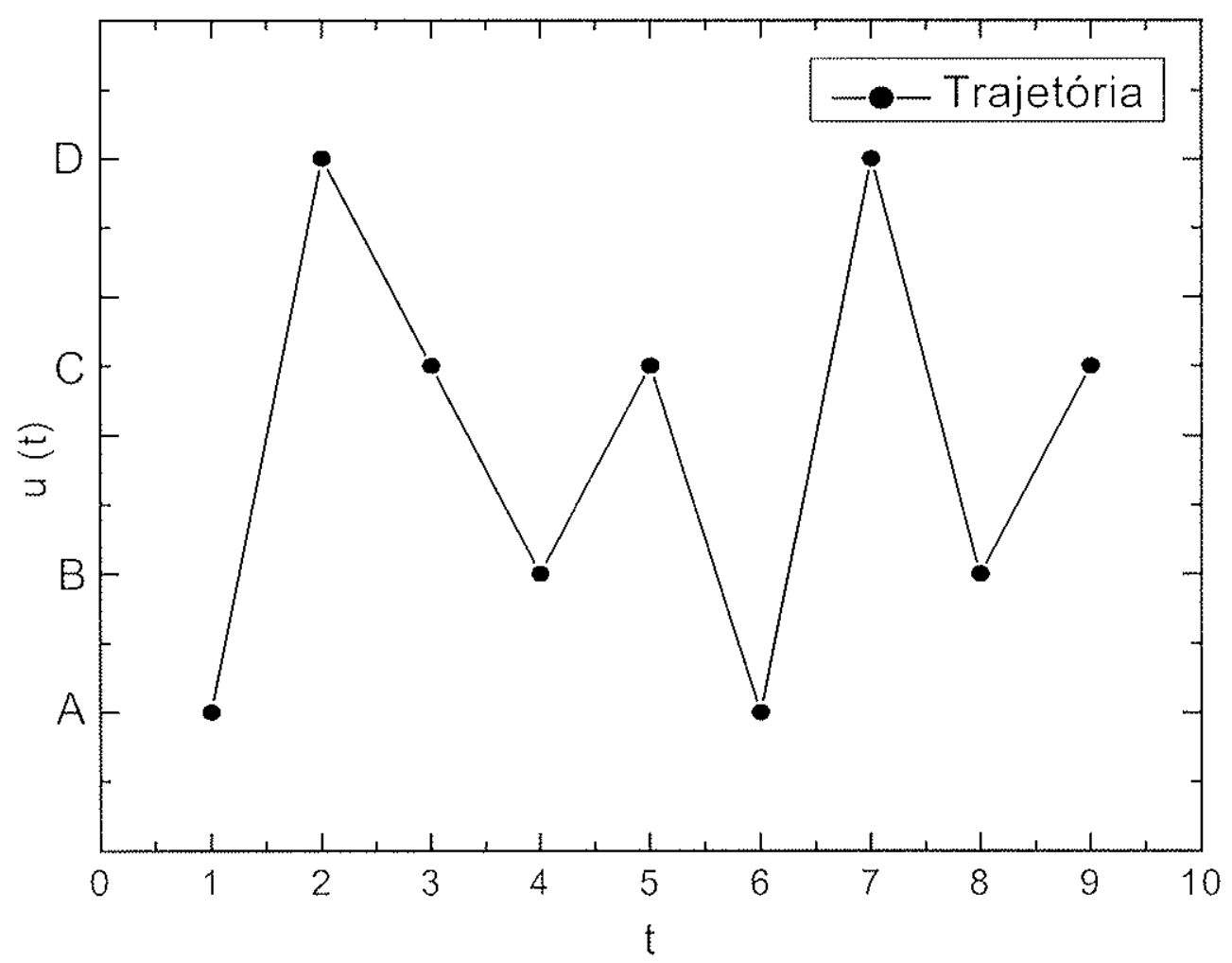

Figura 4.32 - Trajetória aleatória.

As propriedades conliguracionais de um dado sistema mudam com o progresso da trajetória, c o valor médio de um certo observável $A_{n}=A\left(r, r, \ldots, r_{N}\right)$ sobre as configuraçòes consideradas durante a trajetória com T passos é

$$
\langle A\rangle_{r}=\frac{1}{T} \sum_{i=1}^{T} A_{t(t)}
$$

O valor médio de um observável no equilíbrio térmico, é dado por:

$$
\langle A\rangle=\lim _{T \rightarrow \infty}\langle A\rangle_{T}
$$

desde que as trajetórias construídas sejam tais que a lei de distribuição de Boltzmann seja Salisleita.

Metropolis e colaboradores ${ }^{10 \%}$ propuseram um método para fazer essa média no equilibrio, mas nào seguiram o caminho de escolher estados sucessivos $\left\{v_{i}\right\}$ independentes um do outro, mas construíram uma cadeia de Markov onde cada estado do sistema $y_{i \neq 1}$ é 
construído de estados anteriores $v_{i}$ através da matriz probabilidade de transição $W\left(v \rightarrow v^{\prime}\right)$. Eles mostraran que é possivel escolher a probabilidade de transição $W$ tal que no limite $i \rightarrow \infty$, a função distribuição $p(v)$ dos estados gerados por este processo Markov tende para al distribuição de equilíbrio

$$
p(v)=\frac{1}{Z} \exp \left(-\frac{-E(v)}{K_{b} T}\right)
$$

onde $Z$ é um fator de nomalização. Considerando a condição do balanço detallado ("letailed balance") temos que

$$
p(v) w\left(v \rightarrow v^{\prime}\right)=p\left(v^{\prime}\right) w\left(v^{\prime} \rightarrow v^{\prime}\right)
$$

As equaçōes 4.24 e 4.25 implicam que a razão das probabilidades de transiçōes para "mover" do estado $v \rightarrow v^{\prime}$ e do estado $v^{\prime} \rightarrow v$ depende somente dá mudança de energía $\Delta E=E_{1},-E_{,}$,

$$
\frac{w\left(v \rightarrow v^{\prime}\right)}{w\left(v^{\prime} \rightarrow v\right)}=\exp \left(-\frac{\Delta E}{K_{B} T^{\prime}}\right)
$$

Assim, no algoritmo de Metropolis, temos que

$$
W\left(v \rightarrow v^{\prime}\right) \quad \alpha\left\{\begin{array}{l}
1, \Delta E_{w^{\prime}} \leq 0 \\
\exp \left(-\frac{\Delta E_{w^{\prime}}}{K_{\beta} T^{\prime}}\right), \quad \Delta E_{w^{\prime}} \geq 0 .
\end{array}\right.
$$

Se o estado muda de $v \rightarrow v^{\prime}$ com decréscimo de energía $\left(\Delta E_{w \cdot}<0\right)$, então o movimento é aceito. Porém, se $\Delta E_{w}>0$ para aceitar o movimento com a probabilidade $\exp \left(-\frac{\Delta E}{K_{13} T}\right)$, um número aleatório $\xi$ é gerado unifomemente entre $(0,1)$. Esse número aleatório é comparado $\operatorname{com} \exp \left(-\frac{\Delta E}{K_{B} T}\right)$. Se $\xi$ é menor do que $\exp \left(-\frac{\Delta E}{K_{B} T}\right)$ o movimento é aceito. Entretanto se $\xi \dot{c}$ maior do $\exp \left(-\frac{\Delta E}{K_{B} T}\right)$ o movimento é rejeitado. Este procedimento está ilustrado na Figura 4.33 a seguir. 


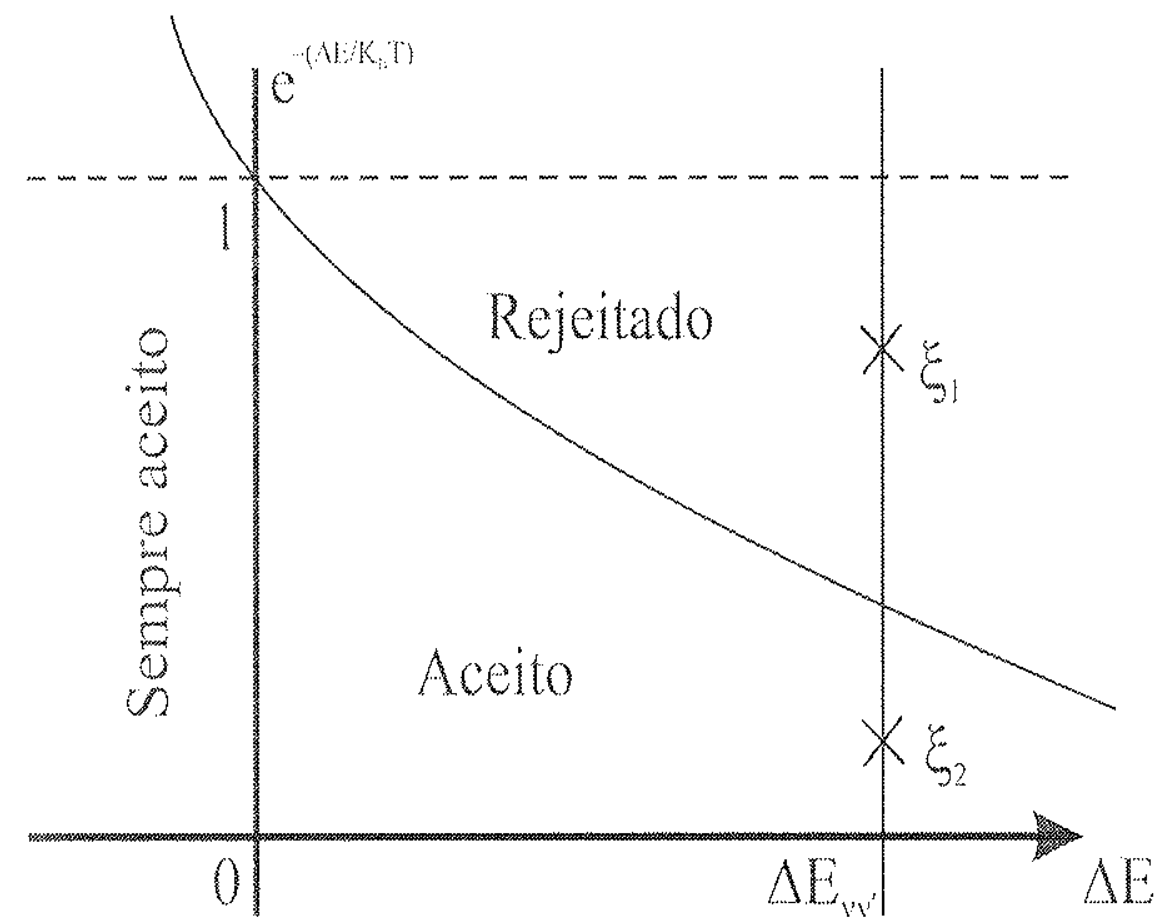

Figura 4.33-Critério para o movimento no método de Monte Carlo.

\subsection{PROPRIEDADES ESTRUTURAIS}

\subsubsection{FUNÇÃO DISTRIBUIÇÃO RADIAL}

Em simulação computacional a função distribuição radial $(g(r))$ é muito utilizada no estudo das propriedades estruturais de materiais, uma vez que esta função pode também ser deteminada experimentalmente, seja por difração de raios $X$, nêtrons ou por espalhamento de raios $X$. Desta forma, pode-se comparar as $g(\%)$ experimentais com as teóricas. A função g( $($ ) corresponde à probabilidade de encontramos um par de átomos a uma distância $r$ a partir de um átomo colocado na origem, relativa à probabilidade esperada para um sistema de densidade uniforme e uma distribuiçào totalmente aleatória. Na Figura 4.34, mostramos uma ilustraçào escuemática da estrutura de um sistema amorfo e a representaçào dos picos la $g(r)$ correspondente. 
Considere um sistema de $N$ particulas com o potencial de interação $U\left(r^{*}\right)$. A função de distribuição confíguracional deste sistema é dada por $P\left(r^{N}\right)$, pois o potencial acopla todas as coordenadas juntas. As funções de distribuição de pares para este sistema são dadas por:

$$
P^{2 N}\left(\ddot{r}_{1}, \ddot{r}_{2}\right)=\int d \vec{r}_{3} \cdots \int d \vec{r}_{N} P\left(r^{N}\right)
$$

onde $P^{2: N}\left(\ddot{r}_{1}, \vec{r}_{2}\right)$ ć a distribuição de probabilidade de encontrar a partícula 1 na posição $\ddot{r}_{1} \mathrm{c}$ a partícula 2 na posiçào $\ddot{r}_{2}$.

Define-se

$$
g\left(\ddot{r}_{1}, \ddot{r}_{2}\right)=\rho^{2 N}\left(\ddot{r}_{1}, \ddot{r}_{2}\right) / \rho^{2}
$$

onde

$$
\rho^{2 N}\left(\vec{r}_{1}, \ddot{r}_{2}\right)=N(N-1) P^{2 N N}\left(\ddot{r}_{1}, \ddot{r}_{2}\right)
$$

$\mathrm{c} p=N / \mathrm{V}$.

Para um sistema isotrópico esta lunçào depende somente de $\left|r_{i}-\ddot{r}_{2}\right|=r$. Assim, podemos reserever a equação acima como sendo

$$
g\left(\ddot{r}_{1}, \ddot{I}_{2}\right)=g(r)
$$

onde $g(r)$ é chamada de funçào distribuição radial.

Na simulação obteve-se a $g_{i j}(r)$ entre o átomo $i$ e o átomo $j$ através de un histograma de distâncias dos pares de átomos $i$ e j pela seguinte relação:

$$
g_{i j}=\frac{n_{i j}(r, r+d r)}{n_{i d t}(r, r+d r)}
$$


onde $n_{i j}(r, r+d r)$ é o número de pares ij que estão separados por uma distânciáa, e $r+d r, \mathrm{e}$ $n_{i t}(r, r+d r)$ é o número de pares equivalente a um gás ideal de densidade uniforme:

$$
n_{i d}=\frac{4 \pi}{3} \rho\left[(r+d r)^{3}-r^{3}\right]
$$

onde $\rho$ é a densidade da espécie átomicaj.

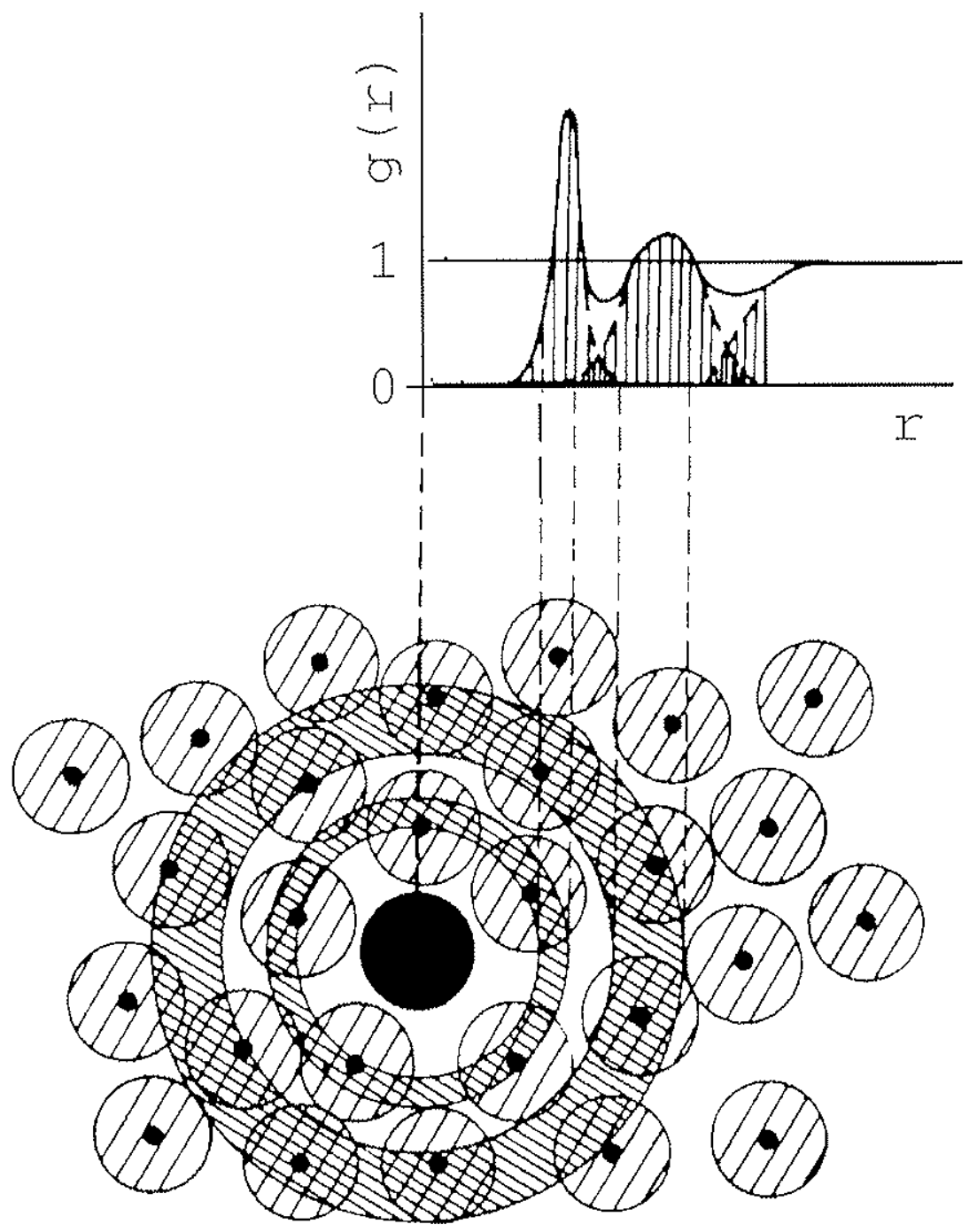

Figura 4.34 - llustração esquemática da estrutura de um sólido amorfo e g (r) correspondente. 


\subsubsection{CORRELAÇÕES ESTRUTURAIS DE TRÊS CORPOS}

A função distribuição de ângulo de ligação entre três corpos $\left(g\left(\theta_{A B C}\right)\right)$ é uma ferramenta muito importante na descrição da estrutura dos semicondutores, devido às interaçòes covalentes existentes nesses materiais. Devemos considerar incialmente um raio de corte para defnir os primeiros vizinhos da espécie $A$ para os átomos dá espécie $B$. Geralmente, o raio de corte é fixado no primeiro mínimo da função $g_{A B}(r)$. A quantidade de distribuiçòes a considerar depende então da quantidade de átomos diferentes no sistema. Considerando um sistema com três componentes $\mathrm{A}, \mathrm{B}$ e C (para o sistema estudado $\mathrm{A}=\mathrm{Si}$, $\mathrm{B}=\mathrm{O}$ e $\mathrm{C}=\mathrm{N}$ ) teríamos várias distribuições de ângulos como por exemplo, Si-O-Si, O-SiO, Si-N-Si, N-Si-N, N-Si-O entre outras. Definida a distribuição a calcular, por exemplo $g\left(O_{s i \cdots, \ldots N}\right)$, todos os ângulos entre todos os átomos Si e os átomos $\mathrm{O}$ e $\mathrm{N}$ são calculados $\mathrm{C}$ um histograma é contruido a partir desses dados.

\subsection{POTENCIAL DE INTERAÇÃO}

Un sistema monoatomico com estruturas fechadas pode ser bem descrito considerando um potencial de interação de dois corpos. A essência deste potencial está na parte repulsiva para descrever a escala de tamanho atomico e a parte atrativa para representar a coesão da fase condensada. Entretanto, este potencial não consegue descrever bem sistemas semicondutores elementares, por exemplo Si e Ge, uma vez que não considera a forte interação covalente existente nesses materiais. Assim, para descrever sistemas semicondutores é crucial a introdução de um termo de três corpos, cuja dependenciá explícita com o ângulo da ligação é essencial para a descrição da interação convalente destes materiais. O potencial de Stillinger-Weber ${ }^{107}$ é um modelo bastante utilizado para descrever a interação covalente em semicondutores elementares ${ }^{108}$.

As simulações de $\mathrm{MC}$ nos amorfos $\mathrm{SiO}_{x} \mathrm{~N}_{y}$ foram baseados em um potencial de interação efetivo que combina as interações de dois e três corpos. Este potential foi desenvolvido com base no potencial modelo (Grupo do P. Vashista, "Louisiana State University") utilizado para descrever os sistemas $\mathrm{SiO}_{2}{ }^{108}$ e $\mathrm{Si}_{3} \mathrm{~N}_{4}{ }^{109}$, onde introduzimos a interação O-N (no termo de dois corpos) e O-Si-N ou N-Si-O (no termo de três corpos). 
A cnergia do sistema a-SiO $\mathrm{N}_{y}$ é então descrita pelá soma das contribuições de interações de dois e três corpos, como descrito a seguir

$$
\begin{aligned}
& V=\sum_{i<i} V_{2}\left(\vec{r}_{i j}\right)+\sum_{i<j<k} V_{3}\left(\vec{r}_{i j}, \vec{r}_{i k}\right) \\
& V_{2}\left(r_{i i}\right)=A\left[\frac{\left(\sigma_{i}+\sigma_{i}\right)}{r_{i j}}\right]^{h_{1}}+\frac{Z_{i} z_{i}}{r_{i j}} e^{i}-\frac{\left(x_{i} Z_{i}^{2}+\alpha_{i} Z_{i}^{2}\right)}{2 r_{i j}} e^{r_{i}}
\end{aligned}
$$

onde $r_{i j}=\left|r_{i}-r_{i}\right|$. O primeiro termo do potencial de interação de dois corpos é a repulsão estérica, o segundo termo descreve a repulsão de Coulomb devido à transferência de cargá, c o terceiro termo descreve a interação carga-dipolo causada pela polarizibilidade dos átomos.

Os parânetros $\eta_{i j}$ (expoente da repulsão estérica), $A$ (força de repulsão estérica), $\sigma_{i}$ (raio iônico), Z/, (carga efetiva), $\lambda$ (expoente da repulsão de Coulomb), $\alpha_{i}$ (polarizibilidade eletrônica do i-ésimo íon), $\xi$ (distância para o decaimento da interação cargáldipolo) e r. (raio de corte) são apresentados na Tabela 4.6.

Este potencial de interação de dois corpos atua até um raio $r=r$, isto é, para valores de $r$ maiores que r:o potencial entre átomos é nulo. Para que o potencial seja contínuo cm r., substitui-se a equação anterior por

$$
V_{2}\left(r_{i j}\right)=V_{2}\left(r_{i j}\right)-V_{2}\left(r_{i}\right)-\left(r_{i j}-r_{i}\right)\left[\frac{d V_{2}\left(r_{i j}\right)}{d r_{i j}}\right]_{r_{i, k}, r_{i}}
$$

O potencial de interação para três corpos é descrito pela seguinte equação

$$
V_{i}\left(\vec{r}_{i j}, \vec{r}_{i k}\right)=B_{i k} f\left(r_{i j}, r_{i k}\right)\left[\frac{\vec{r}_{i j} \cdot \vec{r}_{i k}}{\left|\vec{r}_{i j}\right| \cdot\left|\vec{r}_{i k}\right|}-\cos \left(\overline{\theta_{i j k}}\right)\right]^{2}
$$

onde,

$$
f\left(r_{i,}, r_{i k}\right)=\left\{\begin{array}{l}
\exp \left[\frac{1}{r_{i j}-r_{i j}}+\frac{1}{r_{i k}-r_{i j}}\right] \forall, r_{i j}, r_{i k}<r_{i} \\
0 \quad \forall, r_{i j}, r_{i k} \geq r_{i}
\end{array}\right.
$$


onde $B_{i j k}$ representa a magnitude da interação de três corpos, $f\left(r_{i j}, r_{i k}\right)$ descreve o efeito do estiramento das ligações entre ij c $i k$ e o último termo descreve a variação angular em tomo (lo ângulo $\bar{O}$, sendo que $r_{i}$ corresponde ao raio de corte para o potencial de três corpo e $O_{i j k}$ ć o ângulo de equilibrio entre três átomos com o i-ésimo átomo no vértice (ver figuma 4.35). Estes parâmetros são apresentados na Tabela 4.6.

Tabela 4.6 - Parâmetros para o potencial de interação $S i O_{x} N_{y}$. A unidade de cargá é a carga eletrônica-e.

\begin{tabular}{|c|c|c|c|c|c|}
\hline $\mathrm{A}(\mathrm{cV})$ & $\mu(\hat{A})$ & $\lambda(\bar{A})$ & $\xi(\AA)$ & $r_{0}(\AA)$ & $R_{c}(\AA)$ \\
\hline \multirow[t]{2}{*}{1,592} & 1,00 & 4,43 & 2,50 & 2,60 & 5,50 \\
\hline & $\sigma_{i}(\AA)$ & & $z_{i}(\mathrm{e})$ & & $\alpha_{i}\left(\AA^{3}\right)$ \\
\hline $\mathrm{Si}$ & 0,47 & & 1,76 & & 0,00 \\
\hline 0 & 1,20 & & $-0,88$ & & 2,40 \\
\hline \multirow[t]{2}{*}{$N$} & 1,30 & & 1,104 & & 3,00 \\
\hline & $\eta_{i, j}$ & & & & \\
\hline $\mathrm{Si}-\mathrm{Si}$ & 11 & & & & \\
\hline $\mathrm{Si}-\mathrm{O}$ & 9 & & & & \\
\hline $0-0$ & 7 & & & & \\
\hline $\mathrm{Si}-\mathrm{N}$ & () & & & & \\
\hline$N-N$ & 7 & & & & \\
\hline \multirow[t]{2}{*}{$O-N$} & 7 & & & & \\
\hline & $B_{i j k}(\mathrm{eV})$ & & $\overline{\theta_{i}}$ & & \\
\hline $\mathrm{O}-\mathrm{Si}-\mathrm{O}$ & 4,993 & & 109,47 & & \\
\hline $\mathrm{Si}-\mathrm{O}-\mathrm{Si}$ & 19,972 & & 141,00 & & \\
\hline N-Si-N & 4,993 & & 109,47 & & \\
\hline $\mathrm{Si}-\mathrm{N}-\mathrm{Si}$ & 12,480 & & 120,00 & & \\
\hline $\mathrm{O}-\mathrm{Si}-\mathrm{N}$ & 4,993 & & 109,47 & & \\
\hline
\end{tabular}




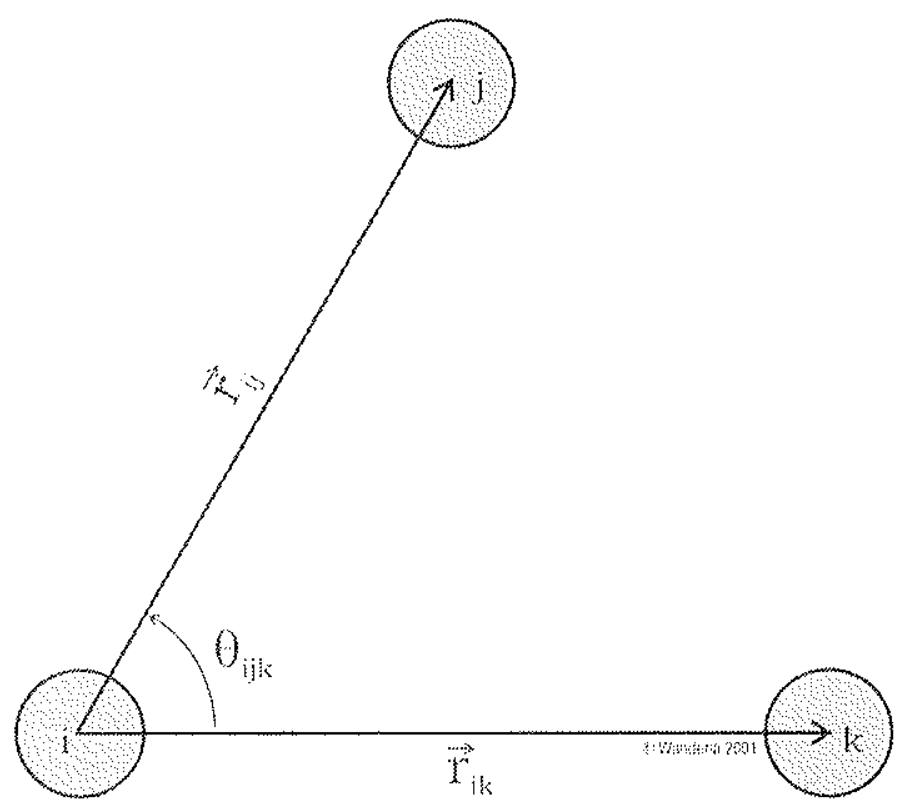

Figura 4.35 - Ângulo interno utilizado no potencial de interação de três corpos.

A contribuição do potencial de interação de dois corpos ao potencial de interação total $(V)$, para diferentes configurações de ligação Si-O, Si-N, Si-Si, O-O, O-N e N-N é mostradá na Figura 4.36 a seguir.

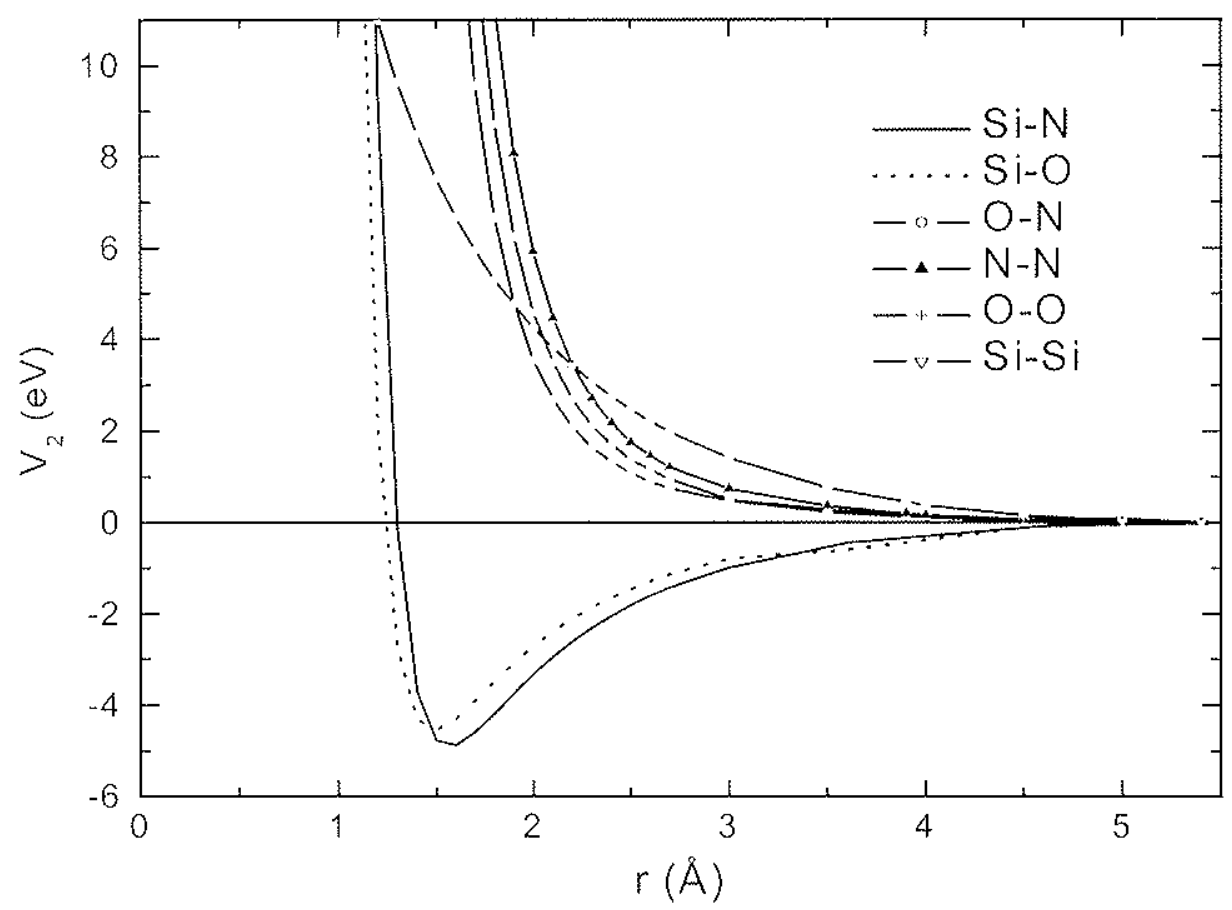


Figura 4.36 - Contribuição do potencial de interação de dois corpos, Si-O, Si-N, Si-Si, O-O, O-N e N-N. A unidade de energia é o elétron-Volt.

Na Figura 4.36 observa-se o comportamento da energia de interação entre dois átomos como função da distância que os separa. O comportamento da energia em função da distância evidencia que as liggações Si-O e Si-N possuem um valor mínimo de energia em $R$ $=1,49$ \& $1,60 \AA$, respectivamente. Por outro lado, as demais ligações (Si-Si, O-N, O-O e N$\mathrm{N})$ possuem um comportamento puramente repulsivo e apresentam um decréscimo exponencial tendendo para zero em $R=5,5 \AA$. Entretanto, a interação Si-Si possui um alcance maior do que as interações $(\mathrm{O}-\mathrm{N}, \mathrm{O}-\mathrm{O}$ e $\mathrm{N}-\mathrm{N})$.

A contribuição do potencial de interação de três corpos ao potencial de interação total (V) é mostrada na Figura 4.37 e Figura 4.38 a seguir:

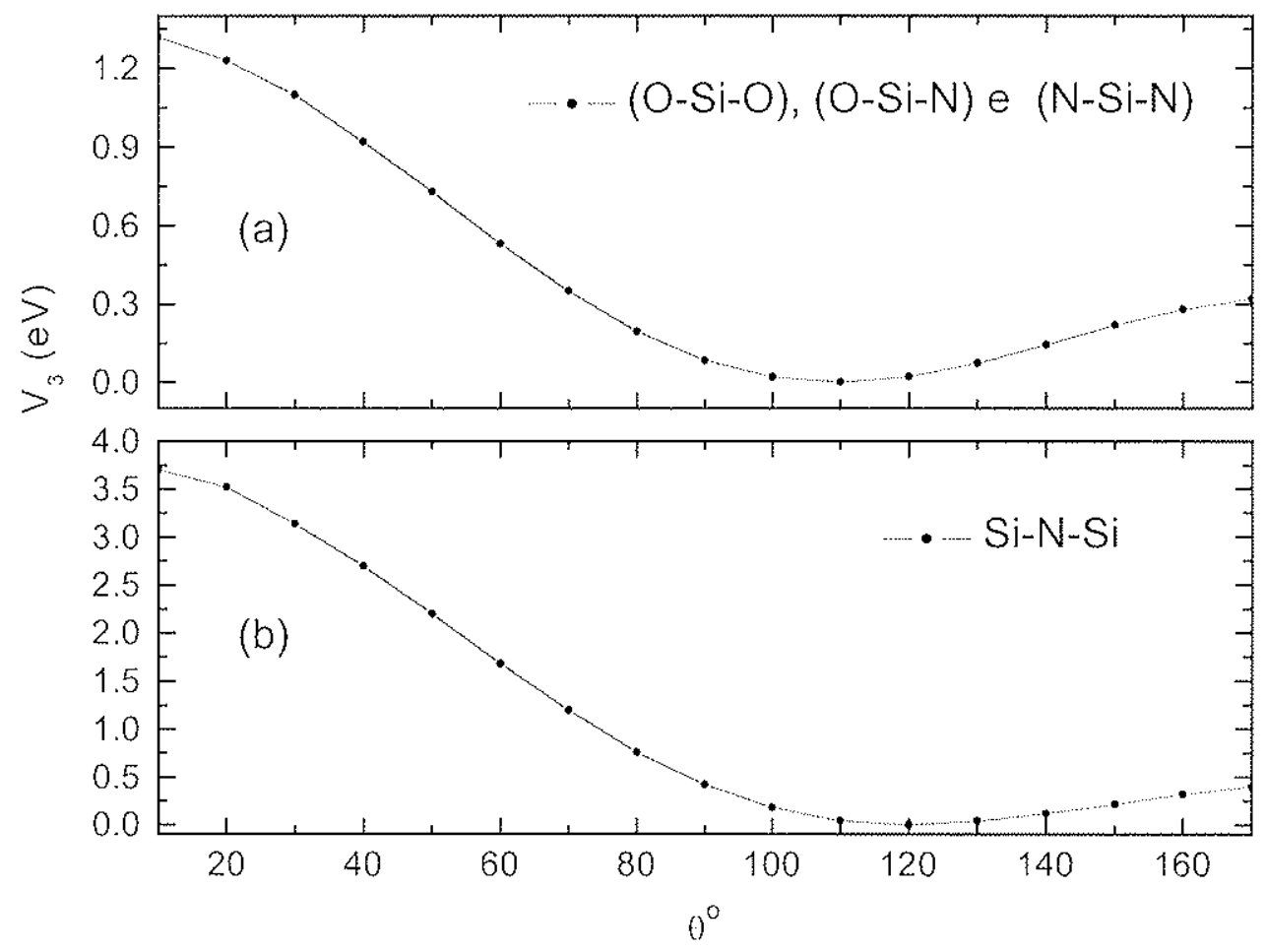

Figura 4.37- Contribuição do potencial de três corpos devido a ligações do tipo $O_{-S i-O}$, $O_{-S} i_{-N}$ e $N-S i-N$. Unidade da energia $(\mathrm{eV})$. 


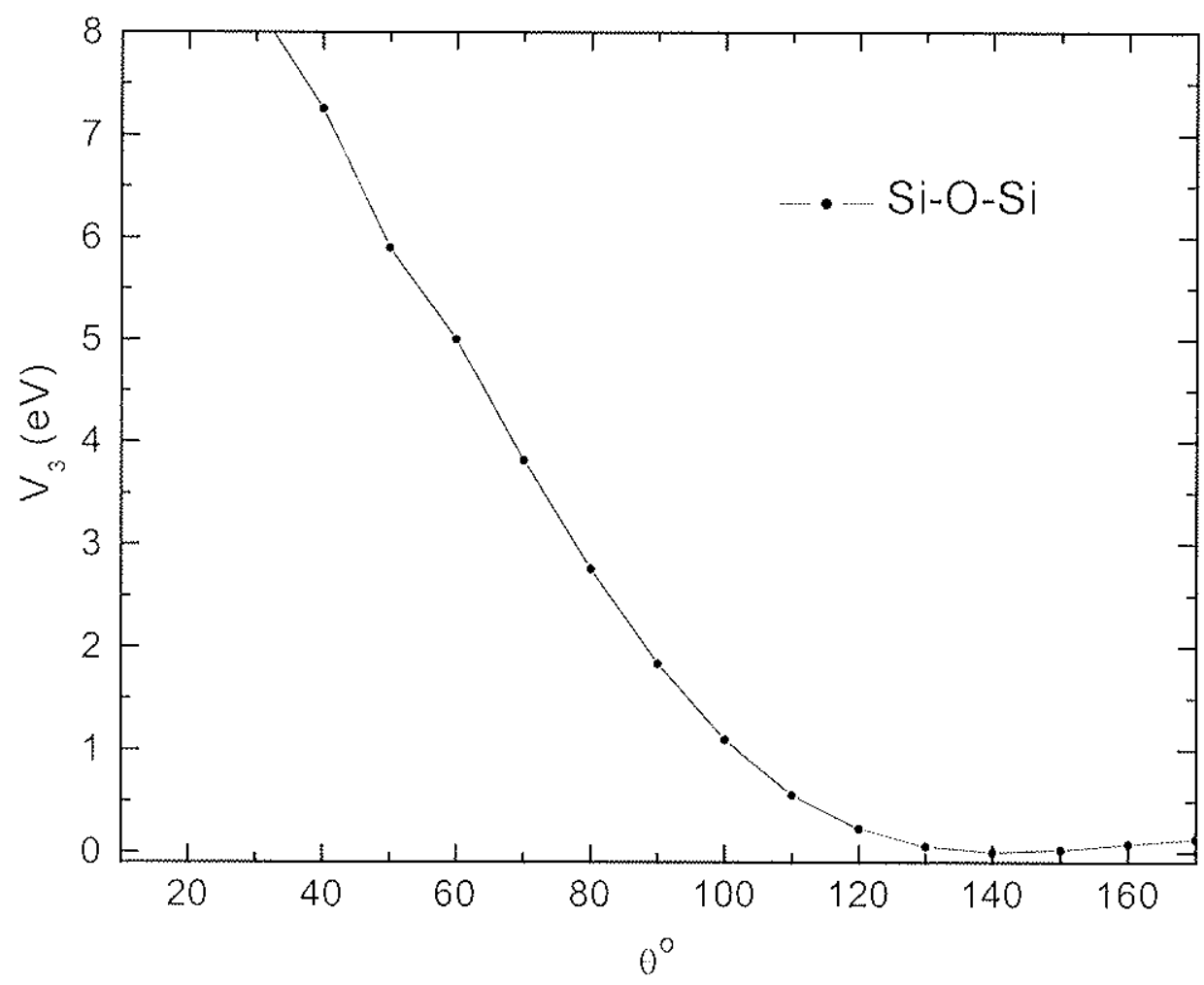

Figura 4.38 - Contribuição do potencial de três corpos devido a ligações do tipo Si-OSi. Unidade da energia (eV).

Na Figuma 4.37 (a), (b) e Figura 4.38 observamos o comportamento do potencial de interação de três corpos para as configurações relevantes em função do ângulo. O mínimo de energia para as configurações (O-Si-O, O-Si-N e N-Si-N) ocorre em 109 ", enquanto que a configuraçào Si-N-Si possti um mínimo em $\sim 120^{\circ}$. Por outro lado, observamos que a energia é mínima quando o ânguto da configuação Si-O-Si for $141^{\circ}$.

\subsection{PREPARAÇÃO DO ESTADO AMORFO}

A partir de ama super cela de $\mathrm{Si}_{3} \mathrm{~N}_{4} \operatorname{com} 616$ átomos na fase cristalina $(a=b=15,19 \AA$, $\left.c=31,922 \AA, \rho=2,78 \mathrm{~g} / \mathrm{cm}^{3}\right)$ fizemos uma substituição de átomos de $\mathrm{N}$ por $\mathrm{O}$, de formal a manter a mesma concentração relativa de espécies atômicas ( $\mathrm{Si}$, O e $\mathrm{N}$ ) dos filmes depositados $($ Re $=2,00$ e 3,00). Em seguida, o sistema foi aquecido até a temperatura de 70000 K ("ensemble" NPT, número de partículas, pressão e temperatuma são mantidos 
constantes) e executou-se mais 90.000 passos de MC ("ensemble" NVT, número de partículas, volume e temperatura são mantidos constantes) para atingir o equilibrio. Este número grande de passos de MC foi utilizado para evitar qualquer influêneia do estado inicial do sistema sobre o estado final $(7000 \mathrm{~K})$. Na primeira ctapa de resfriamento, atilizamos 30.000 passos MC para cada decréscimo de $1000 \mathrm{~K}$ de temperatura, permanecendo no equilibrio por mais 30.000 passos. Essa mesma taxa de resfriamento foi utilizada até o sistema atingir uma temperatura de $1000 \mathrm{~K}$. Na fase final de resfriamento, ulitizamos 30.000 passos de MC para cada descréscimo de 100 K e mais 30.000 pássos no equilibrio. Este procedimento foi repetido até o sistema atingir a temperatura ambiente $(30)$ K). É importante ressaltar que iniciamos também nossa simulação a partir de uma super cola de $\mathrm{SiO}_{2}$ e nenhuma diferença significativa foi observada na estrutura. Fizemos também simulaçòcs com super cela maiores ( 2161 átomos) e não observamos diferença significativa quando comparada com a super cela menor ( 616 átomos).

\subsection{RESULTADOS DA ESTRUTURA ATÔMICA: TEÓRICO E EXPERIMENTAL}

Os resultados apresentados neste trabalho foram obtidos a partir de una super cela com - 616 átomos. Em particular, estudamos concentrações atômicas equivalentes às das amostras crescidas com $R e=2,00(50 \%$ [O], 14\% [N] e 36\% [Si]) e $R e=3,00(57 \%$ $[0], 7 \%[\mathrm{~N}]$ e $36 \%$ [Si]), além das ligas estequiométricas $a-\mathrm{SiO}_{2}$ e $a-\mathrm{Si}_{3} \mathrm{~N}_{4}$. A estrutura geométrica resultante da simulação equivalente à amostra com $R e=2,00$ na temperatura (le $300 \mathrm{~K}$, é mostrada a seguir: 


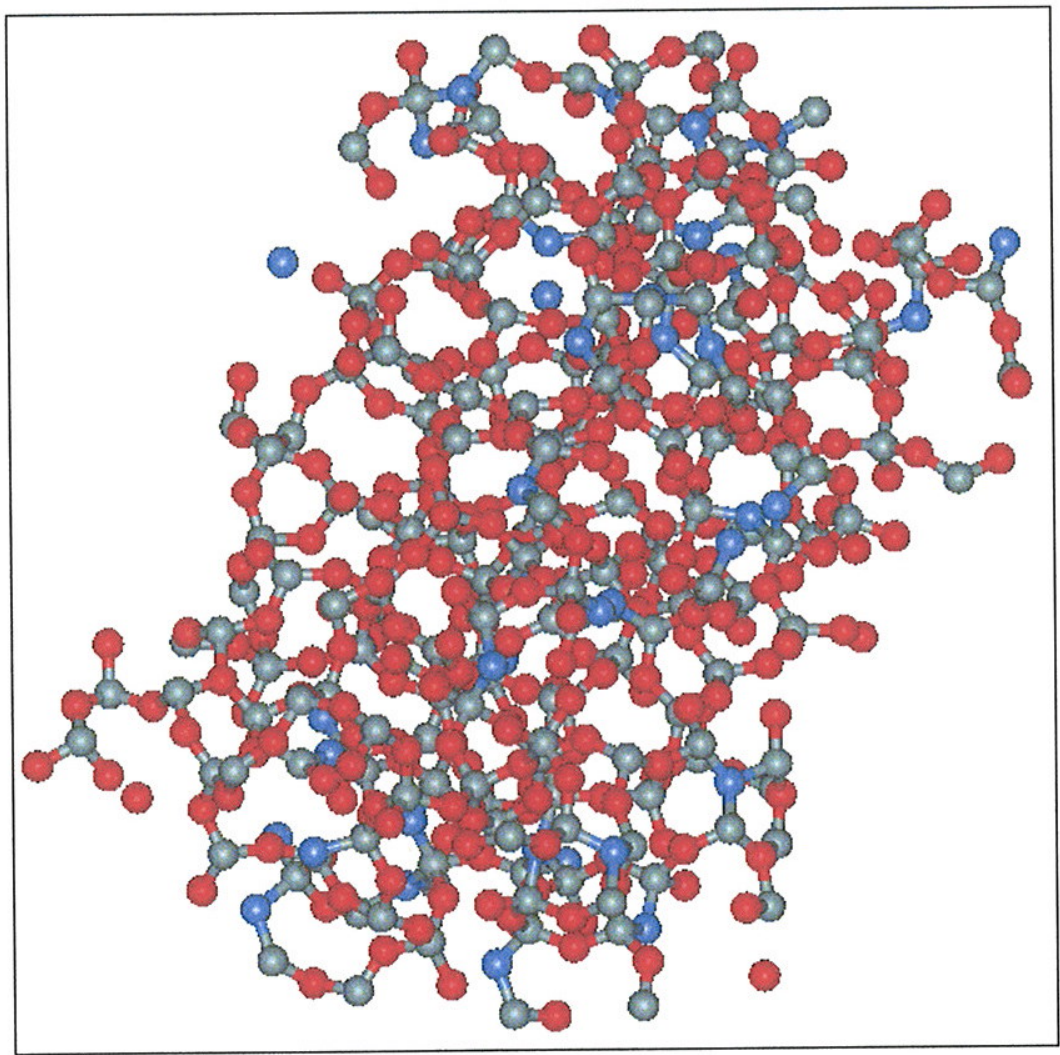

Figura 4.39- Estrutura geométrica obtida por MC equivalente a amostra com $R e=$ 2,00. Os círculos cinza, vermelho e azul representam os átomos de $\mathrm{Si}, \mathrm{O}$ e $\mathrm{N}$, respectivamente. Esta supercela representada se repete no espaço a partir de condições periódicas de contorno.

A Figura 4.39 indica que do ponto de vista morfológico, observamos uma estrutura homogênea, isto é, a estrutura não é composta de fases distintas de $\mathrm{SiO}_{2}$ e $\mathrm{Si}_{3} \mathrm{~N}_{4}$. A estrutura de ordem local média em torno dos átomos de silício é na sua maioria composta por átomos de oxigênio, mas alguns átomos de silício possuem também como primeiros vizinhos átomos de nitrogênio. Este resultado é consistente com a composição química relativa.

A partir da estrutura atômica mostrada na Figura 4.39, fizemos uma estatística do número de átomos de $\mathrm{O}$ vizinhos aos de $\mathrm{Si}$, dentro de um raio de corte de 1,70 $\AA$. $\mathrm{O}$ resultado é mostrado na Figura 4.40, juntamente com o resultado obtido do modelo de RBM (Random Bonding Model). A estatística de distribuição para diferentes tetraedros prevista pelo modelo RBM foi calculada a partir da composição química obtida experimentalmente por RBS. 


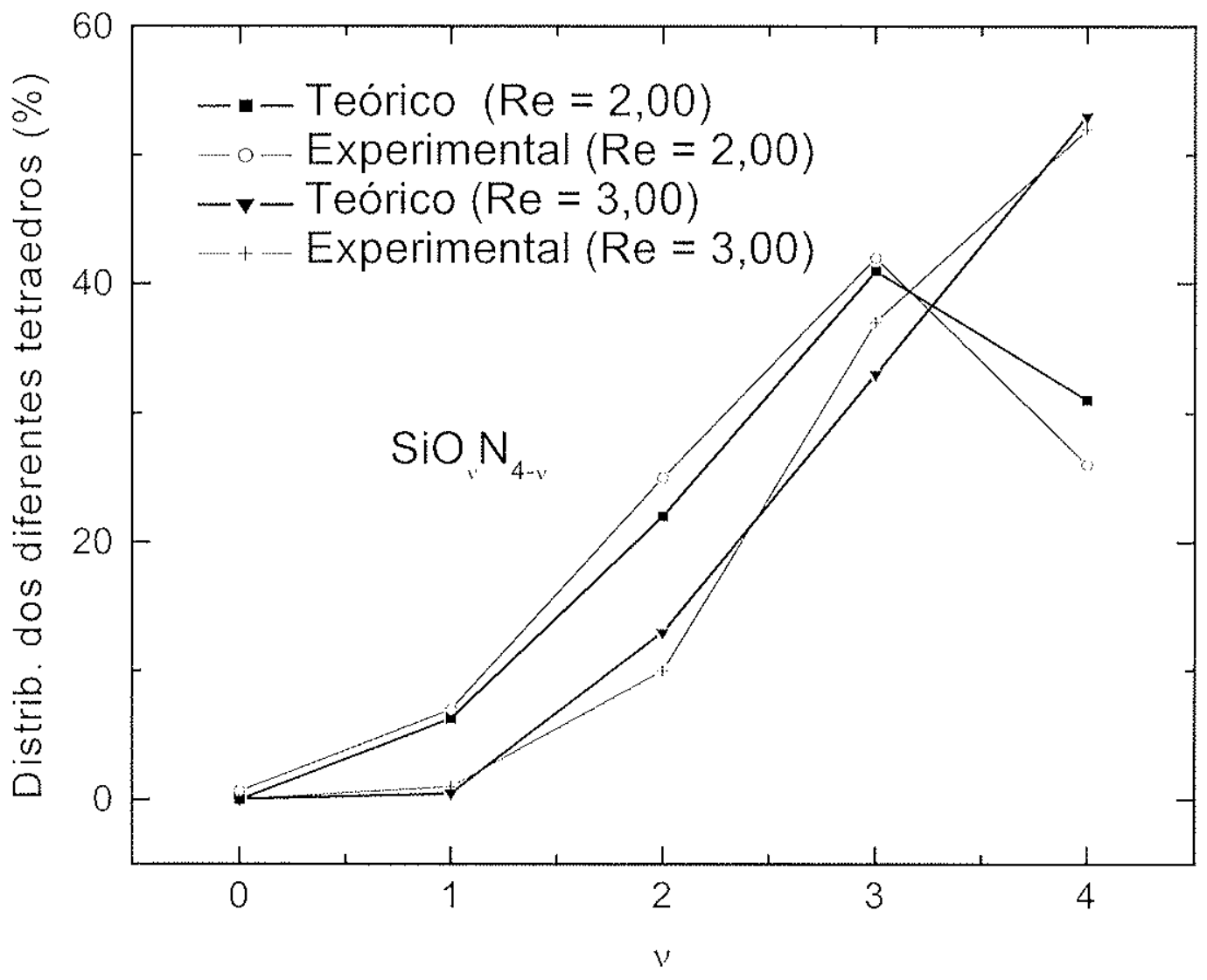

Figura 4.40- Distribuição de diferentes tetraedros referentes as amostras com $R e=2,00$ e 3,00 .

Da Figura 4.40 observamos uma boa concordância entre os resultados tcóricos e os obtidos pelo modelo RBM (utilizando dados experimentais). Observamos também na ligura acima que o tetraedro mais abundante em média na amostra com $R e=2,00$ é do tipo $\mathrm{SiO}_{3} \mathrm{~N}_{1}$. Por outro lado, observamos que com o descréscimo de $\mathrm{N}$, o tetraedro mais abundante tornase do tipo $\mathrm{SiO}_{4}$ para amostra com $R e=3,00$, que é similar à estrutura do $a$ - $\mathrm{SiO}_{2}$. Estes resultados estão em bom acordo, considerando un erro experimental de 10\%, com o número de coordenação total obtido dos dados de EXAFS (Tabela 3.2). Esta comparação pode ser fcita adicionando-se o número de átomos de $\mathrm{O}$ em cada tetraedro, ponderado por súa respectiva probabilidade. Assim, este resultado teórico veio a confirmar que as propricdades estruturais dos films de oxinitreto de silício amorfo são explicadas pelo modelo RBM.

A figura abaixo mostra a densidade dos filmes de oxinitreto de silício amorfo ricos cm oxigênio $\left(R e=2,00,3,00\right.$ e $\left.5,00\left(\sim a-\mathrm{SiO}_{2}\right)\right)$. 


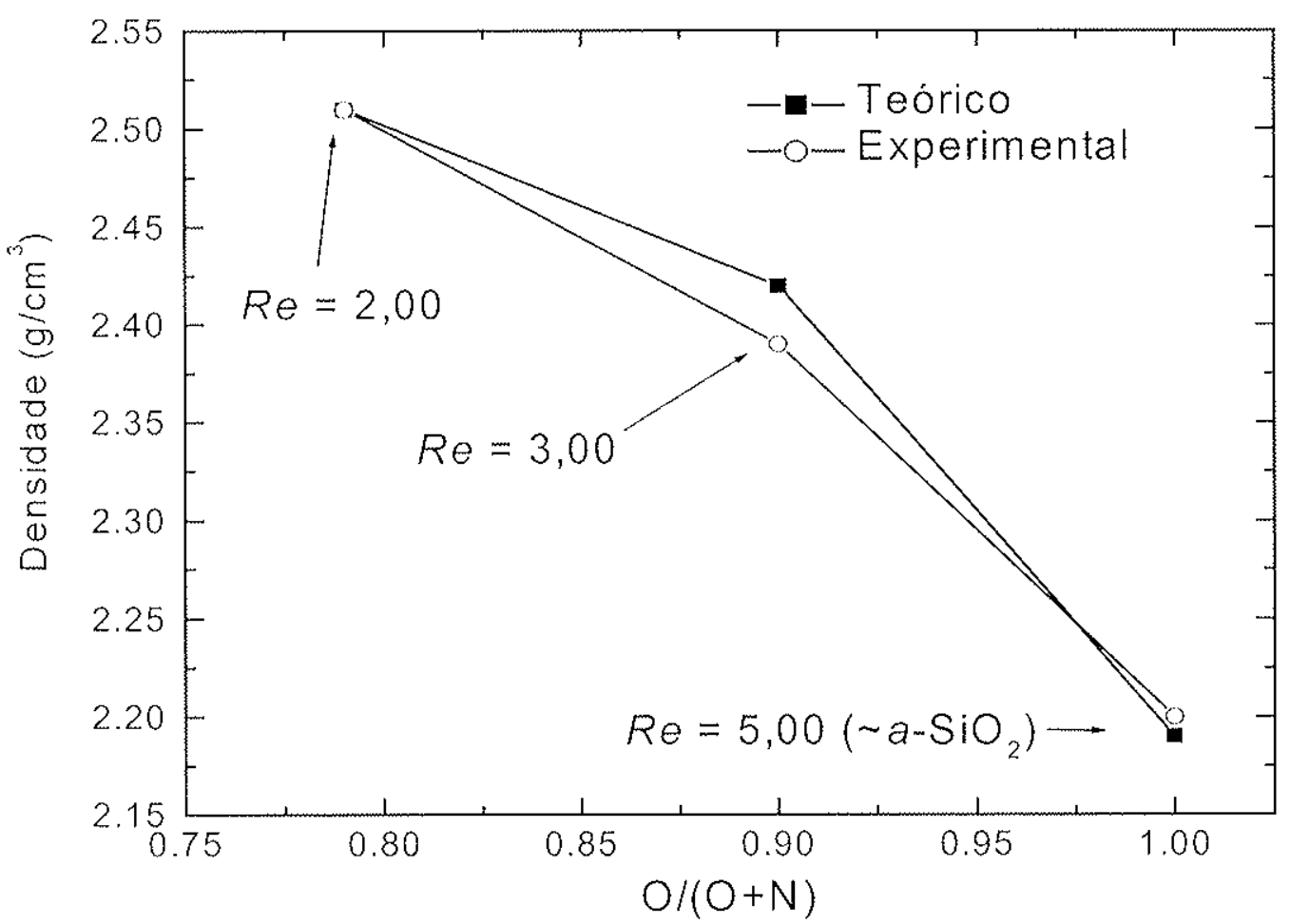

Figura 4.41- Densidade $\left(\mathrm{g} / \mathrm{cm}^{3}\right)$ do oxinitreto de silício amorfo $\left(a-\mathrm{SiO}_{\mathrm{x}} \mathrm{N}_{y}\right)$ obtida por simulação de Monte Carlo comparada com os resultados experimentais.

A Figura 4.41 mostra uma boa concordância entre a densidade obtida da simulação de MC e a obtida experimentalmente. Com aumento de Re (menor incorporação de nitrogênio nos filmes) observamos un decréscimo da densidade dos filmes. A amostra com Re $=5,00$ possui o mesmo valor numérico da densidade $\left(\sim 2,20 \mathrm{~g} / \mathrm{cm}^{3}\right)$ do reportado ná literatura para o a-SiO 2 .

As funções distribuição radial obtida por MC para a liga ternária $a-\mathrm{SiO}_{\mathrm{x}} \mathrm{N}_{\mathrm{y}}$, referente às ligaçōes Si-Si, Si-O, Si-N e O-O correpondentes às amostras com Re $=2,00$ e 3,()0 são mostradas a seguir: 

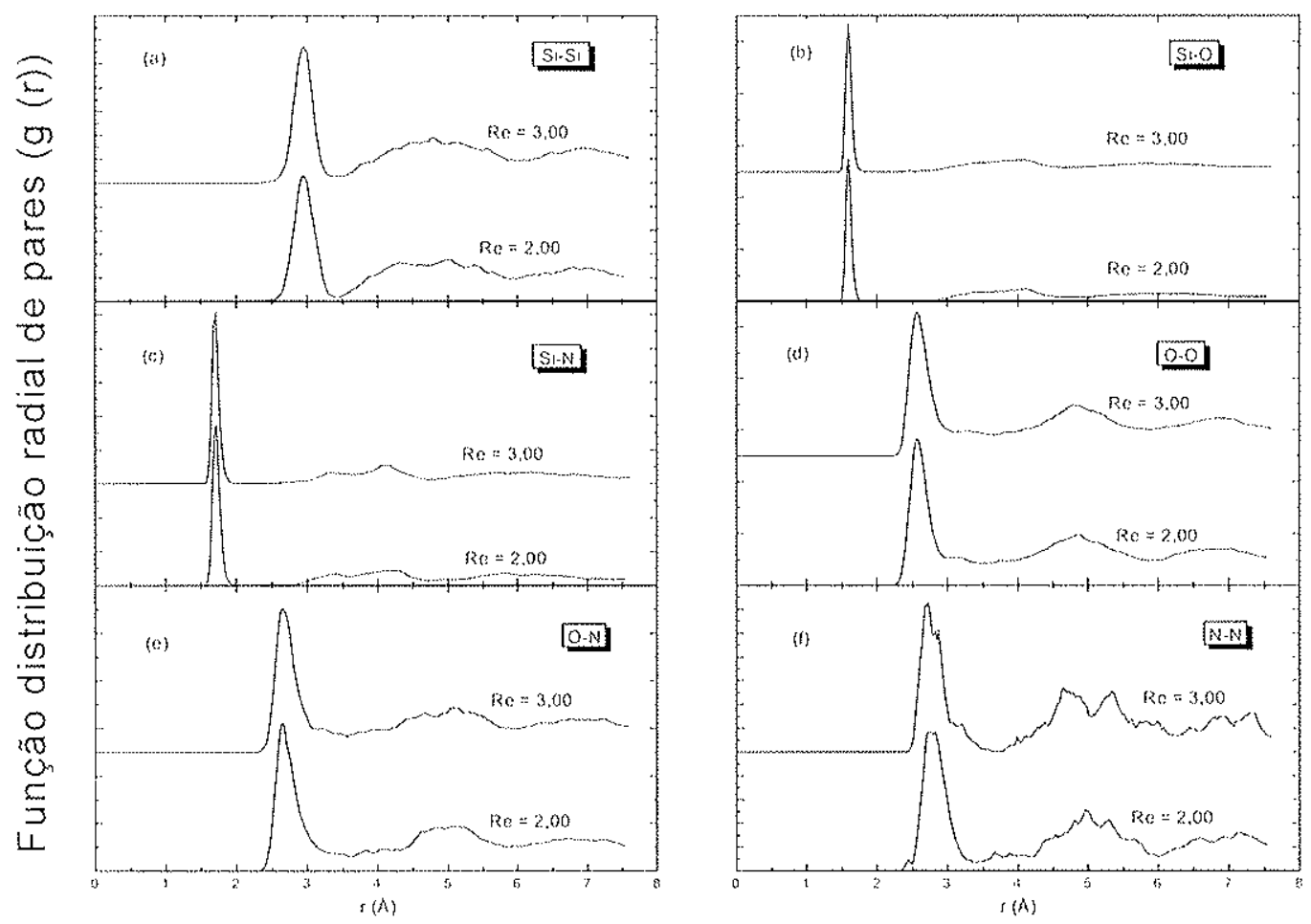

Figura 4.42- Funções de distribuição radial de pares obtida por MC equivalente às amostras ricas em $\mathrm{O}\left(a-\mathrm{SiO}_{x} \mathrm{~N}_{y}\right)$ a temperatura de $300 \mathrm{~K}$.

Da Figura 4.42 podemos observar que não existe nenhuma mudança significativa no comprimento das ligações para as amostras com diferentes composições químicas. No a$\mathrm{SiO}_{x} \mathrm{~N}_{y}(\mathrm{Re}=2,00$ e 3,00$)$, a posição do primeiro pico na $g$ Si-o $(r)$ é o comprimento dá liggaçăo $\mathrm{Sim} O(1,60 \pm 0,04) \AA$. Este valor está em acordo com os resultados experimentais obtidos por EXAFS (Tabela 3.2) e com os resultados da literatura para o $a-\mathrm{SiO}_{2}$, considerando-se a incerteza experimental. A posição do primeiro pico na $g$ Si-N $(r)$ é o comprimento da ligação Si-N $(1,71 \pm 0,06) \AA$. Este valor está em acordo com os resultados experimentais obtidos por EXAFS (Tabela 3.2) e com os resultados da literatura para o $\mathrm{Si}_{3} \mathrm{~N}_{4}$ e para o a-SiO $\mathrm{N}_{y}{ }^{110}$, considerando-se também a incerteza. Os átomos de O e $\mathrm{N}$ só $\mathrm{tem}$ como primeiros vizinhos átomos de Si, logo a partir da área sob o primeiro pico das funçòes distribuição radial $(g$ si-o $(r)$ e $g$ si-N $(r)$ ), determinamos o número de Si primeiros vizinhos dos átomos de $\mathrm{O}$ e $\mathrm{N}$, respectivamente. O número de coordenação obtido para a composição química equivalente à amostra com Re $=2,00$ foi de 2 para o oxigênio e 2,54 para o 
nitrogenio. Para a amostra com Re $=3,00$ a coordenação do O foi também de 2 , enquanto que para o $\mathrm{N}$ foi de 2,42 . Um outro resultado importante é que o número de coordenaçào do átomo de Si com seus primeiros vizinhos ( $\mathrm{N}$ e O) obtido por $\mathrm{MC}$, relativo às amostras com $R e=2,00$ e 3,00, são 4 e 3,9, respectivamente. Este resultado é consistente com os dados de EXAFS, considerando-se o erro experimental. Observamos também da figura acima que o comprimento das ligações O-O e Si-Si são $(2,57 \pm 0,08 \AA)$ e $(2,95 \pm 0,12 \AA)$, respectivamente. Estes resultados são consistentes com os da literaturál ", pelo menos pará o $\left(1-\mathrm{SiO}_{2}\right.$. O comprimento das ligações $\mathrm{O}-\mathrm{N}$ e $\mathrm{N}-\mathrm{N}$ são $(2,60 \pm 0,20 \AA)$ e $(2,80 \pm(), 20 \AA)$, respectivamente. É importante salientar que, embora fosse possivel determinar por EXAFS o comprimento da ligação Si-Si, esta ligação não foi detetada nas amostras ricas em O. Já as ligações $\mathrm{O}-\mathrm{O}, \mathrm{O}-\mathrm{N}$ e N-N foram determinadas somente por simulação computacional, uma ve\% que experimentalmente os dados de EXAFS na borda $K$ do Si fornece apenas a vizinhança no entorno desse átomo.

A função distribuição radial total equivalente às amostras com Re $=3,00 \mathrm{e} 2,00$ é mostrada a seguir:

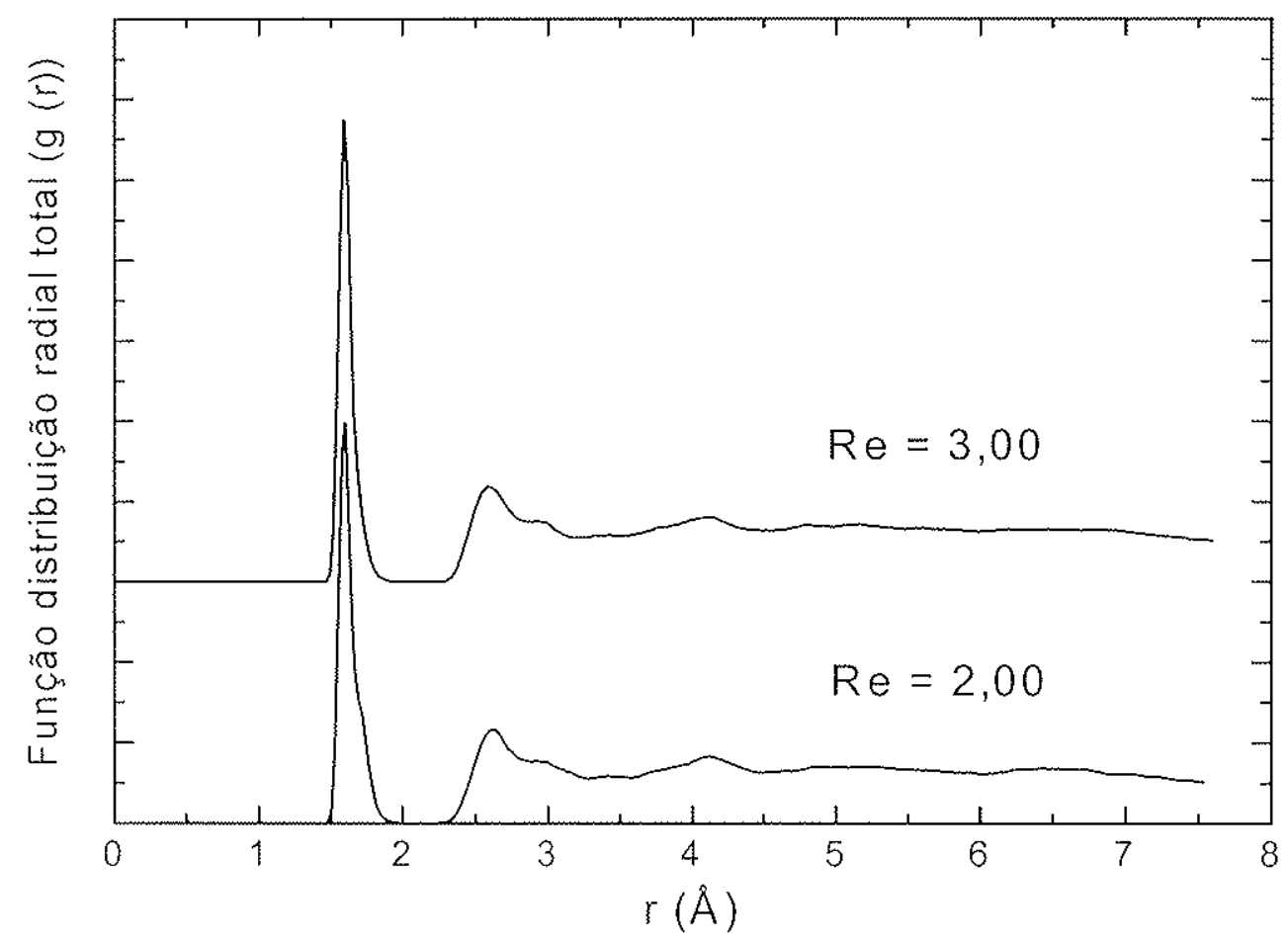

Figura 4.43- Função distribuição radial total obtida por MC equivalente às amostras ricas em $\mathrm{O}\left(a-\mathrm{SiO}_{x} \mathrm{~N}_{y}\right)$ à temperatura de $300 \mathrm{~K}$. 
Da Figurara 4.43 podemos observar que não existe nenhuma mudança significativa na posição dos picos como função da pequena variação $(\sim 10 \%)$ da composição química. Outro resultado importante é que o primeiro pico da função de distribuição radial é composto basicamente pela correlação de pares $\mathrm{Si}-\mathrm{O}$ e Si-N, uma vez que não existe evidência de qualquer outra contribuição. Este resultado vem consolidar os resultados de EXAFS, uma ver, que na análise dos dados experimentais consideramos que o primeiro pico na T.R. correspondia somente à contribuição das ligações Si-O e Si-N, como discutido no Cap. 3.

As funções distribuição angular obtida por MC para a liga ternária $a-S_{-} O_{x} N_{y}$, referente às ligações Si-O-Si, O-Si-O, Si-N-Si, N-Si-N e O-Si-N relativas às amostras com $R e=2,00$ e 3,00 são mostradas a seguir:
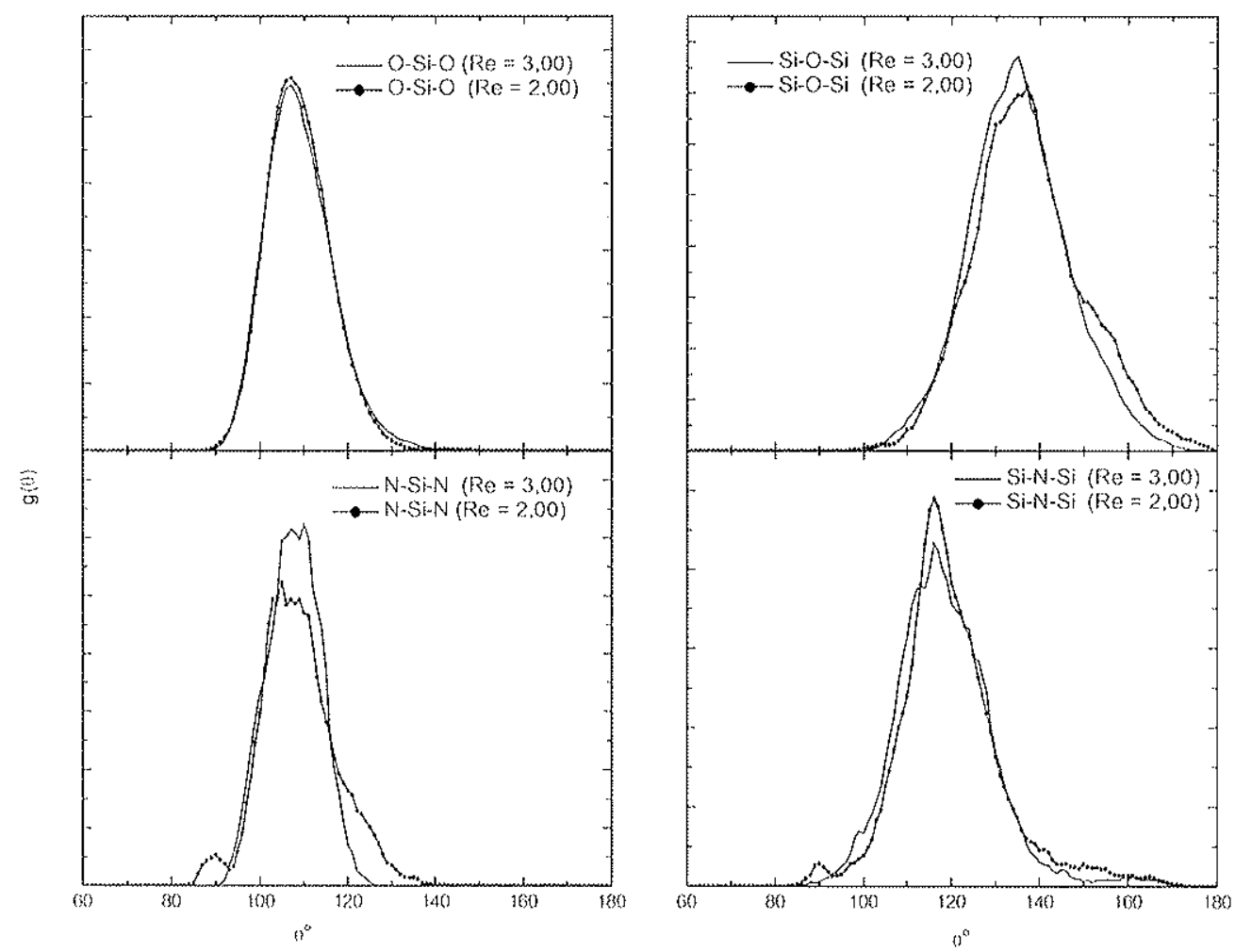

Figura 4.44- Funções distribuição angular obtida por MC referentes as ligações Si-O$\mathrm{Si}, \mathrm{O}-\mathrm{Si}-\mathrm{O}, \mathrm{Si}-\mathrm{N}-\mathrm{Si}$ e $\mathrm{N}-\mathrm{Si}-\mathrm{N}$ relativo às amostras ricas em $\mathrm{O} \operatorname{com} R e=2,00 \mathrm{e} 3,00$. 


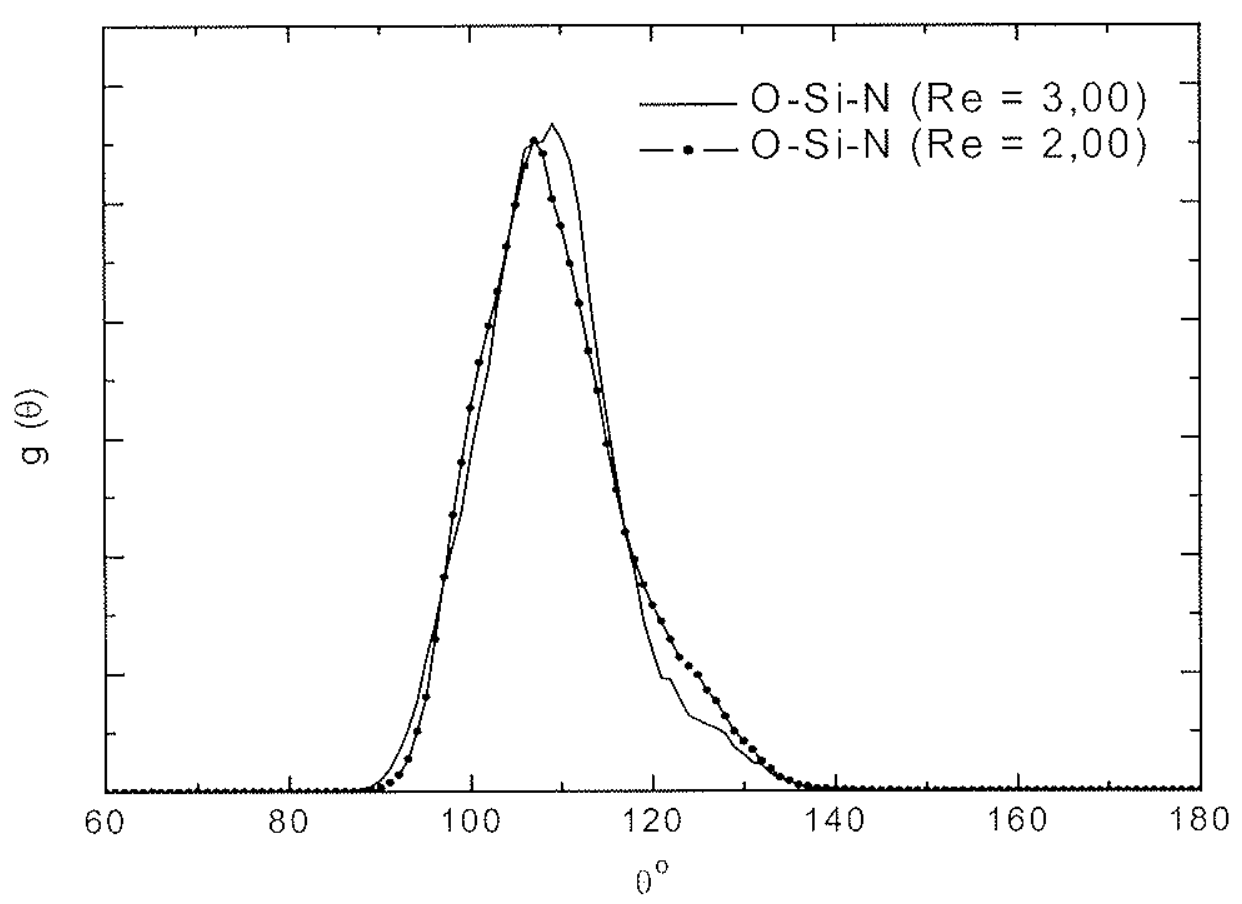

Figura 4.45- Funções distribuição angular obtida por MC referente à ligação $\mathrm{O}-\mathrm{Si}$-N ou $\mathrm{N}$-Si-O correspondente às amostras com $R e=2,00$ e 3,00.

Da Figura 4.44 e da Figura 4.45 podemos observar que não existe um deslocamento significativo na posição do pico das distribuições angulares como função do aumento da concentraçào de $\mathrm{N}$.

Por fim, utilizamos as posições atômicas (Figura 4.39) obtidas por MC para determinar o signal de EXAFS teoricamente. Utilizamos as posições equivalentes à amostra com Re $=2,00$ obtidas por MC no estado amorfo, à temperatura de $300 \mathrm{~K}$. O sinal de EXAFS foi obtido a partir do programa FEFF, considerando a absorção na borda $K$ do Si. A partir do sinal de EXAFS obtido determinamos a transformada de Fourier nas mesmas condições utilizadas no tratamento dos dados experimentais. Uma comparação entre a T.F do sinal de EXAFS experimental e teórico relativo à amostra com $R e=2,00$, é mostrado na figura abaixo. O cálculo foi efetuado tomando uma combinação linear das configguraçoos para os vários tetraedros $\mathrm{SiO}_{\vee} N_{1-k}$, ponderadas pelas respectivas distribuições porcentuais. 


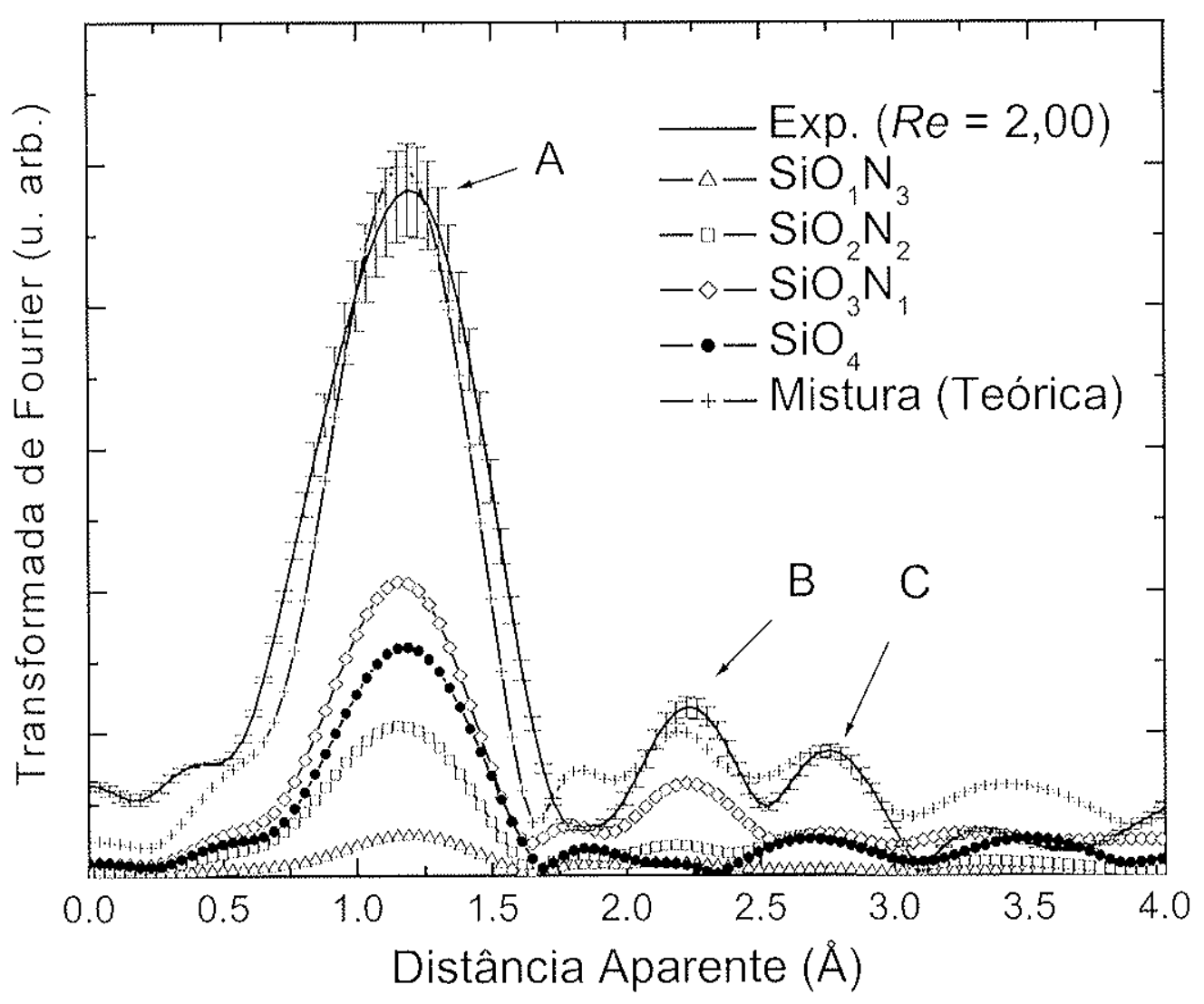

Figura 4.46- Transformada de Fourier do sinal de EXAFS, teórico (obtido pelo FEFF) e experimental, relativo à amostra $\operatorname{com} R e=2,00$. 


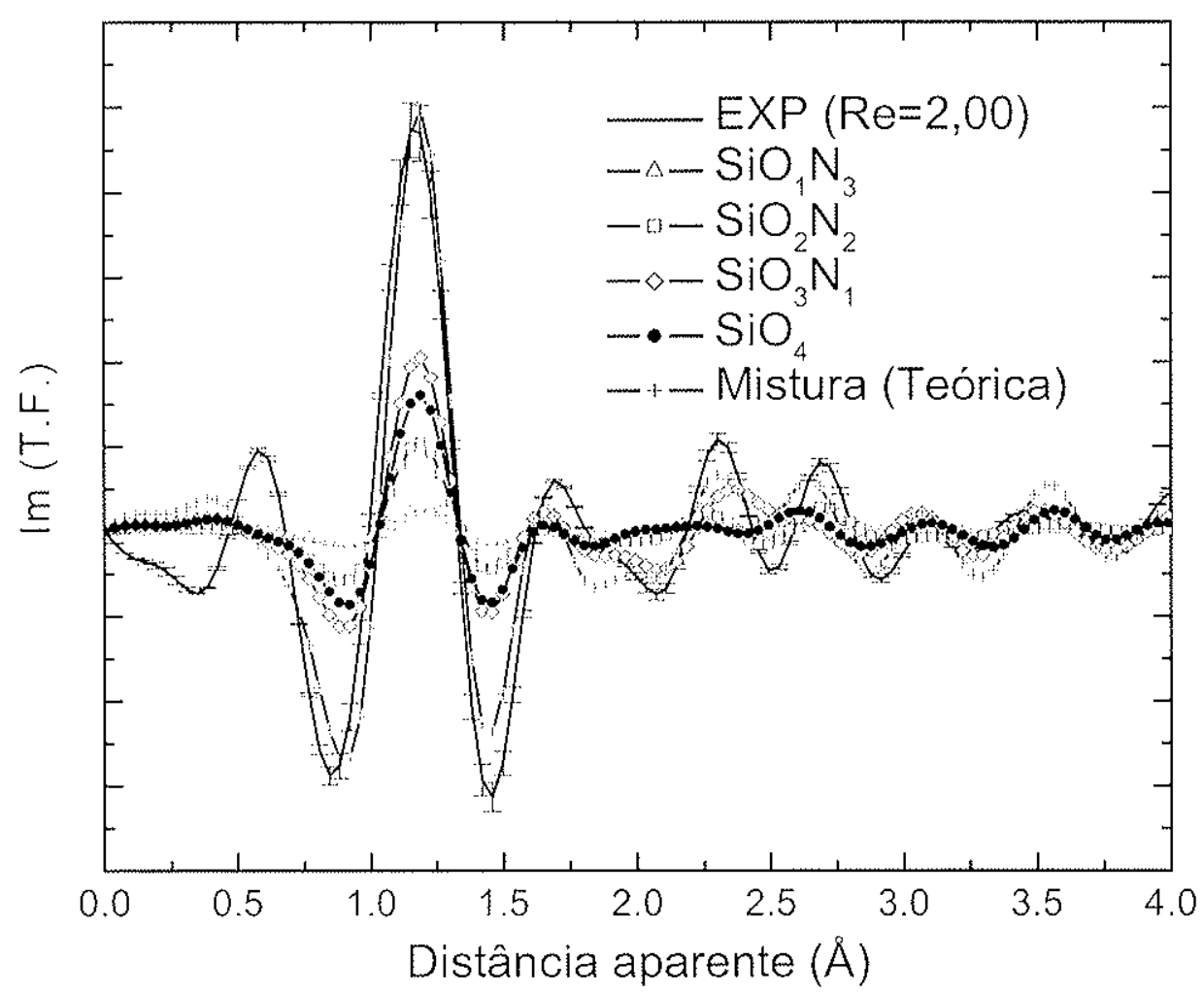

Figura 4.47-Parte Imaginária da tranformada de Fourier para diferentes tetraedros e amostra. Mistura é a combinação linear dos 4 tipos possíveis tetraedros ponderado.

Da Figura 4.46 podemos observar uma boa concordância entre a magnitude dos picos A, B e C da T.F teórica comparada a experimental. Entretanto, a posição dos picos A e B da T.F: teórica estão ligeiramente deslocados para "menores, quando comparadá como experimental. Este resultado é una indicação que a correlação de pares teórical correspondente, possue uma desordem estática maior do que a prevista pelo modelo teórico. A presença do pico entre A e B na T.F teórica não é bem entendida ainda. Por outro lado, a figurara 4.47 mostra a parte imaginária da transformada de Fourier, onde podemos observar que o modelo teórico é condizente com os dados experimentais. Embora exista um defasamento entre a posição do pico C teórico e o correspondente experimental. Este resultado indica que a desordem estática prevista pelo nosso modelo está subestimada cm relação a desordem prevista experimentalmente. Este fator de fase é fortemente dependente do caminho percorrido pelo elétron no fenômeno de absorção descrito por EXAFS. Novas simulações com o programa FEFF serão feitas, no intuito de melhorarmos a estatística, além 
de variarmos por exemplo, o número de caminhos possiveis percorrido pelo fóton e o lamanho do agregado.

Devido à dificuldade em implementar a interação entre o hidrogênio e os demais átomos da liga, as simulações teóricas foram empreendidas para o composto rico $\mathrm{cm}$ oxigênio, não hidrogenado, sem invalidar a comparação entre os resultados experimentais e tcóricos. Isto porque, apesar da existência de hidrogênio nos filmes analisados experimentalmente, sua concentração relativa é baixa $(<4$ at.\%). 


\section{CONCLUSÕES E PERSPECTIVAS FUTURAS}

O processo de deposição por PECVD utilizando os gases $\mathrm{N}_{2} \mathrm{O}$ e $\mathrm{SiH}_{4}$ deu origem a lilmes de $a-\mathrm{SiO}_{x} \mathrm{~N}_{y}: \mathrm{H}$ com composição química diferente, dependente da razão de fluxos Re $=\left[\mathrm{N}_{2} \mathrm{O} / \mathrm{SiH}_{4}\right]$. Os dados de RBS evidenciaram a formação de filmes de óxido-nitreto de silicio, que variaram desde lilmes ricos $\mathrm{em} O$ a filmes ricos em Si. Para Re $\geq 2$ obtivemos filmes de oxinitreto de silicio ricos em oxigênio, enquanto que para $R e<2$, obtivemos filmes ricos cm silício. O filme com maior conteúdo de oxigênio possui 65 at.\% de $\mathrm{O}$, enquanto que o filme com maior contcúdo de silício possui 50 at.\% de Si.

O estudo morfológico dos filmes ricos em oxigênio $(2 \geq R e \geq 5)$ mostrou que o material é bastante homogêneo. Há poros com tamanhos diferentes, mas não maiores que $40 \AA$, tendo a maioria raio médio de $20 \AA$. Há aglomerados com raios entre 50 A e 100 A que contêm os mesmos átomos da matriz, mas provavelmente com uma densidade atômica um pouco maior. A fração de poros determinada apresenta um comportamento não linear com a razão de $\left[\mathrm{N}_{2} \mathrm{O} / \mathrm{SiH}_{4}\right]$. A fração de poros é menor do que $10 \%$ e decresce com o alumento da quantidade de $\mathrm{N}_{2} \mathrm{O}$ na mistura do gás, isto é, com o aumento da quantidade de oxigênio nos filmes. Este resultado aponta para a possibilidade de obtermos por PECVD um material a baixa temperatura, morfologicamente homogêneo, similar ao $\mathrm{SiO}_{2}$ crescido termicamente.

Do ponto de vista estrutural, tanto os resultados experimentais quanto os teóricos, oblidos por simulação de Monte Carlo para amostras ricas em oxigênio, apontaram para a Cormação de um material homogêneo e amorfo, cuja estrutura de ordem local é descrita pelo modelo RBM- "Random Bonding Model". Neste modelo, o átomo de Si está numa configuração tetraédrica, cuja primeira esfera de coordenação é parcialmente preenchida por O e N, sendo suas proporções similares às concentrações químicas obtidas por RBS. Por outro lado, para amostras ricas em Si $(R e<2)$ nossos resultados experimentais cvidenciaram a transição de um material homogênio tipo Sim O-N para um material composto de agregados de Si, embebidos dentro de uma matriz de Si-O-N. Estes agregados de Si são morfologicamente mais bem definidos para $R e=0,25$.

A presença de hidrogênio neste filmes foi detetada por FTIR, onde observamos liggaçoes Si-H e N-H. O efeito do tratamento térmico nestas ligações mostrou que as ligações N-H são mais estáveis do que as ligações Si-H, pois as primeiras desaparecem no espectro de 
infravermetho em temperatura superior àquela verificada para a total efusão de hidrogênio das ligaçoes Si-H. Em particular, para a amostra rica $\mathrm{em} O($ Re $=2,50)$ nossos resultados indicaran que o aumento da temperatua de tratamento térmico induz a formação de um material composto por duas fases distintas $\left(\mathrm{SiO}_{2}\right.$ e $\left.\mathrm{Si}_{3} \mathrm{~N}_{4}: \mathrm{H}\right)$. Por outro lado, para a amostra rica em Si $($ Re $=0,25)$, o cfeito da temperatura de tratamento térmico é uma maior definiçào morfológica dos agregados de $\mathrm{Si}$, além da dissociação do $\mathrm{H}$ do fllme através da quebra de todas as ligaçòes Si-H a partir da temperatura de $550^{\circ} \mathrm{C}$.

Os diferentes filmes crescidos e analisados podem ser utilizados em aplicaçòes como guias de onda (material rico em O) ou em dispositivos luminescentes (material rico em Si).

Como trabalhos futuros pretendemos fazer medidas de absorção na borda $K$ do oxigênio c nitrogênio, para estudar experimentalmente a vizinhança destes átomos nos nossos filmes. Na parte de simulações pretendemos implementar no potencial a interação com hidrogênio e lazer novas simulações com a rotina FEFF, além de considerar outras relações de concentrações atômica. 


\section{REFERÉNCIAS}

11] R. Chalu, J. Kavaleiros, B. Roberds, R. Schenker, D. Lionberger, D. Barlage, B. Doyle, R. Arghavani, A. Murthy, G. Dewey, Tech. Dig. Int. Electron Devices Meet (2000) 45.

[2] M. Hoffman, P. Koka, E. Voges, J. Lightwave Technol. 16(1998) 395.

[3] J.B. Neaton, D.A. Muller, N.W. Ascroft, Phys. Rev. Lett. 85 (2000) 1298.

[4] D. A. Muller, T. Sorsch, S. Moccio, F.H. Batumann, K. Evans-Lutterodt, G. Timp, Nature (London) $399(1999) 758$.

[5] D.A. Buchanan, IBM I. Res. Dev. 43 (1999) 245.

[6] C.S. Mian, L.S. Flora, Solid State Eletron. 43 (1999) 1997.

[7] T.M. Pan, T.F. Lei, T.S. Chao, IEEE Electron Device Lett, 21 (2000) 378.

[8] S. Bernerjee, A. Gibaud, D. Chateigner, S. Ferrari, M. Fanciulli, J. Appl. Phys, 91 (2002) 540 .

[9] K.A. Ellis, R.A. Buhrman, Appl. Phys, Lett. 69 (1996) 535.

[10] A.P. Lie, L.D. Zhang, Y.P. Qiao, G.G.Qin, Z.C. Ma, W.H. Zong, W. Xin, X.W. Hu, J. phys: Condens. Matter 9 (1997) 5245.

[11] H. Kato, A. Masuzawa, H. Sato, T. Noma, K.S. Seol, M. Fujimaki, Y. Ohki, 1. Appl. Phys. $90(2001) 2216$.

[12] K.l. Price, L.R. Sharpe, L.E. McNeil, E.A. Irene, J. Appl. Phys. 86 (1999) 2638.

[13] T. Noma, K.S. Scol, M. Fujimaki, H. Kato, T. Watanabe, Y. Ohki, Jpn. J. Appl. Phys. Part $139(2000) 6587$.

[14] M. Voos, P.H Uzan, C. Delalande, G. Bastard, and H. Halimaoui, Appl. Phys. Letl. 61 (1992) 943.

[15] N. Noguchi, I. Suemune, Appl. Phys. Lett. 62 (1993) 1429.

[16] F. Rui\%, C.Vázquez-Lopes, I. Gonzales-Hemándes, David D. Allred, J. Vac. Sci. Technol. A $12(1994) 2565$.

[17]Z.H. Lu, D.L. Lockwood, J.M. Baribeau, Nature 378 (1995) 258.

[18] L. Pavesi, L. Dal Negro, C. Mazzoleni, G. Franzo and F. Priolo, Nature $408(2000) 440$.

119 L. Canham, Nature $408(2000) 411$.

[20] T.S. Iwayama, D.E. Hole, I.W. Boyd, Microelectron. Reliab, $40(2000) 849$.

[21] A.I. Kenyon, P.F. Trwoga, C.W. Pitt, G. Rehm, .I. Appl. Phys. 79 (1996) 9291. 
[22] V.G. Baru, A.P. Chermushich, V.A. Luzanov, G.V. Stepanov, L.Y. Zakharov, K.P. O'Domnell, I.V. Bradley, N.N. Melnik, Appl. Phys. Lett. 69 (1996) 4148.

[23] S. Zhang, W. Zhang, J. Yuan, Thin Solid Films 326 (1998) 92.

[24] K.A. Littau, P.F. Szajowksi, A.J. Muller, A.R. Kortan, L.E. Brus, J. Chem. Phys. 97 (1993) 1224.

[25] L.R. Tessler and I. Solomon, Phys. Rev. B 52 (1995) 10962.

[26] D.J. Lockwood, Z.H. Lu, and J. -M. Baribeau, Phys. Rev. Lett. 76 (1996) 539.

[27] M. I. Estes and G. Moddel, Phys. Rev. B 54 (1996) 14633.

[28] A. Sassella, A. Borghesi, F. Comi, A. Monelli, G. Ottaviani, R. Tonini, B. Pivac, M. Bacchetta, L. Zanotti, J. Vac. Sci. Technol. A 1 (1997) 377.

[29] K. Worhoff, A. Driessen, P.V. Lambeck, L.T.H. Hilderink, P.W.C. Linders, Th. J.A. Popma, Sensors and Actuators A 74 (1999) 9.

[30] M.S. Haque, H.A. Nasseem, W.D. Brown, J. Electrochem. Soc. 144 (1997) 3265.

[3!] M.S. Haque, H.A. Nasseem, W.D. Brown, J. Electrochem. Soc. 142 (1995) 3864.

[32] A.J. Kenyon, P.F. Trwoga, M. Federighi, C. Pitt, J. Phys.: Condens. Matter. 6 (1994) 1.319

[33] D.A.P. Bulla, N.I. Morimoto, Thin Solid Films 334 (1998) 60.

[34] M.I. Alayo, I. Pereira, M.N.P. Carrenõ, Thin Solid Films 332 (1998) 40.

[35] I. Pereira, M.I. Alayo, J. Non-Cryst. Solids 212 (1997) 225.

[36] C. Domínguez, J.A. Rodrígue\%, F.J. Muño\%, N. Zine, Vacuum 52 (1999) 395.

[37] M.I. Alayo, I. Pereyra, W.L. Scopel, M.C.A. Fantini, Thin Solid Films 402 (2002) 154.

[38] O. Benkherourou, S. Sahanoune, M. Djabi, J.P. Deville Vacuum 53 (1999) 427.

139] S. Hasegawa, L. He, T. Inokuma, Y. Kurata, Phys. Rev. B 46 (1992) 12478.

[40] G. Wiech, A. Simunek, Phys. Rev. B 49 (1994) 5398.

[41] V.A. Gritsonko, R.W.M Kwok, Hei Wong, J.B. Xu, J. Non-Crys. Solids 297 (2002)96.

[42] D.L. Griscom, J. Non-Crys. Solids 24 (1977) 155.

[43] E. Parthe, Crystal Chemistry of Tetrathedral Structure (Gordon and Breach, New York) $(1964) 73$

[44] M.N.P. Carrenò, I.P. Bottechia, I. Pereyra, Thin Solid Films 308 (1997) 219.

[45] J. Reilly, W.N. Rac, Physico-Chemical Methods (Methen \& Co. Lid., London, Fourth Edition). 
[46] F. Danicls, Experimental Phisical Chemistry, McGraw-Hill Book Company, Inc., $(1962)$

[47] S.A. Campbell, The Science and Engineering of Microelectronic Fabrication, Edit. Oxford University Press (1996) 151.

[48] R.R. Cuzinatto, Relatório de atividades apresentado ao CNPQ (1999).

[49] O. Glatter, O. Kratky, Small Angle X-Ray Scattering, Academic Press, New York, $(1082)$

150] A. V. Semenyuk and D. Svergun, J. Appl. Cryst. 24 (1991) 537.

[51] D. L. Willamson, A. H. Mahan, B. P. Nelson, and R. S. Crandall, Appl. Phys. Lett. 55 (1989) 783

[52] W.K. Chu, J.W. Mayer, and M.A. Nicolet, Backscattering Spectrometry, Academic Press, Now York, (1978).

[53] M.H. Tabacniks, Análise de filmes finos por PIXE e RBS, Apostila do curso ministrado no Instituto da Fisica da USP, (1999).

[54] Wei-Kan Chu, /BM, California, (1978).

M.H. Tabacniks, Análise de fílmes finos por PIXE e RBS, Apostila do curso ministrado no Institulo da Fisica da USP, (1999).

[55] L.R. Doolittle, Nucl. Inst. e Meth. B9 (1995) 344.

[56] B.K. Tco, EXAFS: Basic Principles and Data Analysis, Springer-Verlag, Berlin Heidelberg New York Tokyo, (1985).

157] L.A. Grunes, Phys. Rev. B 27 (1983) 2111.

[58] P.A.M. Dirac, The principles of Quantum Mechanics, 4 ed., Oxford at the Clarendon press, (1981).

[57] D.E. Sayers e B.A. Bunker, in X-ray Absorption, D.C. Koningsberger e R.Prins, John Wilcy e Sons, NY, (1989).

[60] M. Abbate, F.C. Vicentin, V. Compagnon-Cailbol, M.C. Rocha, H. Tolentino, I. Syncrotron Radiation 6 (1999) 964.

[61] ^. Michalowic\%, EXAl:S pour le Mac, Logiciels por la Chimie, Société Française de Chimie, Paris, (1991) 102.

[62] A.G. Mckale, B.W. Veal, A.P. Paulikas, S.K. Chau, G.S. Knapp, J. Am. Chem. Soc. $110(1988) 3763$.

[63] J.C. Decius and R.M. Hexter, Molecular Vibrations in Crystals, McGraw-Hill, (1977). 
[64] E.B. Wilson, Jr., J.C. Decius, and P.C. Cross, Molecular Vibrations, Dover Publications Inc., New York, (1955).

[65] W.A. Lanford and M.l. Rand, J. Appl. Phys. 49, (1978) 2473.

[66] O. Gatter e O. Kratky, Small Angle X-ray Scattering, Academic Press, New York, (1982).

[67] A.H. Mahan, D.L. Williamson, B.P. Nelson, R.S. Crandall, Solar Cells 27 (1989) 465.

[68] M.N.P.Carreno, I. Pereyra, M.C.A. Fantini, H. Takahashi and R. Landers, I. Appl. Phys.75(1994) 538

[09] S. M. Sze, Physics of Semiconductor Devices, $2^{\text {ind }}$ ed., John Willey \& Sons (1991) 852.

[70] J. Viard, R. Berjoan and I. Durand, J. Eur. Ceram. Soc. 17 (1997) 2001.

[71] G. Lucovsky, J. T. Fitch, D. V. Tsu, and S. S. Kim. J. Vac. Sci. Technol. A 7 (1989) 3.

[72] I. Simon, in Modern Aspects of the Vitreous State, edited by J.D. Mackenzie (Butterworths, London) (1960) 120.

173] W. Primak, Compacted States of Vitreous Silica (Gordon and Beach), New York, (1975).

[74] D.L. Williamson, A.H. Mahan, B.P. Nelson, R.S. Crandall, Appl. Phys. Lett. 55 (1989) 783.

[75] S.R. Elliott, Physics of Amorphous Materials, Edit. Longman Group (1990) 174.

[76] P.G. Pai, S.S. Chao, Y. Takagi, J. Vac. Sci. Technol. A4 (1986) 689.

[77] W.A.P Clasen, H.A.J.Th.v.d Pol, A.H Goemans, A.E.T Kuiper, J. Electrochem. Soc. $133(1986) 1458$

[78] H.I. Schliwinski, U. Schnakenberg, W. Kindbracke, H. Neff and P. Lange, I. Electrochem. Soc. $139(1992) 1730$.

[79] M.N. Brodsky, M. Cardona, J.J. Cuomo, Phys. Rev. Bl6 (1977) 3556.

[80] J.C. Knights, G. Lucovsky, R.I. Nemanich, Phil. Mag. B37 (1978) 467.

[81] G. Lucovsky, R.J. Nemanich, J.C. Knights, Phys. Rev. B 19 (1979) 2064.

[82] P. Lagarde, A.M. Flank, J.P. Itie, Jpn. J. Appl. Phys. 32 (1993) 613.

[83] F. Ténégal, A.M. Flank, N. Herlin, Phys. Rev. B 54 (1996) 12029.

[84] R.T. Sanders, Science 114 (1951) 670.

[85] H.R. Phillip, J. Non-Cryst. Solids 8-10 (1972) 627.

[86] R.J. Temkim, J. Non-Cryst. Solids 17 (1975) 215.

[87] O. Sánche», M.A. Aguilar, C. Falcony, I.M. Martinez-Duart, M. Hernández Véle\%, Thin 
Solid Films $317(1998) 149$.

[88] L. Levien, C.T. Prewitt, D.J. Weidner, Am. Miner, 65 (1980) 920.

[89] M. Misawa, T. Fukinga, K. Nihara, T. Hirai, K. Suzuki, J. Non-Cryst. Solids 34 (1979) 313.

[90] R.W.G. Wyckoff, Crystal Structures (Wiley, Interscience), New York, (1965).

[91] B. Lengeler, Phys. Rev. Lett. 53 (1984) 74.

[92] C.M.M. Denisse, K.Z. Troost, F.H.T.M. Habraken, W.F. van der Weg, J. Appl. Phys. $60(1986) 2543$.

[93] F.H.P.M. Habraken, R.H.G. Tijhaar, W.F. van der Weg, A.E.T. Kuiper, M.F.C.

Willemsen, J. Appl. Phys. 59 (1986) 447.

[94] V.S. Nguyen, S. Burion and P. Pan, J. Electrochem. Soc. 131 (1984) 2348.

[95] F.H.P.M. Habraken, R.H.G. Tijhaar, W.F. Van der Weg, et al., J. Appl. Phys. 59 (1986) 447.

[96] C.M.M. Denisse, K.Z. Troost and et al., I. Appl. Phys. 60 (1986) 2543.

197| J.D. Kubicki, A.C. Lasaga, Am. Mineral 73 (1988) 941.

198| B. Feuston, S.H. Garofalini, J. Chem. Phys. 89)(1988) 5818.

[99] N. Umesaki, N. Hirosaki, K. Hirao, J. Non-Crys. Solids 150 (1992) 120.

[100] P. Vashista, R.K. Kalia, J.P. Rino, and I. Ebbsjö, Phys. Rev. B 41 (1990) 12197.

[101] F. de Brito Mota, J.F. Justo, A. Fazzio, Phys. Rev. B 58 (1998) 8323.

[102] F. de Brito Mota, J.F. Justo, A. Fazzio, J. Appl. Phys. 86 (1999) 1843.

[103] K. Plucinski, I.V. Kityk, M. Makowska-.Janusik, Cryst. Res. Technol, 35 (200) 1305

[104] J.J. Rehr, R.C. Albers, C.R. Natoli, E.A. Stern, Phys. Rev B 34 (1986) 4350.

[105] P.P.M. Vene»uela, A. Fazzio, Phys. Rev. Lett. 77 (1996) 546.

[106] N. Metropolis, A.W. Rosenbluth, M.N. Rosenbluth, A.H. Teller, E. Teller, J. Chem. Phys. 21 (1953) 1087.

[107] F.H. Stillinger, T.A. Weber, Phys. Rev. B 31 (1985) 5262.

[108] A. Nakano, R.K. Kalia, P. Vashista, J. Non-Cryst. Solids 171 (1994) 157.

[109] P. Vashista, R.K. Kalia, W. Li, I. Ebbsjo, (M.F. Thorpe and M.I. Mitkova (Eds.), Amorphous Insulators e Semiconductors, Kluwer, Netherlands) (1997) 151.

[110] K.M. Behrens, E.D. Klinkenberg, I. Finster, K.H. Meiwes-Broer, Surface Science 402, $(1998) 729$. 


\section{TRABALHOS DECORRENTES DA PRESENTE TESE}

\section{ARTIGOS PUBLICADOS}

1. W.L. Scopel, R.R. Cuzinatto, M.H. Tabacniks, M.C.A. Fantini, M.I. Alayo, I. Pereyra, J. Non-Crys. Solids $288(2001) 88$.

2. M.I. Alayo, I. Pereyra, W.L. Scopel, M.C.A. Fantini, Thin Solid Fims 402 (2002) 154.

3. W.L. Scopel, M.C.A. Fantini, M.I. Alayo, I. Pereyra, Brazilian Journal of Physics 32 (2A) (2002) 366 .

4. W.L. Scopel, M.C.A. Fantini, M.I. Alayo, I. Pereyra, Thin Solid Films $413(1-2)(20(2))$ 59 .

5. W.L. Scopel, M.C.A. Fantini, M.I. Alayo, I. Pereyra, Thin Solid Films (2002)-Aceito. 


\section{TRABALHOS APRESENTADOS EM CONFERENNCIAS}

1. W.L. Scopel, M.C.A. Fantini, M.l. Alayo, I. Pereyra, "Caracterização química c morfológica de filmes $a-\mathrm{SiO}_{x} \mathrm{~N}_{y}: H^{\prime \prime}$, ENCONTRO SOBRE DIAMANTES, CARBONO AMORFO, CARBETO DE SILICIO E NITRETOS, RIO de Janeiro/RJ (1999).

2. M.I. Alayo, I. Pereyra, M.N.P. Carreno, W.L. Scopel, M.C.A. Fantini "Filmes de SiO $N_{y}$ para aplicações em microestruturas e guias de onda", ENCONTRO SOBRE DIAMANTES, CARBONO AMORFO, CARBETO DE SILICIO E NITRETOS, Rio de Janciro/RJ (1999).

3. W.L. Scopel R.R. Cuzinatto, M.H. Tabacniks, M.C.A. Fantini, M.I. Alayo, I. Pereyra, "Chemical and morphological properties of a amorphous silicon oxynitride lilmes deposited by plasma enchanced chemical vapor deposition", X REUNIÃO ANUAL DE USUÁRIOS DO LNLS, Campinas/SP (1999).

4. W.L. Scopel, R.I. Prado, M.C.A. Pantini, I. Pereyra, "Morphological investigation of hydrogenated Si-based amorphous films", X REUNIÃO ANUAL DE USUÁRIOS DO LNLS, Campinas/SP (1999).

5. W.L. Scopel, M.C.A. Fantini, 1. Pereyra, "Estrutura de ordem local de filmes de oxinitreto de silicio amorto hidrogenado", X REUNIÃO ANUAL DE USUÁRIOS DO LNLS, Campinas/SP (2000).

6. M.C.A. Fantini, R.J. Prado, W.L. Scopel, M.H. Tabacnicks|"Combination of X-ray absorption spectroscopy and Rutherford backscattering for the analysis of amorphous Sibased thin fims ", VII SEMINÁRIO LATINO-AMERICANO DE ANÁLISES POR TÉCNICAS DE RAJOS X, São Pedro/SP (2000). 
7. M.I. Alayo, I. Pereyra, W.L. Scopel, M.C.A. Fantini, "Control of the Refractive Index in PECVD SiO $\mathrm{N}_{\mathrm{y}}$ Fims", INTERNATIONAL CONFERENCE ON MICROELECTRONICS AND PACKAGING, Manaus/AM (2000).

8. W.L. Scopel, M.C.A. Fantini, M.I. Alayo, I. Pereyra, "Propriedades químicas c estruturais de filmes de oxi-nitreto de silício amorfo hidrogenado", VII ESCOLA BRASILEIRA DE ESTRUTURA ELETRÔNICA, Goiânia/GO (2000).

9. W.L. Scopel, M.C.A. Fantini, M.I. Alayo, I. Pereyra, "Local order structure of $\mathrm{SiO}_{x} \mathrm{~N}_{y}: \mathrm{H}$ glown by PECVD", $10^{\text {th }}$ BRAZILIAN WORKSHOP ON SEMICONDUCTOR PHYSICS, Guarujá/SP (2001).

10. M.C.A. Fantini, T.F. D'Addio, R.I. Prado, W.L. Scopel, "Annealing effects on the properties of amomphous silicon based alloys", FIRST INTERNATIONAL SYMPOSIUM ON NON-CRYSTALLINE SOLIDS IN BRAZIL AND FIFTH BRAZILIAN SYMPOSIUM ON GLASS AND RELATED MATERIALS, Fo do lgutaçu/PR (2001).

11. W.L. Scopel, M.C.A. Fantini, M.I. Alayo, I. Pereyra, "Efeitos de tratamento térmicos nas propriedades estruturais de filmes de oxinitreto de silício", XII REUNIÃO ANUAL DE USUÁRIOS DO LNLS, Campinas/SP (2002).

12. W.L. Scopel, W. Orellana, A. Fazzio, A.J.R. da Silva, M.C.A. Fantini, "Propriedades Químicas e Estruturais de Óxido e Oxinitreto de Silicio Amorfo Hidrogenado", XXV ENCONTRO NACIONAL DA MATÉRIA CONDENSADA, Caxambú/MG (2002).

13. W.L. Scopel, W. Orellana, A. Fazzio, A.J.R. da Silva, M.C.A. Fantini, "Short range order structure of oxygenrich a-SiOX $\mathrm{N}_{y}$ ", VIII ESCOLA DE ESTRUTURA ELETRÔNICA, Juiz de Fora/MG (2002). 
14. M.I. Alayo, I. Pereyra, W.L. Scopel, M.C.A. Fantini, "Optical waveguides of PECVD silicon oxynitride films", SOCIEDADE BRASILEIRA DE PESQUISA EM MATERIAIS, Rio de Janeiro/RJ, (2002). 